\title{
IVth Brazilian Consensus Conference on Helicobacter pylori infection
}

\author{
Luiz Gonzaga Vaz COELHO', James Ramalho MARINHO², Robert GENTA3 , Laercio Tenório RIBEIRO, \\ Maria do Carmo Friche PASSOS 5 , Schlioma ZATERKA ${ }^{6}$, Paulo Pimentel ASSUMPÇÃO', \\ Alfredo José A BARBOSA ${ }^{8}$, Ricardo BARBUTI ${ }^{9}$, Lucia Libanês BRAGA ${ }^{10}$, Helenice BREYER ${ }^{11}$, \\ Aloisio CARVALHAES ${ }^{12}$, Décio CHINZON ${ }^{13}$, Marcelo CURY $^{14}$, Gerson DOMINGUES ${ }^{15}$, Jorge Luiz JORGE ${ }^{16}$, \\ Ismael MAGUILNIK ${ }^{17}$, Frederico Passos MARINHO ${ }^{18}$, Joaquim Prado de MORAES-FILHO' ${ }^{19}$, \\ José Miguel Luz PARENTE ${ }^{20}$, Celso Mirra de PAULA-E-SILVA ${ }^{21}$, José PEDRAZZOLI-JÚNIOR ${ }^{22}$, \\ Ana Flávia Passos RAMOS ${ }^{23}$, Heinrich SEIDLER ${ }^{24}$, José Nonato SPINELLl ${ }^{25}$ and José Vitor ZIR $^{26}$
}

ABSTRACT - Significant progress has been obtained since the III Brazilian Consensus Conference on H. pylori infection held in 2012, in Bento Gonçalves, Brazil, and justify a fourth meeting to establish updated guidelines on the current management of $\mathrm{H}$. pylori infection. Therefore, the Núcleo Brasileiro para Estudo do Helicobacter pylori e Microbiota (NBEHPM), association linked to Brazilian Federation of Gastroenterology (FBG) held its fourth meeting again in Bento Gonçalves, RS, Brazil, on August 25-27, 2017. Twenty-six delegates, including gastroenterologists, endoscopists, and pathologists from the five regions of Brazil as well as one international guest from the United States, participated in the meeting. The participants were invited based on their knowledge and contribution to the study of $H$. pylori infection. The meeting sought to review different aspects of treatment for infection; establish a correlation between infection, dyspepsia, intestinal microbiota changes, and other disorders with a special emphasis on gastric cancer; and reassess the epidemiological and diagnostic aspects of $\mathrm{H}$. pylori infection. Participants were allocated into four groups as follows: 1) Epidemiology and Diagnosis, 2) Dyspepsia, intestinal microbiota and other afections, 3) Gastric Cancer, and, 4) Treatment. Before the consensus meeting, participants received a topic to be discussed and prepared a document containing a recent literature review and statements that should be discussed and eventually modified during the face-to-face meeting. All statements were evaluated in two rounds of voting. Initially, each participant discussed the document and statements with his group for possible modifications and voting. Subsequently, during a second voting in a plenary session in the presence of all participants, the statements were voted upon and eventually modified. The participants could vote using five alternatives: 1) strongly agree; 2) partially agree; 3) undecided; 4) disagree; and 5) strongly disagree. The adopted consensus index was that $80 \%$ of the participants responded that they strongly or partially agreed with each statement. The recommendations reported are intended to provide the most current and relevant evidences to management of $H$. pylori infection in adult population in Brazil.

HEADINGS - Helicobacter pylori. Helicobacter pylori infection. Helicobacter pylori treatment. Helicobacter pylori diagnosis.

\section{INTRODUCTION}

Infection with Helicobacter pylori (HP) is one of the most common chronic bacterial infections in humans and causes several digestive problems, including chronic gastritis, peptic ulcer, and gastric cancer (GC). As a strategy to optimize the management of this infection in Brazil, three consensus meetings organized by the Brazilian Nucleus for the Study of Helicobacter pylori, recently renamed to Brazilian Nucleus for the Study of Helicobacter pylori and Microbiota (Núcleo Brasileiro para Estudo de Helicobacter pylori e Microbiota-NBEHPM), were held in $1995^{(1)}, 2004^{(2)}$, and $2012^{(3)}$. Recent advances in knowledge of resistance to commonly used antimicrobials with a significant impact on patient therapy, the recognition that chronic gastritis secondary to Helicobacter pylori infection is an infectious disease with an indication for antimicrobial therapy regardless of the presence of symptoms ${ }^{(4)}$, and progress in the study of the gut microbiota and its potential interactions with HP demonstrate the need for another consensus meeting on the subject. Therefore, the NBEHPM held its fourth meeting in Bento Gonçalves, Rio Grande do Sul, Brazil, on August 25-27, 2017. Twenty-six delegates, including gastroenterologists, endoscopists, and pathologists from the five regions of Brazil as well as one international guest from

\footnotetext{
Universidade Federal de Minas Gerais, Instituto Alfa de Gastroenterologia, Belo Horizonte, MG, Brasil. ORCID: https://orcid.org/0000-0002-8721-7696. ${ }^{2}$ Universidade Estadual de Ciências da Saúde de Alagoas, Departamento de Doenças Infecciosas, Maceió, Al, Brasil. ${ }^{3}$ Miraca Life Sciences, GI Pathology, Irving, Texas, United States. ${ }^{4}$ Hospital Universitário Prof. Alberto Antunes, Divisão de Endoscopia, Maceió, Al, Brasil. ${ }^{5}$ Universidade Federal de Minas Gerais, Faculdade de Medicina, Departamento de Clínica Médica, Belo Horizonte, MG, Brasil. ${ }^{6}$ Universidade de Campinas, Disciplina de Gastroenterologia, Campinas, SP, Brasil. ${ }^{7}$ Universidade Federal do Pará, Núcleo de Pesquisas em Oncologia, Belém, PA, Brasil. ${ }^{8}$ Universidade Federal de Minas Gerais, Faculdade Medicina, Anatomia Patológica, Belo Horizonte, MG, Brasil. ${ }^{9}$ Universidade de São Paulo, Hospital das Clínicas, Gastroenterologia, São Paulo, SP, Brasil. 10 Universidade Federal do Ceará, Medicina Interna, Gastroenterologia, Fortaleza, CE, Brasil. ${ }^{11}$ Universidade Federal do Rio Grande do Sul, Hospital de Clínicas, Endoscopia, Porto Alegre, RS, Brasil. 12 Hospital São Lucas, Endoscopia, Campinas, São Paulo, Brasil. ${ }^{13}$ Universidade de São Paulo, Hospital das Clínicas, Gastroenterologia, São Paulo, São Paulo, Brasil. ${ }^{14}$ Clínica SCOPE, Endoscopia avançada, Campo Grande, MS, Brasil. ${ }^{15}$ Universidade Estadual do Rio de Janeiro, Gastroenterologia, Rio de Janeiro, RJ, Brasil. ${ }^{16}$ Consultório Médico, Gastroenterologia, Florianópolis, SC, Brasil. ${ }^{17}$ Universidade Federal do Rio Grande do Sul, Medicina Interna, Endoscopia, Porto Alegre, RS, Brasil. ${ }^{18}$ Universidade Federal de Minas Gerais, Hospital das Clínicas, Instituto Alfa de Gastroenterologia, Minas Gerais, BH, Brasil. ${ }^{19}$ Universidade de São Paulo, Faculdade de Medicina, Disciplina de Gastroenterologia, Sao Paulo, SP, Brasil. ${ }^{20}$ Universidade Federal do Piaú, Gastroenterologia, Teresina, Piauí, Brasil. ${ }^{21}$ Consultório Médico, Gastroenterologia, Belo Horizonte, MG, Brasil. ${ }^{22}$ Universidade São Francisco, Farmacologia Clínica, Bragança Paulista, SP, Brasil. ${ }^{23}$ Universidade Federal de Minas Gerais, Hospital das Clínicas, Instituto Alfa de Gastroenterologia, Minas Gerais, BH, Brasil. ${ }^{24}$ Universidade Católica de Brasília, Patologia, Brasília, Distrito Federal, Brasil. ${ }^{25}$ Endovídeo, Gastroenterologia, Endoscopia Digestiva, João Pessoa, PB, Brasil. ${ }^{26}$ Consultório Médico, Gastroenterologia, Bento Gonçalves, RS, Brasil. Work performed by: Núcleo Brasileiro para Estudo do Helicobacter pylori e Microbiota
}

Corresponding author: Luiz Gonzaga Vaz Coelho. E-mail: Icoelho22@gmail.com 
the United States, participated in the meeting. The participants were invited based on their knowledge and contribution to the study of HP infection. The meeting sought to review different aspects of treatment for infection; establish a correlation between infection, dyspepsia, gut microbiota changes, and other disorders with a special emphasis on GC; and reassess the epidemiological and diagnostic aspects of HP infection.

\section{METHODS}

Participants were allocated into four groups according to the main area of interest/practice as follows: Epidemiology and Diagnosis; Dyspepsia, Gut Microbiota Changes and other Disorders; Gastric Cancer; and Treatment. A rapporteur was assigned to each group. Before the consensus meeting, all participants received a topic to be discussed and prepared a document containing a recent literature review and statements that should be discussed and eventually modified during the faceto-face meeting. All statements were evaluated in two rounds of voting. Initially, each participant discussed the document and statements with his group for possible modifications and voting. Subsequently, during a second voting in a plenary session in the presence of all participants, the statements were voted upon and eventually modified. The participants could vote using five alternatives: 1) strongly agree; 2) partially agree; 3) undecided; 4) disagree; and 5) strongly disagree. The adopted consensus index was that $80 \%$ of the participants responded that they strongly or partially agreed with each statement. The levels of evidence and the strength of the recommendation were defined according to the Guidelines of the Brazilian Medical Association/Federal Council of Medicine (Associação Médica Brasileira/Conselho Federal de Medicina - AMB/CFM) ${ }^{(5)}$. The recommendations are reported below.

\section{GROUP 1 - EPIDEMIOLOGY AND DIAGNOSIS}

\section{Statement 1}

In Brazil, the risk factors for acquiring HP infection are inadequate living conditions, sanitary status, and socioeconomic status. There is no well-established evidence on the dynamics of the prevalence of HP infection in Brazil.

Level of evidence: $3 B$

Grade of recommendation: B

Humans are the only reservoir and primary source of transmission of $\mathrm{HP}^{(6-9)}$. Childhood is considered the period of highest risk for acquiring this pathogen because of the higher interpersonal contact at this life stage ${ }^{(10-15)}$. The most important risk factors for transmitting HP are a large number of people living in the home, bed-sharing between children and adults, unhealthy environments, and precarious conditions in the domicile and peridomicile. Other contributing factors include the absence of basic sanitary facilities (drinking water supply, adequate disposal of household waste and sewage or septic tanks), inappropriate personal and family hygienic practices, lack of adequate food preservation systems, and parents low educacional level or of other adults living in the house ${ }^{(16-24)}$. The mode of interpersonal transmission of HP is unknown, but it may occur by the fecal-oral, oral-oral, and gastro-oral routes ${ }^{(6,9)}$. The fecal-oral route predominates in countries with low socioeconomic conditions, households with large families, and population groups with poor hygiene and sanitary conditions; in these cases, transmission occurs directly from person to person ${ }^{(19,25)}$. In developed countries, transmission occurs mainly via the oral-oral route, and the gastro-oral route may predominate among institutionalized individuals and children in day-care centers ${ }^{(17,26)}$.

Epidemiological studies in Brazil have shown that the prevalence rates of HP infection are high in urban and rural areas and that infection starts in childhood ${ }^{(27-29)}$. The prevalence of infection is high in the first 2 years of life among individuals residing in urban or rural areas as well as areas with poor living conditions, low income, and limited health resources. In these regions, HP infection affects up to $50 \%$ of children aged 2 to 5 years. In children aged $\leq 10$ years, the prevalence rate can reach $70 \%-90 \%$, and this percentage is similar in adults ${ }^{(27,30)}$. In contrast, studies involving individuals with a higher education, children whose parents were more educated, families with a better socioeconomic status, and individuals living in cities with better sanitation and housing conditions demonstrated that the prevalence rates of HP infection were lower than those in populations with worse living conditions ${ }^{(27-30)}$.

\section{Statement 2}

The 13C-urea breath test is the gold standard method for non-invasive diagnosis of HP infection. The stool antigen test using monoclonal antibodies is a good alternative. However, the availability of these two methods in Brazil is limited.

Level of evidence: $1 \mathrm{~A}$

Grade of recommendation: A

The 13C-urea breath test (13C-UBT) is the gold standard test for non-invasive diagnosis of HP infection, with excellent accuracy, low cost, and easy execution ${ }^{(31-35)}$. In addition, this test has been validated in Brazil for adults and children aged $>6$ years ${ }^{(36-38)}$. It is considered the first-choice for eradication control of HP and implementation of the test-and-treat strategy $^{(32,39,40)}$. Despite its excellent accuracy, use of the 13C-UBT has not been incorporated into daily practice in Brazil to date due to national authorities restrictions to acquire the substrate. The recent development of the 13C-urea isotope in Brazil may facilitate the dissemination of this test $\mathrm{t}^{(41)}$.

The need to determine the fasting period before undergoing 13C-UBT is controversial because of the possibility of false negative results ${ }^{(32,42,43)}$. Although the dose of labeled urea described in the pioneering study by Graham et al. ${ }^{(31)}$ was 5 $\mathrm{mg} / \mathrm{kg}$ body weight, the current dose of $75 \mathrm{mg}$ for adults is the most recommended and adopted in clinical trials and commercial kits ${ }^{(43-45)}$. Ascorbic acid (e.g., orange juice) or citric acid is used as a vehicle for 13C-urea to accelerate the hydrolysis of urea and delay gastric emptying, favoring the distribution of the substrate in the stomach ${ }^{(32)}$. Despite small variations in the methodologies used by different research groups, the sensitivity and specificity of $13 \mathrm{C}$-UBT are $>95 \%{ }^{(35)}$.

Considering that the absolute values for 13C-UBT depend on urease activity in the stomach, its importance as a semiquantitative or quantitative measurement of gastric colonization has been speculated ${ }^{(46,47)}$. A large study in Brazil confirmed the results of previous population studies ${ }^{(48-50)}$, demonstrating that 13C-UBT values in women were mildly but significantly higher than those in men, suggesting a higher density of infection in women $^{(51)}$. More studies are needed to confirm these findings. 
The stool antigen test (SAT) by enzyme-linked immunosorbent assay (ELISA) is another good option when $13 \mathrm{C}$-UBT is not available ${ }^{(52)}$, provided that monoclonal antigen is used as the reagent ${ }^{(53-56)}$. Although less accepted in some countries, the SAT has been validated for the initial diagnosis of infection and eradication therapy (ET) in adults, and its sensitivity and specificity are $>92^{\circ} \%^{(54,57-59)}$. Brazilian studies have also shown the effectiveness of SAT in the adult and pediatric populations ${ }^{(60-62)}$.

Statement $\mathbf{3}$
For the study of HP using the rapid urease test (RUT), is rec-
ommended a collection of one biopsy from antrum and one from
corpus. For histological examinations, collection of two biop-
sies from the antrum and two from the corpus is recommended
because it allows morphological analysis of the mucosa. RUT
alone is not recommended for eradication therapy control.
Level of evidence: $\mathbf{1 A}$
Grade of recommendation: A

For patients with an indication for upper gastrointestinal endoscopy, the RUT is an inexpensive, rapid, easy to perform, and highly accurate invasive test for initial diagnosis of HP infection $^{(63)}$. In most cases, the specificity and sensitivity are approximately $95 \%$ and $87 \%-95 \%$, respectively ${ }^{(64)}$. The number of analyzed stomach biopsies can increase the sensitivity of the test, and previous studies have demonstrated that collection of biopsies from the antrum and corpus increases the accuracy of the test, reduces false negative results due to the low density and segmental location of HP in the gastric mucosa, and increases the reaction time of the test ${ }^{(65,66)}$.

Histology is considered the gold standard method for detecting HP infection and allows evaluation of morphological changes in the gastric mucosa ${ }^{(65)}$. Its accuracy is affected by several factors, including location and number of biopsies, staining technique, use of proton pump inhibitors (PPIs) and antibiotics, and level of experience of the pathologist. Antrum and corpus biopsies are usually recommended in clinical practice, although the most sensitive strategy consists of obtaining two antrum biopsies and two corpus biopsies from the small and greater curvature of the stomach ${ }^{(67)}$. Corpus biopsies are important for diagnosing $\mathrm{HP}$ in cases of atrophic gastritis ${ }^{(66)}$. With respect to the staining technique used in histology, immunohistochemistry is the most sensitive and specific method for detecting HP, but it is time-consuming and expensive. Thus, hematoxylin-eosin (HE) staining is the most commonly used technique in clinical practice. Among the additional staining techniques used to facilitate bacterial identification, Giemsa is the preferred method because it is simple, sensitive, and inexpensive ${ }^{(63,68)}$.

Recently, with the technological advancement of endoscopic imaging, there has been increasing interest in the real-time identification of HP infection during the endoscopic procedure without biopsies, resulting in cost reduction and early diagnosis of infection $^{(69)}$. The Japanese school divides the status of the gastric mucosa into three categories based on endoscopic findings: normal gastric mucosa without HP infection (absence of gastritis), active HP infection (active gastritis), and previous HP infection (inactive gastritis). The endoscopic classification of Kyoto for endoscopic gastritis lists 19 endoscopic findings to characterize gastric mucosa inflammation and the presence of HP infection with high accuracy, depending on the methods used ${ }^{(70-75)}$.

Statement $\mathbf{4}$
The screening of HP after eradication therapy should be
performed at least 4 weeks after the end of treatment. The
$13 C$-UBT test and SAT with monoclonal antibody are the meth-
ods of choice. Histology is an alternative invasive method.
Level of evidence: $\mathbf{1 A}$
Grade of recommendation: A

The screening of HP after ET requires special attention because of the possible loss of sensitivity in some cases. For instance, use of the RUT is not recommended after eradication because the sensitivity is significantly decreased. Nishikawa et al. ${ }^{(76)}$ compared the sensitivity of two RUTs (Helicocheck $^{\mathrm{TM}}$ and PyloriTek ${ }^{\mathrm{TM}}$ ) before and after ET and found that the sensitivity of both tests was $91 \%$ and $92 \%$ before ET and $60.5 \%$ and $60.5 \%$ after therapy, respectively. The sensitivity of the tests increased when biopsies of the corpus and antrum were combined compared with the use of biopsies from each region separately. In contrast, sensitivity and specificity of histological diagnosis are maintained before and after ET, as confirmed by Yoshimura et al. ${ }^{(77)}$, wherein the sensitivity of histology after ET in children was $100 \%$. Therefore, histology is used as a control for determining the sensitivity of other tests. During ET testing, special care should be taken about the maintenance of the use of PPIs after administering antimicrobials because they may affect the sensitivity of the tests. Graham et al. ${ }^{(78)}$ demonstrated that PPIs affected the sensitivity of 13C-UBT, which presented a false negative rate of $33 \%$ when performed 3 days after treatment suspension. Moreover, the sensitivity of the test began to increase after 4 days of discontinuation of PPIs and was highest 14 days after treatment suspension. Similar results were observed by Gatta et al. ${ }^{(79)}$, wherein the sensitivity of $13 \mathrm{C}$-UBT and SAT were decreased during PPI use. However, antacids did not affect the sensitivity of the tests. Yoshimura et al. ${ }^{(77)}$ reported, with respect to the above recommendations, a high sensitivity of 13C-UBT for confirmation of ET. Similarly, Kuloglu et al. ${ }^{(80)}$ found that the sensitivity of $14 \mathrm{C}-\mathrm{UBT}$ one month after ET, with suspension of PPIs, bismuth, and antibiotics during this period, was $100 \%$. Shirim et al. ${ }^{(81)}$ performed $13 \mathrm{C}$-UBT to confirm eradication control 7 and 14 days after ET and observed that the sensitivity was $76 \%$ and $83.9 \%$, respectively. The attempt to anticipate the confirmation of eradication to 7 days after completing ET yielded a false negative rate of $7.3 \%$. Therefore, eradication should be confirmed 4 to 6 weeks after completing $\mathrm{ET}^{(6)}$. Systematic reviews and meta-analyses indicated that 13C-UBT had good accuracy in all age groups ${ }^{(35,38)}$.

The SAT is also a robust test for diagnosing HP infection and eradication control. The sensitivity of the SAT is maintained by storing stool samples at room temperature for a maximum of 24 hours or at $4{ }^{\circ} \mathrm{C}$ for up to 72 hours. This storage procedure and suspended use of antibiotics and bismuth for 30 days and PPIs for 14 days before the test yielded good sensitivity. The sensitivity with monoclonal antibodies was significantly higher than with polyclonal antibodies ${ }^{(82)}$. The sensitivity of 13C-UBT was higher than that of SAT. Perri et al. ${ }^{(83)}$ compared the sensitivity of $13 \mathrm{C}$-UBT and SAT using monoclonal antibodies and obtained similar results. Gisbert and Pajares ${ }^{(84)}$ conducted a systematic review to determine SAT sensitivity and concluded that this test had good accuracy for confirming HP eradication after 4 weeks 
of treatment, and the results were slightly better when performed after 8 weeks of treatment.

The choice of HP eradication test should be based on low invasiveness and high accuracy. The non-invasive 13C-UBT and SAT are good alternatives for eradication control with a slight advantage for 13C-UBT.

\section{Statement 5 \\ Molecular tests may be used to assess HP antimicrobials resis- tance after second or third treatment failure. However, the lack of availability of bacterial cultures and antibiograms limits the use of these tests. \\ Level of evidence: 4 \\ Grade of recommendation: $\mathrm{C}$}

One the most important causes of eradication failure is the increasing resistance to clarithromycin and levofloxa$\operatorname{cin}^{(85)}$. Resistance to nitroimidazoles is considered the most common type of resistance ${ }^{(86)}$. Resistance rate to amoxicillin and tetracycline is considered low and stable ${ }^{(87)}$.

Resistance to clarithromycin is caused by mutations in the $r r l$ gene encoding two nucleotides of rRNA 23S: 2142 and 2143. A2142G and A2143G are the most common mutations, whereas the A2142C mutation is less common. Other mutations have been described, but their clinical importance is unknown. Quinolones resistance involves genes encoding DNA gyrase (gyrA and gyrB) at gyrA positions $86,87,88,91$, or 97. The most common mutations are in positions 87 and $91^{(86)}$. A rate of resistance to clarithromycin $<15 \%$ was adopted by the European Consensus for therapies without previous assessment of resistance ${ }^{(40)}$

Several methods for evaluating resistance based on phenotype (culture and antibiogram) and genotype (molecular biology) are available. Phenotypic methods, including bacterial culture and antibiogram, allow determination of the minimum inhibitory concentration (MIC) of antibiotics and are considered the gold standard. In addition to discrepancies in terms of the methodology and use of different MICs for some compounds, the small number of laboratories that perform these test limits the use of such methods in clinical practice. Molecular biology-based genotypic tests are fast, reproducible, easy to standardize, and do not depend on the presence of live bacteria. These tests can assess resistance to clarithromycin, levofloxacin, and tetracycline and are commercially available for levofloxacin and clarithromycin; however, they are not yet available for amoxicillin and metronidazole because of the lack of knowledge of the mechanisms of resistance to these antimicrobials ${ }^{(86,87)}$.

Two meta-analyses and two studies evaluating ETs in geographical areas with high resistance to antibiotics reported that therapies based on antimicrobial susceptibility tests were superior to empirical therapy ${ }^{(88-91)}$.

\section{Statement 6}

Locally validated serological tests are the methods of choice for population-based screening studies. Serology may be used as the initial test for diagnosing HP infection, especially in the presence of gastrointestinal bleeding, atrophic gastritis, gastric mucosa-associated lymphoid tissue lymphoma, and gastric cancer. Level of evidence: $\mathbf{2 A}$

Grade of recommendation: B
Serological tests are based on the detection of anti-HP IgG antibodies and are non-invasive, widely available, inexpensive, easy to perform, and widely accepted by patients ${ }^{(92,93)}$. The most used serological tests are enzyme immunoassays (ELISAs), immunochromatographic assays (rapid tests), and immunoblot assays. ELISA is the most commonly used assay because of its higher accuracy compared with rapid tests ${ }^{(63,94)}$. Immunoblotting, despite its higher specificity than ELISA without the loss of sensitivity, is more expensive, requires greater expertise for interpretation, and is not widely available in clinical laboratories ${ }^{(95)}$.

The accuracy of the serological tests depends on the antigen used in the commercial kit and prevalence rate of the HP-specific strain used as the antigen source. The heterogeneity of HP strains is well known, and the prevalence of specific strains varies significantly in different regions. Therefore, the success of these test depends on the use of antigens from HP strains found in the population in question ${ }^{(96,97)}$. A previous study compared the accuracy of 29 commercially available kits and indicated that the variability was high $(66.7 \%$ to $91.3 \%)$. In turn, the accuracy of rapid tests was lower $(66.7 \%$ to $91.3 \%$ ) than that of ELISA $(73.9 \%$ to $97.8 \%$ ). Four ELISA kits presented excellent results and sensitivity, specificity, positive and negative predictive values (PPV and NPV) $>90 \%{ }^{(94)}$. Similarly, the sensitivity, specificity, PPV, and NPV of serological tests using high-molecular-weight antigens, recombinant antigens, and higher immunogenicity antigens were $>90 \%{ }^{(98-}$ 100). Ideally, locally validated tests with an accuracy $>90 \%$ are recommended ${ }^{(40)}$. Studies performed in Brazil evaluating serological tests by ELISA and immunoblot found a sensitivity of $93.9 \%-97.4 \%$ and specificity of $88.9 \%-100 \%{ }^{(101-103)}$.

Serology is primarily indicated for screening HP infection in epidemiological studies. Its main limitation is the inability to distinguish between active and past infections because the serum levels of anti-HP IgG antibodies may remain high for long periods, even after HP eradication. Thus, serology cannot be used for eradication control after treatment ${ }^{(63,92)}$. Serological tests, particularly highly accurate and locally validated tests, may be used as initial non-invasive tests for screening HP infection and should be especially considered in clinical situations involving a low gastric bacterial load, such as gastrointestinal bleeding, atrophic gastritis, gastric mucosa-associated lymphoid tissue (MALT) lymphoma, and gastric cancer (GC), because the sensitivity is not altered, and false negatives are not produced in these situations ${ }^{(40,93,104-106)}$.

\section{Statement 7}

The use of PPIs should be discontinued up to 2 weeks before performing diagnostic tests for HP infection, except serology. The use of antibiotics and bismuth salts should be discontinued up to 4 weeks before using the diagnostic tests.

Level of evidence: $2 B$

Grade of recommendation: B

PPIs may yield false negative results in the RUT, 13C-UBT, SAT, and histological diagnosis because these drugs have moderate anti-HP activity, leading to a reduced bacterial load and inhibition of urease activity ${ }^{(78,79,107-113)}$. A few discordant studies found that 13C-UBT accuracy was not significantly affected by a short-term PPI pantoprazole use ${ }^{(110)}$ and that PPIs did not significantly affect SAT using monoclonal antibodies ${ }^{(111)}$. Molec- 
ular studies with more sophisticated techniques can detect the presence of HP in patients treated with PPIs ${ }^{(114,115)}$.

Considering this evidence, the adequate interval between PPI use suspension and diagnostic tests performance is 14 days, except when serological tests are requested, which are not affected by PPIs ${ }^{(63,111,116-120)}$. Antibiotics and bismuth salts use should be discontinued 4 weeks before performing diagnostic tests ${ }^{(63,117,119)}$. H2 blockers have minimal effects on the results of breath tests, and antacid drugs do not affect the sensitivity of breath tests or the detection of stool anti$\operatorname{gens}^{(79,121,122)}$.

\section{Statement 8}

Endoscopy indication for upper gastrointestinal bleeding patients turns histology the recommended test in patients with an indication for HP screening. Breath tests are an alternative. A new diagnostic screening of HP should be conducted in patients with negative results in the first test.

Level of evidence: 4

Grade of recommendation: $\mathrm{C}$

The diagnosis of HP infection in patients with upper gastrointestinal bleeding (UGIB) has specific characteristics that should be considered. The occurrence of bleeding in the gastric cavity decreases the accuracy of endoscopic tests (RUT, histological diagnosis, culture, and PCR), and the bactericidal effect of human plasma on HP may explain the decrease in the sensitivity of these tests ${ }^{(123)}$. Different studies have shown a significant sensitivity decrease of the RUT and culture in patients with $\mathrm{UGIB}^{(124-128)}$, and a few studies have presented discordant results ${ }^{(129)}$. A prospective case-control study demonstrated that RUT sensitivity was decreased in UGIB history patients with or without gastric cavity bleeding ${ }^{(127)}$. Lee et al. ${ }^{(130)}$ suggested that increasing the number of biopsies might increase the sensitivity of the RUT, although the sensitivity remained low. The use of molecular tests (PCR) using gastric mucosa biopsies presented conflicting results ${ }^{(131,132)}$ and increased costs. These results suggest that the use of invasive tests for HP diagnosis in UGIB patients is not the ideal choice and non-invasive tests are recommended in these cases. The sensitivity and specificity of SAT are decreased in UGIB patients ${ }^{(133-135)}$. In contrast, 13C-UBT consistently presents good sensitivity and specificity for HP diagnosis in UGIB patients ${ }^{(136-138)}$. A systematic review and a meta-analysis compared invasive and non-invasive tests and concluded that invasive tests (RUT, histology, and culture) had lower sensitivity in patients with $\mathrm{UGIB}^{(139)}$. Among the non-invasive tests, SATs have lower sensitivity while 13C-UBTs have higher accuracy in these patients.

Therefore, the best test for HP screening in patients with UGIB is 13C-UBT. Nonetheless, this test is not widely available in Brazil to date. It is also evident that endoscopic examination should be performed for diagnosing and/or treating UGIB cause. Therefore, in this context, histological examination is recommended and/or RUT and 13C-UBT in cases in which the results of the first two tests are negative. If the 13UBT test is unavailable, HP screening should be repeated at least 1 month after bleeding is resolved to confirm the results. Güell et al. ${ }^{(140)}$ conducted a retrospective study to evaluate the results of HP retesting in patients with gastric or duodenal ulcer who presented with UGIB but were negative in the RUT and histology performed in urgent care, and they observed that the second test was positive in $79 \%$ of the participants.

\section{GROUP 2 - DYSPEPSIA, MICROBIOTA, AND OTHER DISORDERS}

\section{Statement 9}

The test-and-treat strategy is recommended for patients aged $<40$ years with dyspepsia not yet diagnosed with $\mathrm{HP}$ and without alarming signs. The test of choice for diagnosis and treatment control is the $13 C-U B T$.

Level of evidence: $1 \mathrm{~B}$

Grade of recommendation: A

The test-and-treat strategy using a non-invasive test should be considered for adult patients aged $<40$ years with dyspepsia but without alarming signs, including unintentional weight loss, dysphagia, persistent vomiting, palpable mass in the abdomen, jaundice, gastrointestinal bleeding, and absence of history of gastric cancer in first-degree relatives. As previously recommended in the last Brazilian Consensus ${ }^{(3)}$, 13C-UBT and SAT are recommended as non-invasive tests for diagnosis and eradication control, with a preference for the former. Several prospective studies support the use of this strategy, particularly in regions with a high rate of infection like Brazil ${ }^{(40)}$.

\section{Statement 10}

Dyspepsia is very common and is classified as investigated and uninvestigated. After investigation, dyspepsia is now classified as organic, HP-associated, or functional.

Level of evidence: $1 \mathrm{C}$

Grade of recommendation: A

Dyspepsia is defined as persistent or recurrent pain and/or discomfort in the central and upper abdomen (epigastrium) (141). The prevalence of this condition is high worldwide, with an estimated rate of $10 \%$ to $30 \%{ }^{(142)}$, and most patients do not present organic changes that justify the symptoms ${ }^{(143)}$. A study conducted in Pelotas, Rio Grande do Sul, Brazil, reported that the prevalence of complaints compatible with dyspepsia was $44.4 \%$ in the study population ${ }^{(144)}$.

Dyspepsia is classified as investigated or uninvestigated. After screening, dyspepsia is classified as organic, HP-associated, or functional ${ }^{(4,145)}$. Upper gastrointestinal endoscopy with HP screening should be performed in patients aged $>40$ years with uninvestigated dyspepsia; patients who do not respond to empirical treatment with $\mathrm{H} 2$ blockers, PPIs, or prokinetics, among others; and patients of any age with alarm signs $^{(145)}$. Three classifications are possible after endoscopic examination and HP screening: 1) patients with dyspepsia who present endoscopic changes that justify the symptoms are considered as having organic dyspepsia (e.g., peptic ulcer and GC); 2) patients with dyspepsia with normal endoscopy and without HP infection are considered as having functional dyspepsia; and 3) patients with dyspepsia with normal endoscopy and HP infection. In the latter situation, patients should be treated for bacterial eradication. The diagnosis when symptoms improve steadily after treatment (6 to 12 months) is HP-associated dyspepsia. Patients with continued complaints of dyspepsia, despite confirmed eradication, are considered to have functional dyspepsia. 
According to the Rome Consensus IV, functional dyspepsia is a clinical syndrome that impacts activities of daily living and is characterized by the presence of recurrent and chronic dyspepsia in the absence of underlying structural or metabolic lesions detected in clinical routine (including endoscopy) capable of justifying the clinical picture. Functional dyspepsia is confirmed by meeting the following diagnostic criteria ${ }^{(145)}$ : 1) recurrent complaints of dyspepsia in the past 3 months that began at least 6 months prior; 2) the presence of one or more of the following symptoms: a) postprandial indigestion, b) early satiety, c) epigastric pain, and d) epigastric burning; and 3) the absence of structural lesions on digestive endoscopy that justify the symptoms.

For better therapeutic orientation, patients with functional dyspepsia should be classified into two syndromes according to the main symptom: a) postprandial discomfort syndrome (meal-related symptoms), especially postprandial indigestion and/or early satiety at least 3 times a week in the past 3 months; and/or b) epigastric pain syndrome (symptoms not necessarily related to meals), predominating moderate to intense intermittent pain and/or epigastric burning at least once a week in the past 3 months. Of note, the two syndromes may be present in the same patient ${ }^{(145)}$.

Some regions of Brazil present a high rate of intestinal parasitic infections, particularly those caused by Ascaris lumbricoides, Strongiloides stercoralis, and Giardia lamblia. Parasitological examinations of stool should be requested serially (in at least three samples), and the execution of larval concentration methods (Baermann method modified by Moraes and its variations) and direct stool examination are essential, especially for the detection of giardiasis and strongyloidiasis. The World Health Organization (WHO) recommends the use of antiparasitic drugs at regular intervals for populations at high risk of developing intestinal parasitic diseases ${ }^{(146)}$. This consensus maintains the recommendation of the previous Brazilian Consensus related to the execution of parasitological stool examination or empirical use of antiparasitic drugs together with the criteria established by the Rome Consensus IV for diagnosing functional dyspepsia ${ }^{(3)}$.

\section{Statement 11 \\ Patients with dyspepsia and HP should be subjected to eradi- cation treatment. \\ Level of evidence: $3 \mathrm{~A}$ \\ Grade of recommendation: B}

Standard ET is indicated after confirming the presence of HP either by endoscopy or non-invasive tests ${ }^{(145)}$. The diagnosis in cases with sustained improvement of symptoms (6 to 12 months) is HP-associated dyspepsia ${ }^{(4,145)}$. This new guideline of the Kyoto Consensus ${ }^{(4)}$ confirmed by the Rome Consensus IV ${ }^{(145)}$ and Maastricht $\mathrm{V}^{(40)}$ has been consolidated by several studies and meta-analyses demonstrating that HP eradication is better than placebo in relieving the symptoms of dyspepsia and results in a therapeutic gain of $4 \%-14 \%{ }^{(147,148)}$. The main justification for eradicating HP in patients with dyspepsia is symptom relief in a subset of patients, lower risk of late development of clinical sequelae (e.g., peptic ulcer and GC), and interruption of HP transmission.

\section{Statement 12}

HP and the drugs used in ET affect the physiology of the gastric and intestinal microbiota and may modify the microbiota with severe consequences to overall health.

Level of evidence: 5

Grade of recommendation: D

HP is part of the stomach microbiota and can modify the gastric physiology and vice versa. HP initially infects the antrum and increases gastrin production in this region. Gastrin stimulates the secretion of pepsin by enterochromaffin-like (ECL) cells and promotes hyperplasia and hypertrophy in oxyntic cells. The increased secretion of pepsin prevents bacterial overgrowth in the stomach and intestine and directly stimulates the release of secretin, which in turn increases the release of pancreatic enzymes. A low $\mathrm{pH}$ also triggers the release of cholecystokinin (CCK), which regulates biliary flow and gallbladder contraction ${ }^{(149)}$. Bile salts and pancreatic enzymes help maintain the balance of the intestinal microbiota $^{(150,151)}$. Intestinal motility may be indirectly regulated by the effects of HP on ghrelin, GLP-1, GLP-2, PYY, and melatonin ${ }^{(152-155)}$. Gastric and intestinal chemoreceptors are also affected by $\mathrm{pH}$ changes, directly affecting the gut-brain axis and ultimately the whole organism ${ }^{(156)}$.

HP eradication may affect all these factors, causing changes in the stomach, intestine, pancreas, biliary system, and other systems.

The existing eradication strategies use drugs that decrease gastric secretion (usually PPIs) and antimicrobials, which are administered together in most cases. The impact of many antibiotics on the microbiota is evident. First, these drugs have broad-spectrum activity and therefore affect microorganisms other than HP, including commensal bacteria. This problem may be aggravated with repeated antimicrobial treatments, and the modified microbiota may require months to years to recover. Some arqueas are unable to recolonize the digestive system. During the initial stages, dysbiosis may be due to mild or severe changes in bowel habits (post-antibiotic diarrhea) and conditions such as pseudomembranous enterocolitis, which are fatal in some cases. The gut microbiota is known to modulate different body systems, and the potentially definitive microbiota imbalance may be transmitted to future generations and may have a significant impact on our descendants $^{(157-161)}$.

Some strategies may be used to minimize this problem, including reviewing HP treatment indications, using HP-specific antibiotics, optimizing initial treatment as much as possible by avoiding retreatments, and supplementing with probiotics. Therefore, probiotics may play an important role by increasing eradication rates and minimizing intestinal adverse effects (post-antibiotic diarrhea, pseudomembranous enterocolitis, and inflammation of the gastric mucosa). Moreover, probiotics may have positive effects via bactericidal activity (competition for nutrients and receptors, production of bacteriocins, and modulation of urease function of HP strains), immunomodulatory activity through pattern recognition receptors, and anti-inflammatory activity by modulating the production and scavenging of free radicals in the stomach. As previously reported, HP and ET may strongly affect gastric physiology, and changes in the gastric region affect different body systems in various ways. 


\section{Statement 13}

Probiotics use associated with ET is an attempt to optimize HP eradication and minimize adverse events, rebalancing the microbiota. Further studies are needed to better define the strain, amount, time, and period of supplementation.

Level of evidence: 4

Grade of recommendation: $\mathbf{C}$

In theory, prebiotics, probiotics, and symbiotics can reestablish the gut microbiota, competing for nutrients with pathogenic bacteria, inhibiting the activity of toxins, and performing immunomodulatory functions ${ }^{(162)}$. Experimental animal studies have shown that surface proteins in probiotic strains limit the colonization of the stomach by $\mathrm{HP}^{(163)}$. Strains of Lactobacillus salivarius and L. casei may inhibit HP urease activity (by producing lactic acid) and synthesize cytokines, which are involved in inflammatory processes ${ }^{(164)}$. Therefore, these species of Lactobacilli may reduce the HP load, mucosal inflammation (by inhibiting IL-8 production), and gastric hyperacidity ${ }^{(165)}$

Some probiotics containing Lactobacillus, Bifidobacterium, and Saccharomyces boulardii exert anti-HP activity in vitro and reduce antibiotics associated side effects (particularly diarrhea and nausea) administered during ET with PPIs and antibiotics $^{(166)}$.

Although some authors found promising results using pre- and probiotics as adjuvant therapy in anti-HP regimens, most clinical trials found that this association did not improve eradication rates, bacterial colonization, gastric inflammation scores, and side effects ${ }^{(165-167)}$. A prospective, randomized, double-blind, placebo-controlled study in Brazil evaluated the role of an anti-HP regimen combined with probiotics ( $\mathrm{Lac}$ tobacillus acidophilus, L. rhamnosus, Bifidobacterium bifidum, and Streptococcus faecium) in eradicating HP and decreasing the number of adverse events. The eradication rate and adverse effects in the group treated with the antibiotic regimen and probiotics were not significantly different from those in the placebo group ${ }^{(168)}$.

Recently, three important consensus meetings on the use of probiotics for the treatment of HP considered that, despite some encouraging results, probiotics appeared to increase bacterial eradication rates by reducing the adverse effects associated with antimicrobial treatment and not by a possible direct effect on the bacterial strains ${ }^{(40,169,170)}$. Additional randomized, double-blind, and controlled trials are necessary to define the strain, concentration, optimal time, and period of probiotic use. In addition, routine use of probiotics in ET is not recommended.

\section{Statement 14}

There is evidence of an association between HP infection, iron deficiency anemia of unknown etiology, immune thrombocytopenic purpura (ITP), and vitamin B12 deficiency. In other extra-gastroduodenal conditions, there may be negative and positive associations with no proven causality.

Level of evidence: $3 \mathrm{~A}$

Grade of recommendation: B

The role of HP in iron deficiency anemia, ITP, and vitamin B12 deficiency is well established, and baseline disease is improved with bacterial eradication in both adults and children ${ }^{(171-176)}$. Three recent meta-analyses evaluated iron defi- ciency anemia of obscure etiology and found that the levels of hemoglobin and ferritin were increased after HP eradication in adults and children ${ }^{(174,177,178)}$, and these findings have motivated international guideline to recommend ET to treat iron deficiency anemia of obscure etiology ${ }^{(179)}$.

With respect to ITP, some nonrandomized studies, and randomized studies with small sample sizes, have suggested that platelet counts are increased in adults after HP eradication $^{(180-1820)}$; however, the evidence in the pediatric population was weaker ${ }^{(183)}$. A systematic review involving 25 studies suggests that bacterial eradication tends to cause an increase in platelet counts ${ }^{(184)}$. The response is usually stronger in patients with a mild degree of thrombocytopenia and patients from regions with high infection rates ${ }^{(173,174,176,184,185)}$. The mechanisms underlying HP infection and ITP have not been fully elucidated. One of the most studied mechanisms is molecular mimicry involving HP CagA protein and platelet glycoproteins, particularly GPI and GPII ${ }^{(186)}$.

Some studies have observed that HP infection decreases the absorption of vitamins, especially vitamin B12, leading to the accumulation of serum homocysteine ${ }^{(185,187)}$. Pangastritis induced by HP infection with strong involvement of the oxyntic mucosa may promote achlorhydria or hypochlorhydria and decrease pepsinogen levels, compromising the absorption of cobalamin. A study demonstrated that HP eradication might increase cobalamin levels and decrease serum homocysteine levels in elderly patients with vitamin B12 deficiency in Brazil ${ }^{(188)}$.

Other studies have evaluated a possible association between HP infection and cardiovascular events. Ultrasound images of the intima-media thickness of the carotid wall, which is considered an indirect marker of clinical or subclinical atherosclerosis, showed an increase in thickness in patients with HP infection, particularly those infected with positive CagA strains $^{(189)}$. A recent meta-analysis of prospective studies published from 1992 to 2014 analyzing the association between HP infection and the risk of coronary disease found that HP infection increased the risk of coronary disease by $11 \%(\mathrm{RR}$ : 1.11; $95 \%$ CI: $1.01-1.22)^{(190)}$. Other studies found promising associations - but without sufficient evidence of causalityfor other diseases, including Parkinson's disease and Alzheimer's disease ${ }^{(191,192)}$. In contrast, other studies reported negative associations between HP infection and diseases such as asthma and other atopic conditions, including eosinophilic esophagitis $^{(193,194)}$.

\section{Statement 15 \\ There is no evidence for an association between HP infection and gastroesophageal reflux disease (GERD). Bacterial eradication usually does not lead to the onset of GERD symptoms. Epide- miological evidence indicates a negative correlation between HP infection, Barrett's esophagus, and adenocarcinoma of the distal esophagus. \\ Level of evidence: $3 \mathrm{~A}$ \\ Grade of recommendation: B}

The relationship of HP infection, gastroesophageal reflux disease (GERD), and Barrett's esophagus (BE) has been controversial. However, for adequate distinction of the associations within the context of GERD, it needs to be subclassified into non-erosive reflux disease, erosive reflux 
disease, BE, and adenocarcinoma of the distal esophagus (ADE). Therefore, the collective odds ratio of a meta-analysis for the association between HP infection and GERD in Europe was 0.97 (0.75-1.27), not statistically significant ${ }^{(195)}$. This analysis included only studies in which GERD was defined by erosive esophagitis or abnormal esophageal pH-metry results. A case-control study involving 65,363 patients in Europe revealed that HP infection alone was not associated with a lower risk of developing GERD-related symptoms. Moreover, there was a negative association of GERD symptoms in patients with reduced pepsinogen levels and atrophic gastritis (OR: $0.2 ; 95 \%$ CI: $0.8-1.5)^{(196)}$. Similar results were found in a study in the United States, in which GERD symptoms were not associated with HP infection regardless of the virulence of the strains (CagA status $)^{(197)}$. A case-control study involving more than 5,000 patients in Korea found a negative correlation between HP seroprevalence and the risk and severity of erosive esophagitis (OR: 0.44 [0.39-0.49]) ${ }^{(198)}$.

The studies that sought to evaluate the association between HP, BE, and ADE found a high variability in the methods, selection bias, and characterization of the study population $^{(199,200)}$. A meta-analysis reported that the relative risk of $\mathrm{BE}$ in patients with $\mathrm{HP}$ infection was 0.46 (0.35-0.60); i.e., there was a strong negative association between HP and $\mathrm{BE}^{(201)}$. Another prospective case-control study confirmed the negative association between HP and $\mathrm{BE}$, particularly for CagA-positive strains (OR: 0.36 [0.14$0.90])^{(197)}$. Anderson et al. ${ }^{(202)}$ prospectively analyzed the effect of gastric atrophy and suggested a negative association between HP infection, BE, and ADE in cases of oxyntic mucosal atrophy. These findings indicate that BE and ADE primarily occurred in patients with non-atrophic gastric mucosa. Wang et al. ${ }^{(203)}$ demonstrated that there was no difference in HP infection in patients with BE and control individuals from a blood donor population and individuals with normal endoscopic findings. The comparison between patients with $\mathrm{BE}$ and individuals with normal endoscopy revealed that $\mathrm{BE}$ was associated with a lower rate of $\mathrm{HP}$ infection.

A large number of prospective studies and meta-analyses evaluated the relationship between HP eradication and GERD. Most of these studies found that ET was not associated with the rate of reflux or reflux esophagitis. In addition, ET did not aggravate symptoms in patients with pre-existing $\operatorname{GERD}^{(40,204-207)}$

\begin{tabular}{l} 
Statement $\mathbf{1 6}$ \\
In patients infected with HP, the use of nonsteroidal anti-in- \\
flammatory drugs (NSAIDs) or acetyl salicylic acid (ASA), \\
even at low doses, increases the risk of ulcer and its complica- \\
tions. Anticoagulants (coumarin, clopidogrel, and new oral an- \\
ticoagulants) may increase the risk of ulcer/bleeding in HP-in- \\
fected patients. \\
In patients at high risk of developing ulcers, before the initia- \\
tion of long-term treatment with NSAIDs or ASA, even at low \\
doses, HP should be screened and eradicated. However, eradi- \\
cation alone does not prevent the recurrence of ulcerlbleeding. \\
Level of evidence: $\mathbf{1 B}$ Grade of recommendation: $\mathbf{A}$ \\
\hline
\end{tabular}

NSAIDs are one the most commonly used drugs worldwide. These drugs are effective, but they have many adverse effects. The most common adverse events affect the digestive tract and include dyspepsia, heartburn, abdominal discomfort, and duodenal ulcer and its complications, especially life-threatening bleeding ${ }^{(208)}$. By contrast, HP infection is the most important etiologic factor of gastroduodenal ulcer ${ }^{(209)}$. Huang et al. ${ }^{(210)}$ analyzed 16 studies involving 1,625 NSAID users and observed that uncomplicated ulcer was more common in HP-positive patients $(341 / 817,41.7 \%)$ than in HP-negative patients $(209 / 808,25.9 \%)(\mathrm{OR}=2.12)$. In five controlled studies, ulcer was significantly more common in NSAID users $(138 / 385,35.8 \%)$ than in controls $(23 / 276,8.3 \%)$, but it was not significantly correlated with HP infection. A comparison between HP-negative individuals not using NSAIDs and HP-positive individuals using NSAIDs indicated that the risk of ulcer was 61.1 times higher in the latter. The use of NSAIDs alone $(\mathrm{OR}=19.4)$ and $\mathrm{HP}$ infection $(\mathrm{OR}=18.1)$ increased the risk of ulcer. In NSAID users, HP infection increased the risk of ulcer by 3.53 -fold. The risk of bleeding complications was increased 1.79-fold in HP-infected patients and 4.85-fold in NSAID users. The risk was increased 6.13-fold in HP-positive patients treated with NSAIDs. This meta-analysis indicated that HP infection and NSAIDs were independent risk factors for ulcer and its complications. However, this association significantly increased the risk of uncomplicated ulcer and ulcer bleeding. Lanas et al. ${ }^{(211)}$ observed that in patients using low doses of ASA, HP was an independent risk factor for ulcer bleeding $(\mathrm{OR}=4.7)$. Uemura et al. ${ }^{(212)}$ evaluated 1,454 Japanese individuals with high-risk cardiovascular disease receiving ASA (75-325 $\mathrm{mg} /$ day) and found that the rate of gastroduodenal ulcer was $6.5 \%$. Moreover, HP infection was an important risk factor for gastroduodenal ulcer $(\mathrm{OR}=1.83$; $P<0.0082)$. In addition to HP, an age $>65$ years $(P=0.0246)$ and current smoking $(P<0.0321)$ increased the risk of gastroduodenal ulcer. Kono et al. ${ }^{(213)}$ analyzed 245 patients who were chronically using NSAIDs and observed that an age $>75$ years and HP infection were important risk factors for severe gastric mucosal damage. Iijima et al. ${ }^{(214)}$ used the levels of pepsinogen I and pepsinogen I/II ratio to estimate hyperchlorhydria and observed that hyperchlorhydria was an important risk factor for severe gastric mucosal damage $(O R=34.0)$ and gastric ulcer $(\mathrm{OR}=10.2)$ and recommended that these patients should be treated in advance to prevent mucosal damage.

The effect of HP on the risk of ulcer and/or bleeding in patients using low doses of ASA has been controversial. Sostres et al. ${ }^{(215)}$ found no additive or potentiating effect of HP and ASA on the risk of ulcer or ulcer bleeding, although both conditions were independent risk factors.

Antiplatelets other than aspirin and anticoagulants ${ }^{(216)}$, including recently developed drugs ${ }^{(217,218)}$, increase the risk of ulcer bleeding. The Maastricht V/Florence Consensus concluded that the use of ASA or NSAIDs increased the risk of ulcer bleeding in HP infected patients ${ }^{(40)}$.

Other risk factors for gastroduodenal ulcer in users of NSAIDs/ASA included an age $\geq 65$ years, smoking, previous history of ulcer/UGIB, current smoking, combination of NSAIDs, and concomitant use of antiplatelet or anticoagulant agents. Gabriel et al. ${ }^{(219)}$ analyzed 16 studies $(9$ controlled studies and 7 cohort studies) and concluded that the risk of a 
severe gastrointestinal event in NSAID users was 3-fold higher than that in non-users $(\mathrm{OR}=2.74)$. In addition, the following risk factors were identified: age $>60$ years; concomitant use of corticosteroids; and period of exposure to NSAIDs $<1$ month $(\mathrm{OR}=8.00), 1-3$ months $(\mathrm{OR}=3.31)$, and $>3$ months $(\mathrm{OR}=1.92)$, without significant differences between sexes. Laine et al. ${ }^{(220)}$ evaluated 8,076 rheumatoid arthritis patients aged $>45$ years who were randomized to treatment with either rofecoxib or naproxen, and they found that patients at higher risk of severe events (ulcer bleeding, perforation, obstruction, symptomatic ulcer) in the naproxen group were aged $\geq 75$ years and/or had a history of gastrointestinal complications.

The use of low-dose NSAIDs or aspirin in HP-infected patients has become increasingly common. The interactions between these associations may have a significant impact on the digestive tract. The symptoms caused by NSAIDs/ASA usually appear during the first days of treatment, although some studies suggest that the risk of complications is higher in the first 2 months. Current evidence indicates that the risk of complications is the same during treatment in patients treated with NSAIDs for either short or long periods ${ }^{(221)}$.

Chan et al. ${ }^{(22)}$ conducted a prospective study to assess the effect of HP infection on the risk of ulcer bleeding in three different groups, of which two groups had a history of ulcer bleeding. The first group included patients with ulcer bleeding $(n=249)$ who resumed aspirin use after HP eradication. The second group consisted of patients who were not infected with HP who presented ulcer bleeding due to low-dose ASA $(n=118)$. The third group included patients who started to use ASA without a previous history of ulcer $(n=537)$. None of the patients from the analyzed groups received antisecretory drugs, and the study was terminated in cases of occurrence of ulcer bleeding. In the patients with eradicated HP, the rate of recurrence of ulcer bleeding with the use of ASA was low, whereas the risk of recurrence of ulcer bleeding was high in patients treated with aspirin without past or current HP infection. The authors concluded that it was useful to evaluate the presence of HP to identify patients at high risk of ulcer bleeding among ASA users.

The guidelines of the Italian Consensus advised eradicating HP to decrease the risk of complicated or uncomplicated ulcerative disease, emphasizing that eradication was more effective in prevention when performed before initiating treatment with NSAIDs ${ }^{(223)}$.

Scarpignatto et al. ${ }^{(221)}$ indicated that although the role of HP and the benefit of HP eradication in the potential risk of gastrointestinal complications are controversial, eradication is beneficial in patients with risk factors (age $\geq 65$ years, previous history of ulcer and/or ulcer bleeding, concomitant use of anticoagulants or antiplatelet agents) provided that eradication is performed at the beginning of treatment with low-dose NSAIDs or ASA. HP eradication in patients who initiate treatment with low-dose ASA or NSAIDs reduced the risk of ulcer to an extent similarly to that of treatment with PPIs. However, eradication alone was not sufficient to prevent the relapse of ulcer and/or ulcer bleeding ${ }^{(224)}$.

The use of PPIs is necessary to decrease the risk of ulcers and ulcer bleeding in high-risk patients, even in those using coxibs, which are known to be less gastrotoxic than standard NSAIDs ${ }^{(40,219-221,225-227)}$.
In conclusion, in patients at high risk of ulcer and ulcer bleeding, including those who intend to start treatment with COX-1 and/or COX-2 inhibitors, HP infection should be screened and eradicated. However, eradication alone does not prevent recurrence of the ulcer and its complications, and therefore, the use of PPIs is mandatory.

\section{GROUP 3: GASTRIC CANCER}

\section{Statement 17 \\ Gastric cancer has an intermediate incidence in Brazil and is one of the five main causes of cancer mortality in the country, and its incidence exhibits regional differences. Level of evidence: $2 \mathrm{C}$ Grade of recommendation: $B$}

GC is the most common epithelial gastric neoplasm, representing $95 \%$ of the malignant tumors that affect the human stomach. Although the incidence of GC has decreased in recent decades, it is the second leading cause of cancer death worldwide, with more than 900,000 new cases per year ${ }^{(228)}$. The rate of GC is usually 2 to 3 times higher in developing countries than that in developed countries and is higher in men than in women. The National Cancer Institute of the Ministry of Health of Brazil ${ }^{(229)}$ estimated that there were 20,520 new cases of GC in 2016, including 12,920 cases in men and 7,600 cases in women. These rates correspond to an estimated risk of 13.04 new cases per 100,000 men and 7.37 cases per 100,000 women. There are regional differences in Brazil: without considering non-melanoma skin cancer, GC in men is the second most common cancer in the north $(11.62 / 100,000)$ and northeast $(10.67 / 100,000)$ and occupies the fifth place in the southeast region $(13.79 / 100,000)$. The mortality due to $\mathrm{GC}$ has been decreasing worldwide, including in Latin America $^{(230,231)}$. In Brazil, despite a mild decrease, mortality is high, and the survival rate during the first year of disease is estimated at $32 \%$ and decreases to $9 \%$ at the end of 5 years ${ }^{(232-234)}$.

\section{Statement 18 \\ $H P$ eradication is associated with a decrease in the rate of $G C$. Level of evidence: $1 \mathrm{~A}$ Grade of recommendation: A}

Epidemiological and experimental evidence have demonstrated that HP infection plays a role in $\mathrm{GC}^{(235)}$, leading the World Health Organization (WHO) to recognize HP as the only carcinogen for this type of cancer in group $\mathrm{I}^{(236)}$. Recent studies have validated previous evidence demonstrating that HP eradication interrupts the sequence of events known as Correa's cascade ${ }^{(237)}$ in cases in which the intervention occurs before the establishment of pre-neoplastic lesions such as metaplasia or dysplasia ${ }^{(238)}$. There are controversies concerning the efficacy of HP eradication in preventing GC in the presence of gastric atrophy ${ }^{(238-240)}$.

The role of HP eradication for preventing a second primary tumor is controversial. Studies examining this potential benefit after endoscopic or surgical resection indicate moderate efficacy, insufficient follow-up periods, and conflicting results ${ }^{(238-240)}$.

Although it is impossible to demonstrate, with high levels of evidence, the benefit of HP eradication in the presence of pre-neoplastic lesions or after a gastric tumor, some consider- 
ations are necessary to form a decision matrix: i) pre-neoplastic lesions affect only part of the mucosa, and extensive areas of the mucosa exposed to HP may benefit from HP eradication; ii) the field cancerization theory states that carcinogenic effects act in areas that are more extensive than those restricted to the tumor, justifying the occurrence of a second primary tumor in the same organ or region; iii) HP should be eradicated in relatives of $\mathrm{GC}$ patients because of their possible exposure to the same bacterial strains and presence of similar genetic backgrounds, indicating that the potential benefits of eradication to the gastric mucosa of the relatives are similar to those of individuals who have or had gastric tumors or pre-neoplastic lesions; and iv) most metaplasias do not evolve to $\mathrm{GC}^{(241)}$. Therefore, HP eradication is recommended in individuals with pre-neoplastic lesions, endoscopy-treated gastric tumors, or partial gastrectomy.

Despite the number of indications for HP eradication by different institutions, including this consensus, critical reflections and analyses are important: (i) experimental evidence for the role of HP in GC was obtained using a cancer model that is applicable only to intestinal cancer, including Correa's cascade of events, which do not occur in diffuse cancer; (see also statement 20) (ii) despite the lower exposure to HP due to improved sanitary conditions and higher rate of eradication, the expected decrease in the GC rate is restricted to the intestinal histological type according to Lauren's classification $^{(242-244)}$; and iii) the role of the stomach microbiota, the effects of the antibiotic therapy used to eradicate $\mathrm{HP}^{(245)}$, and prolonged use of drugs that modify the gastric $\mathrm{pH}$ are gaps in knowledge that need to be filled.

\section{Statement 19 \\ Serological analysis of gastric atrophy using pepsinogen I (PGI) and pepsinogen II (PGII), combined with antibodies against HP and gastrin 17, can be used to identify populations at risk of GC. However, further studies are necessary to validate this instrument in Brazil. \\ Level of evidence: $\mathbf{3 A}$

Grade of recommendation: B

Pepsinogens, which are pro-enzymes of pepsin, are classified into two types according to their biochemical and immunological properties: PGI and PGII. Both types are produced by the gastric mucosa, but in different regions. PGI is produced exclusively by chief and mucosal cells of the gastric body, whereas PGII is produced by these cells and by mucous cells of the cardiac region, pyloric glands, and Brunner glands in the duodenal mucosa. Both types are excreted primarily into the gastric lumen, but approximately $1 \%$ diffuse into the bloodstream and can be measured ${ }^{(246-247)}$.

The levels of PGI and PGII increase according to the degree of chronic gastritis associated with HP infection. However, when atrophic changes in the gastric body are accompanied by the loss of cells in the oxyntic mucosa, including cells that secrete PGI, serum levels of PGI are decreased while serum levels of PGII remain high or stable. However, in some cases, mucosal inflammation associated with HP infection may increase PGI and PGII levels, leading to normal PGI levels even in the presence of atrophy ${ }^{(248)}$. To overcome this limitation, the PGI/PGII ratio, which is currently considered the best serological marker of gastric atrophy, is used for gastric cancer screening in Japan and less often in other countries ${ }^{(249-255)}$. It is important to emphasize that the predictive value of measuring pepsinogens can be low in cases in which atrophy is restricted to the gastric antrum ${ }^{(256)}$. In addition to infection with HP and its various phenotypes, other factors may affect the serum levels of pepsinogens, including geographical region, race, age, gender, height, body weight, BMI, smoking, and use of alcohol $^{(257-258)}$. Therefore, the efficacy of pepsinogen and PGI/PGII ratio (PGR) measurement remain controversial, particularly for determining the best cut-off point of the PGR for the diagnosis of gastric atrophy. PGI levels $\leq 70 \mathrm{ng} / \mathrm{mL}$ and PGR $\leq 3$ are the most acceptable values for detecting gastric atrophy, and the sensitivity and specificity of these markers were found to be $66.7 \%-84.6 \%$ and $73.5 \%-87.1 \%$, respectively ${ }^{(250,259,260)}$. Studies have shown that the main commercial tests available for measuring serum levels of pepsinogens have good agreement with each other ${ }^{(261)}$.

The accuracy of the non-invasive diagnosis of gastric atrophy may be improved by including biomarkers other than pepsinogens. A study in Asia demonstrated that the association of the serological quantification of anti-HP antibodies with the level of pepsinogens (ABCD method) might help identify healthy adults at higher risk of developing $\mathrm{GC}^{(262)}$. Another combination of biomarkers $\left(\right.$ GastroPanel $\left.^{\circledR}\right)$ using a single blood sample allows the measurement of pepsinogens and gastrin 17 (for diagnosing antral atrophy) and quantifying anti-HP antibodies by serology. Two recent meta-analyses evaluated this panel. Syrienen ${ }^{(263)}$ analyzed the results of 8,654 patients from different countries and found that the sensitivity and specificity for diagnosing atrophic gastritis were $70.2 \%$ and $93.9 \%$ in the gastric body and $53.8 \%$ and $84.1 \%$ in the gastric antrum. Zagari et al. ${ }^{(264)}$ analyzed 20 studies involving 4,241 participants and found that the sensitivity for diagnosing atrophic gastritis in the gastric body and antrum was $70.4 \%$ and $65.4 \%$, respectively. However, few studies to date have measured the levels of pepsinogens for diagnosing gastric atrophy in Latin America ${ }^{(265)}$ and Brazil ${ }^{(266)}$. Therefore, well-designed studies with a large sample size are necessary to define the performance of this panel in this region.

\section{Statement 20}

Epidemiological, experimental, molecular, and clinical studies have confirmed the role of HP as a risk factor for gastric cancer. Level of evidence: $1 \mathrm{~A}$ Grade of recommendation: A

Epidemiological, laboratory, molecular, and bacterial eradication studies in humans have confirmed that HP is considered the major etiological factor for $\mathrm{GC}^{(267)}$. It is estimated that approximately $80 \%$ of malignant gastric tumors are associated with HP infection $^{(268)}$. The risk of GC due to HP is similar in the diffuse and intestinal subtypes ${ }^{(267)}$. HP eradication may decrease the risk of $\mathrm{GC}^{(269)}$. Clinical trials demonstrated that the incidence of GC might be decreased by $30 \%-40 \%$ in the eradicated bacteria patients group. The groups at risk of developing GC, including first-degree relatives of GC patients and immigrants from regions with a high rate of GC, should be screened and treated ${ }^{(270-273)}$. Treatments at the population level (screening and treatment) are recommended in regions with a high rate of $\mathrm{GC}^{(269)}$. Asian countries are implementing this strategy with promising results ${ }^{(274,275)}$. 
Role of HP in proximal GC: HP infection was believed to be associated only with distal GC. However, detailed studies taking into account the differentiation between proximal $\mathrm{GC}$, esophageal cancer, and junctional cancer found that the prevalence of HP in proximal GC was similar to that of distal $\mathrm{GC}^{(276-278)}$, and thus, HP was also associated with proximal GC. As a result, HP is now considered a risk factor for both types of GC.

\section{Statement 21}

The diagnosis of mucosa-associated lymphoid tissue lymphoma is based on the histopathological and immunohistochemical evaluation of gastric biopsies together with HP screening. Level of evidence: $1 \mathrm{~A}$ Grade of recommendation: A

MALT lymphoma of the stomach is characterized by the clonal expansion of lymphocytes from the extra-nodal marginal zone of lymphoid follicles, in which morphological, immunophenotypic, and MALT behavioral characteristics are reproduced $^{(279)}$. Therefore, diagnosis is based on the identification of these characteristics for determining the nature and staging of the lesion when assessing the natural history of the tissue.

\section{Diagnosis}

Gastric MALT lymphoma affects primarily middle-aged and elderly patients of both sexes ${ }^{(280)}$. These lymphomas are slow-growing, primarily superficial-located in the mucosa and submucosa - with a low incidence of mesenteric lymph node involvement and extra-nodal dissemination ${ }^{(281)}$. The most common presentation symptoms are nonspecific complaints of dyspepsia, which usually lead to endoscopy ${ }^{(281)}$. Endoscopic changes are nonspecific in most cases and present as flat, irregular, granular, or nodular mucosa with minimal ulceration. Mass formation is rare and favors the suspicion of high-grade lymphoma ${ }^{(282)}$. The diagnosis is based on the histopathological evaluation of gastric biopsies ${ }^{(283-285)}$. Samples should be collected from abnormal and normal areas and fixed in separate flasks. Histological analysis reveals a dense lymphoid infiltrate composed of small, morphologically heterogeneous B lymphocytes, which infiltrate the marginal zone of lymphoid follicles, extend into the interfollicular region, invade the germinal centers of the follicles, and infiltrate the epithelium in most cases, forming lymphoepithelial lesions ${ }^{(279,282)}$. Although no immunophenotypic marker specific for MALT lymphoma is available to date, immunohistochemical evaluation (using a marker panel including CD20, CD10, CD5, and cyclin D1) is essential for disease diagnosis and classification and allows characterization of the cell population in the lymphoid tissue ${ }^{(282,285)}$. Diagnosis should be based on the current WHO classification and confirmed by review by an expert in hematopathology $y^{(279,285)}$. HP infection is considered the main risk factor for MALT lymphoma, and disease regression occurs in most patients after HP eradication ${ }^{(286)}$. Therefore, the diagnosis of HP is mandatory. The analysis should be complemented by immunohistochemistry, RUT, the breath test, or serological tests in cases in which HP is not evidenced by HE staining ${ }^{(284,285)}$. In addition to routine histology and immunohistochemistry, fluorescence in situ hybridization (FISH) and polymerase chain reaction (PCR) may be used to identify the $t(11 ; 18)(\mathrm{p} 21 ; \mathrm{p} 21)$ chromosomal translocation in patients who are unlikely to respond to therapy with antibiotics ${ }^{(284-287)}$.

\section{Cancer staging}

During its natural history, MALT lymphoma can evolve with infiltration of the deep layers of the gastric wall and dissemination to lymph nodes, other regions of the body with MALT, regions favorable for the development of MALT lymphoma, and bone marrow. Disease staging evaluates the natural history of the disease, classifies disease spread and is positively correlated with the prognosis and prediction of the response to therapy. Disease spread can be staged using different classification systems. The most common staging systems are Ann Arbor and Lugan ${ }^{(288,289)}$. The recently developed Paris system accurately assesses the depth of gastric wall infiltration $^{(290)}$. The initial staging of MALT lymphoma is based on the clinical history and physical examination (including peripheral lymph nodes and Waldeyer ring), laboratory tests (standard biochemical analysis, complete blood count, lactic dehydrogenase, beta2-microglobulin, protein electrophoresis, in addition to serology for HIV, HBV, and HCV), and computed tomography of the chest, abdomen, and pelvis. Endoscopic ultrasound should be performed during the initial staging to assess the depth of gastric wall infiltration and regional lymph node infiltration. Bone marrow biopsy is recommended in cases in which the lymphoma does not regress after HP eradication and before initiating cancer treatment. Colonoscopy can be considered ${ }^{(284,285)}$.

\section{Statement 22}

The follow-up of patients with MALT lymphoma after HP eradication requires periodic histopathological evaluations. The GELA system is an adequate morphological method for follow-up.

Level of evidence: 4 Grade of recommendation: C

Since a clear majority of primary gastric marginal zone B cell lymphomas (MALT) arise in Helicobacter (H. pylori or $H$. heilmannii) infected stomachs, it is widely accepted that the elimination of Helicobacter would likely prevent most, if not all, these lymphomas. Likewise, the eradication of Helicobacter results in the complete remission of at least $70 \%$ of MALT lymphomas diagnosed in infected stomachs ${ }^{(291)}$, and also in a sizable percentage of patients in whom Helicobacter could not be demonstrated ${ }^{(292,293)}$.

Once the MALT lymphoma is diagnosed and Helicobacter pylori infection is eradicated, it is crucial to follow up the patient and evaluate how the lymphoid proliferation responds to treatment. No clear guidelines for the frequency of the follow up endoscopies have been issued, but a sensible approach would suggest that the first follow-up endoscopy be performed 3-6 months after eradication, and then, in patients with a complete response, every 12 months since an elevated risk for gastric carcinoma has been reported in patients with MALT lymphoma, especially when intestinal metaplasia or dysplasia are found ${ }^{(285)}$. The biopsy protocol should be extensive, since lymphomas are patchy and may be easily missed, particularly when in partial remission. The evaluation of monoclonality, particularly during the first year after eradication, is discouraged because it tends to yield many false positive results ${ }^{(294)}$. 
Pathologists should familiarize themselves with the GELA classification for the histopathologic evaluation of the follow up biopsies ${ }^{(295)}$. A simplified version of the classification is depicted in TABLE 1. A more recent set of guidelines for the diagnosis, treatment, and follow up of gastric marginal zone B cell lymphomas (MALT) of the gastrointestinal tract has been recently published ${ }^{(296)}$.

\section{Statement 23 \\ Staging of pre-neoplastic lesions should be based on at least four endoscopic biopsies (two antrum biopsies and two corpus biopsies) using the OLGA system for histological staging of gastritis. Patients staged as OLGA III or IV should undergo en- doscopic follow-up every 2 years. \\ Level of evidence: $2 \mathrm{C}$ \\ Grade of recommendation: B}

HP colonizes the gastric mucosa and induces the secretion of cytokines and free radicals during active inflammation, leading to the development of mucosal lesions and possible mutations in target cells ${ }^{(297,298)}$. These factors, which are directly or indirectly related to the presence of the bacterium, may act as the initial trigger in the carcinogenic process ${ }^{(299)}$. At some point in this process, the carcinogenic changes may continue regardless of the presence of the bacterium. This possibility reinforces the need for follow-up in patients with these lesions, even in the absence of HP. These lesions can be categorized into (a) gastric atrophy, usually subdivided into mild, moderate, or severe; (b) intestinal metaplasia, usually subdivided into complete and incomplete; and (c) gastric dysplasia, subdivided into low-grade and high-grade ${ }^{(300-302)}$.

Gastric atrophy during its evolution is associated with intestinal metaplasia (IM) in most cases, and both lesion types usually present a multifocal distribution ${ }^{(303)}$. The histological diagnosis of IM is relatively common in endoscopic biopsies. The prevalence of IM varies from $10 \%$ to $60 \%$ in non-selected patients infected with $\mathrm{HP}^{(304)}$. It is believed that the location of IM foci, especially in the incisura angularis, are more closely related to gastric carcinogenesis ${ }^{(305)}$. Of note, the glandular atrophy when restricted to the gastric body may not adequately fit the evolutionary aspects of $\mathrm{GC}^{(306-308)}$. Complete and incomplete IM are described based on the histological pattern and secretion of mucins. Incomplete IM has been more closely correlated with gastric carcinogenesis, particularly in cases in which sulfomucins characteristic of the colon are secreted ${ }^{(241,309,310)}$. In practice, the identification of sulfomucins in histological sections is impractical. However, relevance as pre-neoplastic lesions has been attributed to the extent of the areas of gastric atrophy and $\mathrm{IM}^{(311)}$. The practical effects of using different IM types in prognosis are limited and controversial ${ }^{(312,313)}$.
The same phenomenon occurs with the classification of the different degrees of gastric atrophy. The diagnosis of mild and moderate atrophy is inconsistent among different observers, limiting the diagnosis of possible regression in patients with eradicated $\mathrm{HP}^{(314,315)}$. Similar difficulties are also evidenced in the histological diagnosis of low-grade dysplasia. This diagnosis should be confirmed by at least two experts in pathology.

New histological classifications such as OLGA and OLGIM attempt to solve the problem of precancerous lesions $^{(316-318)}$. Although the histological diagnosis of IM (OLGIM) is more reliable than that of gastric atrophy (OLGA), the two systems seem to complement each other in the staging of chronic gastritis ${ }^{(319)}$. These classifications attempt to categorize patients across the spectrum of risk of GC, and different follow-up schemes are proposed depending on the classification of patients in this spectrum ${ }^{(320)}$

The natural history of gastritis, with its progression to metaplastic atrophy and the establishment of fields of cancerization prone to further molecular and phenotypic changes, possibly resulting in the development of cancer, provides the clinicopathologic rationale for primary and secondary cancer prevention strategies. Helicobacter pylori infection is, by far, the most common etiologic agent of this inflammatory changes and, consequently, the most common cause of non-syndromic gastric cancer, often referred to as environmental cancer. The primary prevention of $H$. pylori infection and its timely eradication (before extensive atrophic changes develop) are currently considered as the most effective cancer preventing strategies ${ }^{(321)}$. Secondary prevention is founded on the early detection and management of its precursor. Most gastric adenocarcinomas (typically the intestinal-type variant most commonly arising in the distal stomach) are the ultimate step of a cascade of phenotypic changes occurring in the gastric mucosa, triggered by non-self-limiting inflammation. This approach requires the complementary competences of gastroenterologists, oncologists, and pathologists be amalgamated into a common strategy of health policy, which must be tailored to country-specific gastric cancer incidence, socioeconomic, and cultural factors.

Since both extension and topographic distribution of gastric atrophy parallel the risk for gastric cancer, histological staging-systems to rank the risk for gastric cancer have been proposed and have become widely used. The OLGA system ${ }^{(322)}$ ranks patients in progressive stages ( 0 to IV) based on extension and topography of the atrophic metaplastic changes. Patients with stages III and IV have been designated as high-risk and dedicated follow-up has been recommended. The OLGIM system, based on similar principles, has restricted the assessment to intestinal metaplasia ${ }^{(318)}$. The prognostic value of both

TABLE 1. A simplified histologic classification of the different levels of remission following the treatment of MALT lymphomas. Modified from Copie-Bergman et al. $(2003)^{(295)}$

\begin{tabular}{lccc}
\hline Score & Infiltrate & LEL & Mucosa \\
\hline Complete remission & None & No & Normal or atrophic \\
Minimal residual Disease & Lymphoid aggregates or nodules & No & Normal or atrophic \\
Responding with residual disease & Scattered aggregates or nodules & Yes & Focally atrophic \\
Not responding & Diffuse or nodular & Yes & Unchanged \\
\hline
\end{tabular}

MALT: mucosa-associated lymphoid tissue; LEL: lymphoepithelial lesion. 
these gastritis staging systems has been documented in several studies involving series of patients in diverse populations.

Several international guidelines suggest that patients with extensive atrophic gastritis be entered in endoscopic surveillance protocols ${ }^{(4,223,320)}$. These guidelines recommend that patients with antrum-to-corpus spreading gastric atrophy have a surveillance endoscopy with biopsies at 3-year intervals. However, recent evidence gathered from a 5-year follow-up of 1,755 patients in an area of moderate to high incidence of gastric cancer indicates that the majority of neoplastic lesions were detected between 1 and 3 years from the initial OLGA staging evaluation ${ }^{(323)}$. This finding supports the recommendation that the 3-year endoscopy-interval for patients with antrum-to-corpus spreading gastric atrophy recommended by some international guidelines is too long. Therefore, based on this evidence and on expert opinion, this Brazilian Consensus recommends that these patients be followed at 2-year intervals.

\section{GROUP 4: TREATMENT}

\section{Statement 24}

Despite the increasing rates of resistance to clarithromycin and fluoroquinolones in Brazil, their use is still recommended for treating HP. Despite the high in vitro resistance of HP to nitroimidazoles, these drugs may be prescribed in specific situations, doses, and periods.

Level of evidence: $2 \mathrm{C}$

Grade of recommendation: B

The rate of bacterial eradication using the standard triple regimen has progressively decreased ${ }^{(324,325)}$. The factors responsible for the decrease in therapeutic efficacy include life habits, baseline disease, poor adherence to treatment, smoking, CYP2C19 genetic polymorphism, high gastric acidity, previous use of antimicrobials, and especially resistance of HP to antimicrobials, including clarithromycin, fluoroquinolone, and metronidazole ${ }^{(326-331)}$. Antibiotic resistance can be investigated in the laboratory using phenotypic or genotypic methods. Bacterial culture and measurement of the minimum inhibitory concentration (MIC) of antibiotics (phenotypic method) is infrequently used in clinical practice because of the difficulty associated with collecting and transporting samples, fastidious bacterial growth, and need for appropriate growth media for culturing ${ }^{(52)}$. More recently, molecular techniques (genotypic method), particularly PCR, have been progressively used to detect bacteria and identify point mutations, which is the main mechanism of antimicrobial resistance ${ }^{(332)}$. These methods are faster and allow the analysis of mixed strains, which is not always possible with culturing; furthermore, these methods can be performed directly in endoscopic gastric biopsies, thus precluding previous bacterial culture ${ }^{(332,333)}$. Commercial kits used for determining genotypic resistance to clarithromycin and fluoroquinolones are widely available, and studies comparing genotypic and phenotypic methods have shown a good correlation $^{(332-335)}$.

However, few studies to date have evaluated the resistance of HP to antimicrobials in Brazil. From 2010 to 2016, six national studies were conducted, of which only one multicenter study evaluated the resistance of HP to clarithromycin. The results indicated that the rate of primary resistance was $16.5 \%$ in Recife $(2010)^{(336)}, 8 \%$ in São Paulo, state of São Paulo(337), $2.5 \%$ in Marília, state of São Paulo (2013) $)^{(338)}, 13 \%$ in Porto Alegre, state of Rio Grande do Sul (2014) ${ }^{(339)}, 12.5 \%$ in Belo Horizonte, state of Minas Gerais (2016) ${ }^{(240)}$, and $16.9 \%$ in a national multicenter study (2016) ${ }^{(341)}$. For fluoroquinolones, the observed rates were $23 \%$ in São Paulo ${ }^{(337)}, 5 \%$ in Porto Alegre $^{(339)}, 11.1 \%$ in Belo Horizonte ${ }^{(340)}$, and $13.4 \%$ at the national level ${ }^{(341)}$. With regard to resistance to metronidazole, an analysis of seven national studies confirmed the previous results, indicating consistently high rates (approximately 54\%) ${ }^{(342)}$. The analysis of double resistance to clarithromycin and metronidazole at the national level suggested that the rates varied from $7.5 \%$ to $10 \%$. A previous study reported that the rates of resistance to amoxicillin, tetracycline, and furazolidone were usually lower than $5 \%{ }^{(342)}$.

\section{Statement 25}

The duration of HP eradication therapies should be 14 days, especially for the standard triple therapy, to achieve high rates of eradication.

Level of evidence: $2 \mathrm{~A}$

Grade of recommendation: B

The rates of HP eradication with first-line regimens have been decreasing in the past few years, especially with the use of triple therapy for 7 days $^{(343)}$. Meta-analyses have consistently demonstrated higher eradication rates in 14-day triple therapies containing clarithromycin than 7-day therapies ${ }^{(344-348)}$. These studies also showed a higher eradication rate using a 10-day therapeutic regimen than a 7-day regimen by approximately 4\%; the 14-day regimen had an increased rate by approximately $5 \%-6 \%$ compared with the 7 -day regimen. Other studies have confirmed these results ${ }^{(349-352)}$, and a recent Cochrane review showed that irrespective of the type and dose of antibiotics, increasing the duration of triple therapy with PPIs from 7 to 14 days significantly increased the rate of eradication of HP (45 studies, $72.9 \%$ vs. $81.9 \%)^{(348)}$. Considering this evidence, extension of the duration of triple therapies containing clarithromycin for 14 days was incorporated into the main guidelines on anti-HP therapy ${ }^{(40,353-355)}$. However, it should be noted that resistance to clarithromycin remains the main cause of failure of triple therapies, and the duration of treatment does not affect the high rates of resistance to clarithromycin in the general population (see below).

Quadruple therapy containing bismuth is used for treating and retreating HP infection. The duration of the bismuth-containing therapies remains controversial, but a study reported that eradication rates using a 7-day regimen were low ${ }^{(356)}$. Most studies suggest a duration of 10 to 14 days $^{(357-361)}$, and a 14-day regimen is recommended in areas with high rates of resistance to metronidazole (including Brazil), where 14-day therapies can overcome resistance ${ }^{(85)}$. It is of interest that randomized studies using capsules containing a combination of bismuth, metronidazole, and tetracycline combined with omeprazole for 10 days found eradication rates during the initial treatment and retreatment of infection $>90 \% 0^{(362-364)}$.

Some studies showed that the rate of eradication using a 14-day concomitant therapy without bismuth was higher than that using shorter regimens, particularly those using second-generation PPIs ${ }^{(365,366)}$. Park et al. conducted a prospective randomized study comparing sequential and concomitant 
therapy for 10 and 14 days and observed that the eradication rates with the concomitant regimen were $94.2 \%$ and $98.5 \%$ in these periods, respectively ${ }^{(367)}$.

Studies evaluating the efficacy of 10- and 14-day sequential therapies reported different results depending on the geographic region and types of medications used. The eradication rates using the 10-day schedule were $94.2 \%$ in Slovenia ${ }^{(368)}$, $91.7 \%$ in Korea ${ }^{(369)}$, and $80.0 \%$ in India ${ }^{(370)}$. Two systematic reviews and meta-analyses compared 10-day and 14-day sequential therapies with other therapies for HP and concluded that the 14-day therapy was the most effective ${ }^{(371,372)}$.

Statement 26
Using PPIs after HP eradication for healing duodenal pep-
tic ulcer is unnecessary. In cases of gastric ulcer or com-
plicated gastroduodenal ulcers, treatment with PPI for 4
to 8 weeks after eradication treatment is recommended.
Level of evidence: 2 C Grade of recommendation: B

Patients with gastric ulcer (GU) or duodenal ulcer (DU) and $\mathrm{HP}$ as the only lesion-triggering factor usually receive ET with antimicrobials associated with a PPI for 7-14 days, and then a 2-4-week course with an antisecretory drug such as PPI to promote ulcer healing. Claessens et al. ${ }^{(373)}$ reported that $75 \%$ of the evaluated ulcer patients continued to receive PPIs after ET. In 2005, Gisbert and Pajares ${ }^{(374)}$ conducted a systematic review and meta-analysis on this subject and found high rates of ulcer healing using ET without additional use of PPIs after antimicrobial withdrawal. A total of 24 studies and 2,342 patients were analyzed, and the rate of healing with 1 -week ET was $86 \%$. The healing rate was increased to $95 \%$ when considering only the patients who achieved HP eradication. The authors concluded that in patients with DU caused by HP, the healing rate of triple therapy without extending the use of PPIs to heal ulcers was $91 \%$, compared with $92 \%$ in those who prolonged the use of PPI for variable periods. The authors concluded that further use of PPIs was recommended only in patients who presented symptoms. Of note, Higuchi et al. ${ }^{(375)}$ randomly allocated 120 GU patients infected with HP to receive either ET or PPI for 8 weeks and concluded that ET complemented with PPI for a specific period might be necessary in patients with $\mathrm{GU}>10 \mathrm{~mm}$.

Gisbert et al. (2012) ${ }^{(376)}$ conducted an observational study and followed-up 1,000 patients who presented UGIB secondary to peptic ulcer and observed that ulcerations and new complications did not occur in patients with eradicated HP, indicating that maintenance of antisecretory therapy after eradication was not necessary. In 2016, the Cochrane group published a systematic review conducted by Ford et al. ${ }^{(377)}$ on this subject and concluded that ET for 1-2 weeks was effective for healing DU. However, the quality of the studies on GU was poor, and thus, there is little scientific evidence to date demonstrating that ET alone is sufficient for healing GU.

Considering this evidence, isolated therapy with ET in patients with GU or DU and infected with HP should use the regimen with higher local eradication capacity. The inclusion of antisecretory drugs may be beneficial to patients with large GUs $(>10 \mathrm{~mm})$ or persistent symptoms after ET. In cases of UGIB, the same therapeutic strategy can be used, reinforcing the importance of HP screening and initiation of treatment during hospitalization.

\section{Statement 27}

Triple therapy consisting of the combination of PPIs, amoxicillin, and clarithromycin for 14 days is recommended as the first-line treatment. Alternatives include quadruple therapy with bismuth for 10-14 days and concomitant therapy for 14 days. Level of evidence: $2 \mathrm{~A}$

Grade of recommendation: B

Among the factors that may affect the success of anti-HP therapy (adherence to treatment, smoking, altered immunity, hypersecretory states, high bacterial load, and associated diseases, among others), antimicrobial resistance is considered the primary contributor to therapeutic failure. Polymorphisms associated with cytochrome CYP2C19 and previous use of macrolides may also affect bacterial eradication when classic triple therapy is used ${ }^{(326,378)}$. During the past 20 years, triple therapy with PPI + clarithromycin + amoxicillin administered for 7 days was the most widely used regimen. However, there has been a marked decrease in efficacy in several countries in recent years, with success rates lower than $80 \%$ due to a significant increase in the rates of resistance to antibiotics, particularly clarithromycin 325). In Brazil, the higher resistance of HP to antimicrobials has become an increasing problem. From 2010 to 2016, six national studies were conducted, of which one multicenter study evaluated the resistance of HP to different antimicrobials and reported a rate of primary resistance to clarithromycin ranging from $2.5 \%-16.9 \%$ (see statement 24 ). These observed values, in some studies, reached the suggested threshold of resistance to clarithromycin of $15 \%$, where the rates higher than this threshold would preclude the use of this antimicrobial as first-line empirical therapy for $\mathrm{HP}^{(40)}$.

Recent studies have been conducted to optimize triple therapy. The results of a meta-analysis indicated that increasing the duration of triple therapy for 14 days slightly but consistently increased the rate of HP eradication (see statement 25). Similarly, the recommended use of high doses of PPIs, preferably rabeprazole or esomeprazole, in classical triple therapy in Europe and North America [where the prevalence of extensive or rapid metabolizers of PPIs is high $(56 \%-81 \%)$ ] increased bacterial eradication rates ${ }^{(379-381)}$. In Brazil, a few regional studies also found a high prevalence of extensive and rapid metabolizers in the general population ${ }^{(382-384)}$; further studies are needed to clarify this finding. Considering these results and despite the absence of controlled studies, the consensus recommends the maintenance of standard triple therapy for 14 days as the first treatment option, preferably using high doses of PPI formulations that are effective in patients who are extensive or rapid metabolizers of PPIs (TABLE 2). Further randomized controlled studies are needed to validate these therapies in Brazil.

The recommended alternatives to 14-day standard triple therapy include quadruple bismuth regimens (PPIs, bismuth, tetracycline, and metronidazole) for 10-14 days or concomitant therapy (PPI, amoxicillin, clarithromycin, and metronidazole or tinidazole) for 14 days $^{(385)}$ (TABLE 2). The use of metronidazole in both regimens may be problematic because of the high levels of resistance of HP to this medication. However, the increase in treatment duration and increase in imidazole dosage may overcome the resistance detected in vitro ${ }^{(85)}$. 
TABLE 2. Drugs, dosage, and duration of first-line treatments of infection with Helicobacter pylori

\begin{tabular}{|c|c|c|c|}
\hline Recommended & Drug & Drug & Length of treatment \\
\hline \multirow[b]{2}{*}{ Standard triple therapy } & PPI* & Full dose at $12 / 12 \mathrm{~h}$ & \multirow[b]{2}{*}{14 days } \\
\hline & Clarithromycin & $500 \mathrm{mg}$ at $12 / 12 \mathrm{~h}$ & \\
\hline \multicolumn{4}{|l|}{ Alternatives } \\
\hline \multirow{3}{*}{ Quadruple therapy with bismuth } & PPI & Full dose at $12 / 12 \mathrm{~h}$ & \multirow{3}{*}{ 10-14 days } \\
\hline & Tetracycline hydrochloride** & $500 \mathrm{mg}$ at $6 / 6 \mathrm{~h}$ & \\
\hline & Metronidazole & $400 \mathrm{mg}$ at $8 / 8 \mathrm{~h}$ & \\
\hline $\begin{array}{l}\text { Concomitant therapy without } \\
\text { bismuth }\end{array}$ & PPI & Full dose at $12 / 12 \mathrm{~h}$ & 14 days \\
\hline
\end{tabular}

*PPIs: proton pump inhibitors. Studies indicated that the use of second-generation PPIs (rabeprazole and esomeprazole) in this situation might increase eradication rates ${ }^{(379-381)}$. Full dose: omeprazole $20 \mathrm{mg}$, lansoprazole $30 \mathrm{mg}$, pantoprazole $40 \mathrm{mg}$, rabeprazole $20 \mathrm{mg}$, dexlansoprazole $60 \mathrm{mg}$, vonoprazan $20 \mathrm{mg}$, or esomeprazole $40 \mathrm{mg}$. **Tetracycline hydrochloride, if not available, may be replaced with doxycycline $100 \mathrm{mg}$ at $12 / 12 \mathrm{~h}^{(3)}$.

Recommended as an alternative to the standard triple therapy in areas of high resistance to clarithromycin $(>15 \%)$, the efficacy of the concomitant regimen is determined by the rates of double resistance of HP to clarithromycin and nitroimidazoles, and it is accepted that the rates of cure can reach approximately $90 \%$ in cases in which the double resistance rate does not exceed 15\%(40,386-388). In Brazil, considering a rate of resistance to metronidazole and clarithromycin of approximately $54 \%{ }^{(342)}$ and $16.9 \% \%^{(341)}$, respectively, the estimated rate of double resistance to both antimicrobials ranges from $7.5 \%-10.0 \%{ }^{(40)}$. However, no controlled studies to date have evaluated these therapeutic options in Brazil. Quadruple regimens containing bismuth and employing furazolidone in place of metronidazole have shown good results in $\mathrm{Brazil}^{(3)}$. However, suspension of the commercialization of furazolidone and the recent unavailability of bismuth salts in Brazil has limited the use of this therapeutic option. From a practical stance, it is important to note that, in quadruple bismuth therapy, tetracycline can be replaced by amoxicillin with similar results ${ }^{(389)}$. This finding is especially relevant because of the irregular availability of tetracycline in Brazil. Sequential therapy with PPI and amoxicillin for the first 5 days followed by maintenance of PPI associated with clarithromycin and tinidazole for another 5 days is no longer considered a first-line option. This therapy is complex, highly variable in different regions, and the results are similar to those of concomitant therapy and 14day triple therapy ${ }^{(390)}$. In Brazil, a study comparing sequential therapy showed that the rate of eradication of HP $(86 \%)$ was similar to that of standard triple therapy for 10 days $^{(391)}$. Furthermore, data on the outcomes of hybrid therapy (PPI associated with amoxicillin for 5-7 days followed by PPI, amoxicillin, clarithromycin, and metronidazole for another 5-7 days) as the first-line option are limited and inconsistent ${ }^{(40)}$.

\begin{abstract}
Statement 28
In cases of failure of triple therapy with clarithromycin or concomitant quadruple therapy, the recommended strategies are triple therapy with levofloxacin or quadruple therapy with bismuth, both for 10-14 days. In cases of failure of one of the two recommended second-line regimens, the other regimen should be used as third-line therapy.

Level of evidence: $2 \mathrm{~A}$

Grade of recommendation: B
\end{abstract}

Bacterial resistance is considered the main factor associated with therapeutic failure, particularly resistance to clarithromycin. Therefore, simple repetition of the standard triple scheme is not recommended because the cure rates achieved in this situation are less than $50 \%{ }^{(392)}$.

The anti-HP regimen with PPI, amoxicillin, and levofloxacin is one of the most commonly used regimens worldwide for retreating HP infections after failure of the first-line regimen using clarithromycin, and a meta-analysis found that the eradication rates were close to $80 \%{ }^{(392)}$. The anti-HP regimen with PPI, amoxicillin, and levofloxacin is well tolerated and may cause mild gastrointestinal adverse events. This regimen is cheap and is available in kits, optimizing adherence to treatment. As a limitation, recent studies have called attention to the increasing rate of resistance of HP to quinolones ${ }^{(324)}$. A recent multicenter study in Brazil found that the rate of resistance of HP strains to fluoroquinolones was $13.4 \%{ }^{(341)}$, which is similar to the rate found in 18 European countries $(14 \%)^{(327)}$. Although the duration of treatment was 10 days in most studies, a comparative study reported higher rates of eradication using 14-day compared with 10-day regimens ${ }^{(393)}$. The dose of $500 \mathrm{mg}$ daily (or $250 \mathrm{mg}$ twice daily) of levofloxacin was better tolerated, the efficacy was similar to that of higher doses, and the dose increase could not overcome drug resistance ${ }^{(394-397)}$. To increase the success rates of quinolone triple therapies, some 
studies have added bismuth salt to the regimen, which provided good results for eradication ${ }^{(398,399)}$.

Quadruple bismuth therapy (PPI, bismuth, tetracycline, and metronidazole) is usually recommended during retreatment, with eradication rates approaching $80 \%{ }^{(392)}$. Although it constitutes the oldest anti-HP regimen, there is variability in the optimal doses of the constituents suggested by different consensuses ${ }^{(40,353)}$. A meta-analysis subanalysis compared retreatment with PPI, levofloxacin, and amoxicillin for 10 days with quadruple therapy with bismuth and demonstrated that triple therapy with levofloxacin was more effective $(89 \% \text { vs } 66 \% \text {; OR }=4.22 ; 95 \% \mathrm{CI}=2.84-6.26)^{(392)}$. The limiting factors of quadruple therapy with bismuth include its complexity, large number of tablets to be ingested, and the varying availability of tetracycline. A single capsule containing a combination of bismuth, tetracycline, and metronidazole with good initial results in different countries (see statement 27) was introduced to the pharmaceutical market, but it is not yet available in Brazil. The objective of this therapy is to optimize the dosage of quadruple therapy with bismuth.
Considering the failure of the second treatment using triple therapy with levofloxacin, a third treatment using quadruple therapy with bismuth and vice versa is recommended. In cases in which the first-line regimen did not include clarithromycin, the standard triple regimen with clarithromycin for 14 days is recommended as second-line therapy.

The main regimens recommended as the second or third option in cases of failure of standard triple scheme are shown in TABLE 3, and other therapeutic regimens used for retreating HP infection are shown in TABLE 4.

\section{Statement 29}

Treatment after three therapeutic failures should be restricted to special cases and guided by phenotypic or genotypic tests of antimicrobial susceptibility. The use of rifabutin, when available, may be an alternative.

Level of evidence: $3 \mathrm{~A}$

TABLE 3. Drugs, dosage, and duration of the main regimens recommended as the second- or third-line regimen in cases of failure of standard triple therapy

\begin{tabular}{lccc}
\hline & Drug & Dose & Length of treatment \\
\hline Recommended & PPIs* & Full dose at $12 / 12 \mathrm{~h}$ \\
Triple therapy with levofloxacin & Amoxicillin & $1.0 \mathrm{~g}$ at $12 / 12 \mathrm{~h}$ \\
& Levofloxacin & $500 \mathrm{mg}$ at $24 / 24 \mathrm{~h}$ \\
Quadruple therapy with bismuth & PPIs & Full dose at $12 / 12 \mathrm{~h}$ & $10-14$ days \\
& Colloidal bismuth subcitrate & $120 \mathrm{mg}$ at $6 / 6 \mathrm{~h}$ or $240 \mathrm{mg}$ at $12 / 12 \mathrm{~h}$ \\
& Tetracycline hydrochloride** & $500 \mathrm{mg}$ at $6 / 6 \mathrm{~h}$ & $10-14$ days \\
\hline
\end{tabular}

*PPIs: proton pump inhibitors. Full dose: omeprazole $20 \mathrm{mg}$, lansoprazole $30 \mathrm{mg}$, pantoprazole $40 \mathrm{mg}$, rabeprazole $20 \mathrm{mg}$, dexlansoprazole $60 \mathrm{mg}$, vonoprazan $20 \mathrm{mg}$, or esomeprazole $40 \mathrm{mg}$. **Tetracycline hydrochloride, if not available, may be replaced with doxycycline $100 \mathrm{mg}$ at $12 / 12 \mathrm{~h}^{(3)}$.

TABLE 4. Drugs, dosage, and duration of alternative regimens used as the second- or third-line regimen for eradicating Helicobacter pylori in cases of failure of the first regimen

\begin{tabular}{|c|c|c|c|}
\hline & Drug & Dose & Length of treatment \\
\hline \multirow{3}{*}{ Quadruple therapy with furazolidone ${ }^{(3) *}$} & PPIs** & Full dose at $12 / 12 \mathrm{~h}$ & \multirow{3}{*}{ 10-14 days } \\
\hline & Amoxicillin & $1.0 \mathrm{~g}$ at $12 / 12 \mathrm{~h}$ & \\
\hline & Colloidal bismuth subcitrate & $240 \mathrm{mg}$ at $12 / 12 \mathrm{~h}$ & \\
\hline \multirow{3}{*}{$\begin{array}{l}\text { Quadruple therapy with levofloxacin and } \\
\text { bismuth }(398,399) * * *\end{array}$} & PPIs & Full dose at $12 / 12 \mathrm{~h}$ & \multirow{3}{*}{14 days } \\
\hline & Levofloxacin & $500 \mathrm{mg}$ at $24 / 24 \mathrm{~h}$ & \\
\hline & Amoxicillin & $1.0 \mathrm{~g}$ at $12 / 12 \mathrm{~h}$ & \\
\hline \multirow{3}{*}{$\begin{array}{l}\text { Standard triple therapy with } \\
\text { clarithromycin**** }\end{array}$} & PPIs* & Full dose at $12 / 12 \mathrm{~h}$ & \multirow{3}{*}{14 days } \\
\hline & Clarithromycin & $500 \mathrm{mg}$ at $12 / 12 \mathrm{~h}$ & \\
\hline & Amoxicillin & $1.0 \mathrm{~g}$ at $12 / 12 \mathrm{~h}$ & \\
\hline
\end{tabular}

*Doxycycline $100 \mathrm{mg}$ at $12 / 12 \mathrm{~h}$ can replace amoxicillin. Eradication rates close to $80 \%{ }^{(3)}$. **PPIs: proton pump inhibitors. Full dose: omeprazole $20 \mathrm{mg}$, lansoprazole $60 \mathrm{mg}$, pantoprazole $40 \mathrm{mg}$, rabeprazole $20 \mathrm{mg}$, dexlansoprazole $60 \mathrm{mg}$, vonoprazan $20 \mathrm{mg}$, or esomeprazole $40 \mathrm{mg}$. *** Few studies, with intention-to-treat eradication rates of $85 \%-90 \%$. ****Recommended as a second regimen when the first regimen was quadruple therapy with bismuth or triple therapy with levofloxacin and as a third regimen when the first treatment was quadruple therapy with bismuth and the second treatment was triple therapy with levofloxacin. 
Treatment after failure of three previous treatments is an exception and should be used in patients known to be adherent to treatment and in situations in which HP eradication is critical, such as patients with MALT lymphoma, GC resection, or a family history of GC. The choice of the antibiotic scheme should, whenever possible, be guided by sensitivity studies (culture or molecular genetic tests) of antibiotic resistance. Previous knowledge of earlier regimens also helps in establishing therapy. Rifabutin (not available in Brazil to date) is an antibiotic with high anti-HP activity, a mean HP resistance rate of only $1.3 \%$, and a mean eradication rate of $73 \%{ }^{(400)}$. A systematic review of 21 trials using rifabutin to retreat HP infection indicated that the eradication rates were $79 \%$ when used as second-line therapy and $66 \%-70 \%$ when used as third-line therapy or higher, with global mean eradication rates of $73 \%(95 \% \mathrm{CI} \text { : } 67 \%-79 \%)^{(401)}$. The most widely used therapeutic regimen included a combination of full-dose PPIs, rifabutin $150 \mathrm{mg}$, and amoxicillin $1.0 \mathrm{~g}$ twice daily for 10 days $^{(400,401)}$. A study using this dosage as the fourthline treatment in 190 patients found that the eradication rates were $52 \%(95 \% \mathrm{CI}: 45 \%-59 \%)^{(402)}$. The most common adverse event was reversible myelotoxicity at the end of treatment ${ }^{(400)}$.

\section{Statement 30}

The recommendation for individuals with allergy to amoxicillin is PPI $2 x$ day + clarithromycin $500 \mathrm{mg} 2 x$ day + levofloxacin $500 \mathrm{mg} 1 \mathrm{x}$ day for 14 days; or IBP $2 x$ day + doxycycline $100 \mathrm{mg}$ $2 x$ day; or tetracycline $500 \mathrm{mg} 4 x$ day + metronidazole $500 \mathrm{mg}$ $3 x$ day + bismuth $240 \mathrm{mg} 2 x$ day for 14 days.

Level of evidence: 4

Grade of recommendation: $\mathrm{C}$

The actual prevalence of penicillin allergy in the population is controversial. Although some studies reported that $3 \%-10 \%$ of the population of Japan and the United States are allergic to penicillin, other studies found that approximately $90 \%$ of these patients had negative skin tests and could tolerate penicillin without hypersensitivity ${ }^{(354,403,404)}$. To date, few studies with adequate sampling have determined the best therapeutic regimen in the impossibility of use of amoxicillin. A recent prospective study reported that the eradication rate using quadruple therapy with PPI, bismuth, tetracycline, and metronidazole in patients allergic to penicillin was $75 \%$ compared with a triple regimen consisting of PPI, metronidazole, and clarithromycin $(59 \% ; P<0.05)$. The most effective regimen as a second treatment or retreatment option was the combination of PPI, clarithromycin, and levofloxacin ${ }^{(405)}$.

\section{Source of funding}

The Núcleo Brasileiro para Estudo do Helicobacter pylori $e$ Microbiota had grant support from EMS, Ache, and Farmoquímica. The fundings source had no role in the study design, conduct, data collection, statistical analysis, manuscript preparation, interpretation or decision to submit the manuscript for publication.

\section{Authors' contribution}

Coelho LGV: designed the meting, conceived the initial statements, writing one statement, discussion and voting all the statements, and manucript writing. Marinho JR: designed the meting, writing two statements, discussion and voting all the statements. Genta R: writing two statements, discussion and voting all the statements. Ribeiro LT: writing two statements, discussion and voting all the statements. Passos MCF: writing two statements, discussion and voting all the statements. Zaterka S: writing one statement, and discussion and voting all the statements. Assumpção PP: writing one statement, and discussion and voting all the statements. Barbosa AJA: writing one statement, and discussion and voting all the statements. Barbuti R: writing two statements, and discussion and voting all the statements. Braga LL: writing one statements, and discussion and voting all the statements. Breyer $\mathrm{H}$ : writing one statements, and discussion and voting all the statements. Carvalhaes A - discussion and voting all the statements. Chinzon D: writing two statements, and discussion and voting all the statements. Cury M: writing one statement, and discussion and voting all the statements. Domingues G: writing one statement, and discussion and voting all the statements. Jorge JL: writing one statement, and discussion and voting all the statements. Maguilnik I: writing one statement, and discussion and voting all the statements. Marinho FP: writing one statement, and discussion and voting all the statements. Moraes Filho JP: writing two statements, and discussion and voting all the statements. Parente JML: writing one statement, and discussion and voting all the statements. Paula e Silva CM: writing one statement, and discussion and voting all the statements. Pedrazzoli Júnior J: writing two statements, and discussion and voting all the statements. Ramos AFP: writing one statement, and discussion and voting all the statements. Seidler $\mathrm{H}$ : writing one statement, and discussion and voting all the statements. Spinelli JN: writing one statement, and discussion and voting all the statements. Zir JV: discussion and voting all the statements.

\section{Conflicts of interest}

Coelho LGV: consultant from EMS; Marinho JR: consultant from EMS and Farmoquímica; Passos MCF: consultant from Apsen, EMS, Farmoquimica, and Mantecorp; Zaterka S: consultant from Takeda, and EMS; Barbuti R: consultant from Ache, and EMS; Chinzon D consultant from Takeda, and Mantecorp; Pedrazzoli Júnior J: consultant from EMS; Marinho FP consultant from EMS, and Farmoquímica; Parente JML; Genta R, Assumpção P, Barbosa AJA, Braga LL, Breyer H, Carvalhaes A, Cury M, Domingues G, Jorge JL, Maguilnik I, JP Moraes Filho, Paula e Silva CM, Ramos AFP, Ribeiro LT, Seidler H, Spinelli JN, Zir JV: no conflicts of interest. 
Coelho LGV, Marinho JR, Genta R, Ribeiro LT, Passos MCF, Zaterka S, Assumpção PP, Barbosa AJA, Barbuti R, Braga LL, Breyer H, Carvalhaes A, Chinzon D, Cury M, Domingues G, Jorge JL, Maguilnik I, Marinho FP, Moraes Filho JP, Parente JML, Paula e Silva CM, Pedrazzoli Júnior J, Ramos AFP, Seidler H, Spinelli JN, Zir JV. IV Consenso Brasileiro sobre a infecção por Helicobacter pylori. Arq Gastroenterol. 2018;55(2):97-121.

RESUMO - Os avanços significativos ocorridos desde o III Consenso Brasileiro sobre H. pylori realizado em 2012, em Bento Gonçalves, justificam este quarto consenso. O evento foi organizado pelo Núcleo Brasileiro para Estudo do Helicobacter e Microbiota, associação vinculada à Federação Brasileira de Gastroenterologia, tendo sido realizado novamente em Bento Gonçalves, RS, nos dias 25 a 27 de agosto de 2017. Participaram 26 delegados provenientes das cinco regiões brasileiras incluindo gastroenterologistas, endoscopistas e patologistas, além de um convidado internacional (EUA). Os participantes foram convidados pelo conhecimento e contribuição ao estudo da infecção por $H$. pylori. O encontro buscou rever diferentes aspectos relacionados ao tratamento da infecção, suas inter-relações com a dispepsia, microbiota e outras afecções, com ênfase especial ao câncer gástrico, além de promover uma reavaliação dos aspectos epidemiológicos e diagnósticos desta infecção. Os participantes foram alocados em quatro grupos, a saber: 1) Epidemiologia e diagnóstico, 2) Dispepsia, microbiota e outras afecções, 3) Neoplasias gástricas, e 4) Tratamento. Previamente à reunião do Consenso, os participantes receberam um tema a ser discutido e elaboraram texto com uma revisão recente da literatura, contendo uma assertiva de sua revisão. Todas as assertivas foram avaliadas em dois turnos de votação. Inicialmente, cada participante apresentava sua compilação e assertiva ao seu grupo, para eventuais modificações e votação. Posteriormente, em uma segunda votação, agora em sessão plenária, as assertivas eram novamente votadas e eventualmente modificadas. As votações obedeceram a cinco alternativas: 1) concorda fortemente; 2) concorda com reservas; 3) indeciso; 4) discorda e; 5) discorda fortemente. O índice de consenso adotado para cada afirmativa foi de $80 \%$ dos votantes respondendo que concorda fortemente ou concorda com reservas. As recomendações aqui apresentadas foram baseadas nas evidências científicas mais relevantes para o manuseio da infecção por H. pylori na população adulta no Brasil.

DESCRITORES - Helicobacter pylori. Infecções por Helicobacter. Infecções por Helicobacter, terapia. Infecções por Helicobacter, diagnóstico.

\section{REFERENCES}

1. Coelho LGV, Barros CAS, Lima DCA, Barbosa AJA, Magalhães AFN, Oliveira CA, et al. Consenso Nacional sobre H. pylori e afecções associadas. GED Gastroenterol Endosc Dig. 1996;15:53-8.

2. Coelho LG, Zaterka S e Representantes indicados pela Federação Brasileira de Gastroenterologia e Núcleo Brasileiro para o Estudo do Helicobacter II Consenso Brasileiro sobre H. pylori. Arq Gastroenterol. 2005;42:128-32.

3. Coelho LG, Maguilnik I, Zaterka S, Parente JM, Passos MC, Moraes-Filho JP. 3rd Brazilian Consensus on H. pylori. Arq Gastroenterol. 2013;50;81-96.

4. Sugano K, Tack J, Kuipers EJ, Graham DY, El-Omar EM, Miura S, et al. Kyoto global consensus report on H. pylori gastritis. Gut 2015;64:1353-67.

5. Projeto Diretrizes. Associação Médica Brasileira e Conselho Federal de Medicina. [Internet]. [Access 2017 Dec 28]. Available from: http://www.portalmedico.org.br/diretrizes/100_diretrizes/Texto_Introdutorio.pdf.

6. Correa P, Piazuelo MB. Natural history of $H$. pylori infection. Dig Liver Dis. 2008;40:490-6.

7. Malaty HM. Epidemiology of H. pylori infection. Best Pract Res Clin Gastroenterol. 2007;21:205-14

8. Go MF. Review article: natural history and epidemiology of $H$. pylori infection. Aliment Pharmacol Ther. 2002;16 Suppl 1:3-15.

9. Bui D, Brown HE, Harris RB, Oren E. Serologic evidence for fecal-oral transmission of H. pylori. Am J Trop Med Hyg. 2016;94:82-8.

10. Escobar ML, Kawakami E. Evidence of mother-child transmission of $H$. pylori infection. Arq Gastroenterol. 2004;41:239-44

11. Krueger WS, Hilborn ED, Converse RR, Wade TJ. Environmental risk factors associated with $H$. pylori seroprevalence in the United States: a cross-sectional analysis of NHANES data. Epidemiol Infect. 2015;143:2520-31.

12. Nguyen T, Ramsey D, Graham D, Shaib Y, Shiota S, Velez M, et al. The prevalence of $H$. pylori remains high in African American and Hispanic veterans. Helicobacter. 2015;20:305-15.

13. Yokota S, Konno M, Fujiwara S, Toita N, Takahashi M, Yamamoto S, et al. Intrafamilial, preferentially mother-to-child and intraspousal, H. pylori infection in Japan determined by mutilocus sequence typing and random amplified polymorphic DNA fingerprinting. Helicobacter. 2015;20:334-42.

14. Osaki T, Konno M, Yonezawa H, Hojo F, Zaman C, Takahashi M, et al. Analysis of intra-familial transmission of $H$. pylori in Japanese families. J Med Microbiol. 2015; 64:67-73.

15. Aziz RK, Khalifa MM, Sharaf RR. Contaminated water as a source of $H$.pylori infection: A review. J Advanced Res. 2015;6:539-47.

16. Eshraghian A. Epidemiology of $H$. pylori infection among the healthy population in Iran and countries of the Eastern Mediterranean Region: A systematic review of prevalence and risk factors. World J Gastroenterol. 2014;20:17618-25.

17. Fox JG. Non-human reservois of H. pylori. Aliment Pharmacol Ther. 1995;9 Suppl 2:93- 103 .
18. Mègraud F, Broutet N. Review article: have we found the source of $H$. pylori? Aliment Pharmacol Ther. 2000;14 Suppl 3:7-12.

19. Dube C, Tanih NF, Ndip RN. H. pylori in water sources: a global environmental health concern. Rev Environ Health. 2009;24:1-14.

20. Brown LM. H. pylori: epidemiology and routes of transmission. Epidemiol Rev. 2000;22:283-97.

21. Leandro Liberato SV, Hernández Galindo M, Torroba Álvarez T, Sánchez Miramón F, Leandro Ciriza SE, Gómez Abadía A, et al. H. pylori infection in the child population in Spain: prevalence, related factors and influence on growth. An Pediatr (Barc). 2005;63:489-94.

22. Weyermann M, Adler G, Brenner H, Rothenbacher D. The mother as source of H. pylori infection. Epidemiology. 2006;17:332-4.

23. Weyermann M, Rothenbacher D, Brenner H. Acquisition of H.pylori infection in early childhood: independent contributions of infected mothers, fathers, and siblings. Am J Gastroenterol. 2009; 104:182-9.

24. Queiroz DM, Carneiro JG, Braga-Neto MB, Fialho AB, Fialho AM, Goncalves MH, et al. Natural history of $H$. pylori infection in childhood: eight-year follow-up cohort study in an urban community in northeast of Brazil. Helicobacter. 2012;17:23-9.

25. Parente JM, Da Silva BB, Palha-Dias MPS, Zaterka S, Nishimura NF, Zeitune JM. $H$ pylori infection in children of low and high socioeconomic status in northeastern Brazil. Am J Trop Med Hyg. 2006;75:509-12.

26. Rodrigues MN, Queiroz DMM, Braga ABC, Rocha AMC, Eulailo EC, Braga LLBC History of breastfeeding and $H$. pylori infection in children: results of a community-based study from northeastern Brazil. Trans R Soc Trop Med Hyg. 2006;100:470-5.

27. Braga AB, Fialho AMN, Rodrigues MN, Queiroz DMM, Rocha AMC, Braga LLBC. $H$. pylori colonization among children up to 6 years: results of a community-based study from Northeastern Brazil. J Trop Pediatr. 2007;53:393-7.

28. Cartágenes VD, Martins LC, Carneiro LM, Barile KA dos S, Corvelo TC. H. pylori in children and association with CagA strains in mother-child transmission in the Brazilian amazon region. Rev Soc Bras Med Trop. 2009;42:298-302.

29. Almeida Cunha RP, Alves FP, Rocha AM, Rocha GA, Camargo LM, Nogueira PO, et al. Prevalence and risk factors associated with $H$. pylori infection in native populations from Brazilian western amazon. Trans R Soc Trop Med Hyg. 2003;97:382-6.

30. Zaterka S, Eisig JN, Chinzon D, Rothstein W. Factors Related to H. pylori Prevalence in an adult population in Brazil. Helicobacter. 2007;12:82-8.

31. Graham DY, Klein PD, Evans DJ Jr, Evans DG, Alpert LC, Opekun AR, et al. Campylobacter pylori detected noninvasively by the 13C-urea breath test. Lancet. 1987;1:1174-7.

32. Gisbert JP, Pajares JM. Review article: 13C-urea breath test in the diagnosis of H. pylor infection: a critical review. Aliment Pharmacol Ther. 2004;20:1001-17.

33. Nocon M, Kuhlmann A, Leodolter A, Roll S, Vauth C, Willich SN, et al. Efficacy and cost-effectiveness of the 13C-urea breath test as the primary diagnostic investigation for the detection of Helicobacter pylori infection compared to invasive and non-invasive diagnostic tests. GMS Health Technol Assess. 2009;5. doi: 10.3205/hta000076 Doc14. 
34. Ferwana M, Abdulmajeed I, Alhajiahmed A, Madani W, Firwana B, Hasan R, et al. Accuracy of urea breath test in H. pylori infection: meta-analysis. World J Gastroenterol. 2015;21:1305-14.

35. Ling D. Carbon-13 urea breath test for H.pylori infection in patients with uninvestigated ulcer-like dyspepsia: an evidence-based analysis. Ontario Health Technology Assessment Series; Vol. 13: No. 19, pp. 1-30, October 2013.

36. Coelho LG, Reber M, Passos MC, Aguiar RO, Casaes PE, Bueno ML, et al. Application of isotope-selective non-dispersive infrared spectrometry for the evaluation of the 13C-urea breath test: comparison with three concordant methods. Braz J Med Biol Res. 1999;32:1493-7

37. Kawakami E, Machado RS, Reber M, Patricio FR. 13C-urea breath test with infrared spectroscopy for diagnosing $H$. pylori infection in children and adolescents. J Pediatr Gastroenterol Nutr. 2002;35:39-43.

38. Leal YA, Flores LL, Fuentes-Pananá EM, Cedillo-Rivera R, Torres J. 13C-urea breath test for the diagnosis of $H$. pylori infection in children: a systematic review and meta-analysis. Helicobacter. 2011;16:327-37.

39. Howden CW, Hunt RH. Guidelines for the management of H. pylori infection. Ad Hoc Committee on practice Parameters of the American College of Gastroenterology. Am J Gastroenterol. 1998;93:2330-8.

40. Malfertheiner P, Megraud F, O'Morain CA, Gisbert JP, Kuipers EJ, Axon AT, et al. Management of Helicobacter pylori infection-the Maastricht V/Florence Consensus Report. Gut. 2017;66:6-30.

41. Coelho LG, Santana CR, Bendasolli JA, Oliveira RB, Ferrioli E, Cezar RC, et al. Performance of 13C-urea breath test using substrate synthesized in Brazil. Helicobacter. 2016;21 Suppl 1:92-3.

42. Epple HJ, Kirstein FW, Bojarski C, Frege J, Fromm M, Riecken EO, et al. 13C-urea breath test in $H$. pylori diagnosis and eradication. Correlation to histology, origin of 'false' results, and influence of food intake. Scand J Gastroenterol. 1997;32:308-14.

43. Klein PD, Graham DY. Minimum analysis requirements for the detection of $H$. pylori infection by the 13C-urea breath test. Am J Gastroenterol. 1993;88:1865-9.

44. Slomianski A, Schubert T, Cutler AF. 13C-urea breath test to confirm eradication of H. pylori. Am J Gastroenterol. 1995;90:224-6.

45. Savarino V, Vigneri S, Celle G. The $13 \mathrm{C}$ urea breath test in the diagnosis of H. pylori infection. Gut. 1999;45:18-22.

46. Moshkowitz M, Konikoff FM, Peled Y, Santo M, Hallak A, Bujanover Y, et al. High H. pylori numbers are associated with low eradication rate after triple therapy. Gut 1995;36:845-7.

47. Atherton JC. Non-endoscopic tests in the diagnosis of H. pylori infection. Aliment Pharmacol Ther. 1997;11 Suppl 1:11-20.

48. Shmuely H, Yahav J, Samra Z, Chodick G, Ofek I. Elevated 13C urea breath test values females infected with $H$. pylori. Dig Dis Sci. 2007;52:402-4.

49. Zevit N, Niv Y, Shirin H, Shamir R. Age and gender differences in urea breath test results. Eur J Clin Invest. 2011;41:767-72.

50. Moshkowitz M, Horowitz N, Beit-Or A, Halpern Z, Santo E. Gender-associated differences in urea breath test for $H$. pylori infection referrals and results among dyspeptic patients. World J Gastrointest Pathophysiol. 2012;3:80-4.

51. Marinho FP, Trindade OR, Ferreira KN, Amaral LA, Coelho LG. 13C-urea breath test values: a large database study focusing at gender differences. Helicobacter. 2012;17 Suppl 1:92.

52. Megraud F, Lehours P. Helicobacter pylori detection and antimicrobial susceptibility testing. Clin Microbiol Rev. 2007;20:280-322.

53. Gisbert JP, de la MF, Abraira V. Accuracy of monoclonal stool antigen test for the diagnosis of $H$. pylori infection: a systematic review and meta-analysis. Am J Gastroenterol. 2006;101:1921-30.

54. Deguchi R, Matsushima M, Suzuki T, Mine T, Fukuda R, Nishina M, et al. Comparison of a monoclonal with a polyclonal antibody-based enzyme immunoassay stool test in diagnosing $H$. pylori infection after eradication therapy. J Gastroenterol. 2009;44:713-6.

55. Zhou X, Su J, Xu G, Zhang G. Accuracy of stool antigen test for the diagnosis of $H$. pylori infection in children: a meta-analysis. Clin Res Hepatol Gastroenterol. 2014;38: 629-38.

56. Korkmaz H, Kesli R, Karabagli P, Terzi Y. Comparison of the diagnostic accuracy of five different stool antigen tests for the diagnosis of $H$. pylori infection. Helicobacter. 2013;18:384-91

57. Vaira D, Malfertheiner P, Mégraud F, Axon AT, Deltenre M, Hirschl AM, et al. Diagnosis of $H$. pylori infection with a new non-invasive antigen-based assay. HpSA European study group. Lancet. 1999;354:30-3.

58. Vaira D, Vakil N, Menegatti M, van't Hoff B, Ricci C, Gatta L, et al. The stool antigen test for detection of $H$. pylori after eradication therapy. Ann Intern Med 2002;136:280-7.

59. Calvet X, Lario S, Ramírez-Lázaro MJ, Montserrat A, Quesada M, Reeves L, et al. Accuracy of monoclonal stool tests for determining cure of $H$. pylori infection after treatment. Helicobacter. 2010;15:201-5.

60. da Silva-Etto JMK, Mattar R, Villares-Lopes CA, Marques SB, Carrilho FJ. Evaluation of diagnostic accuracy of two rapid stool antigen tests using an immunochromatographic assay to detect H. pylori. Clin Biochem. 2017;50:959-62.
61. Raguza D, Machado RS, Ogata SK, Granato CF, Patrício FR, Kawakami E. Validation of a monoclonal stool antigen test for diagnosing Helicobacter pylori infection in young children. J Pediatr Gastroenterol Nutr. 2010;50:400-3.

62. Queiroz DM, Saito M, Rocha GA, Rocha AM, Melo FF, Checkley W, et al. Helicobacter pylori infection in infants and toddlers in South America: concordance between [13C]urea breath test and monoclonal $H$. pylori stool antigen test. J Clin Microbiol. 2013;51:3735-40.

63. Wang YK, Kuo FC, Wu DC. Diagnosis of Helicobacter pylori infection: Current options and developments. World J Gastroentrol. 2015;21:11221-35.

64. Roy AD, Deuri S, Dutta UC. The diagnostic accuracy of rapid urease biopsy test compared to histopathology in implementing "test and treat" policy for Helicobacter pylori. Int J Appl Basic Med Res. 2016;6:18-22.

65. Moon SW, Kim TH, Lee OJ. United rapid urease test is superior than separate test in detecting Helicobacter pylori at the gastric antrum and body specimens. Clin Endosc. 2012,45:392-6

66. Parihar V, Holleran G, McNamara D. A combined antral and corpus rapid urease testing protocol can increase diagnostic accuracy despite a low prevalence of Helicobacter pylori infection in patients undergoing routine gastroscopy. UEG Journal. 2015,3:432-6.

67. Cosgun Y, Yildirim A, Yucel M, Karakoc AE, Koca G, Gonultas A, et al. Evaluation of invasive and noninvasive methods for the diagnosis of Helicobacter pylori infection. Asian Pacific J Cancer Prev. 2016;17:5265-72.

68. Batts KP, Ketover S, Kakar S, Krasinskas AM, Mitchell KA, Wilcox R, et al. Appropriate use of special stains for identifying Helicobacter pylori. Am J Surg Pathol. 2013;37:e12-e22.

69. Bessède E, Arantes A, Mégraud F, Coelho LG. Diagnosis of Helicobacter pylori infection. Helicobacter. 2017;22 Suppl 1:e12404

70. Haruma K, editor. The Kyoto Classification of Gastritis. Tokyo: Nippon Medical Center: (in Japanese); 2014.

71. Kato M. Endoscopic findings of H. pylori infection. In: Suzuki H, Warren R, Marshall B, eds. Helicobacter pylori. Japan: Springer; 2016:157-167.

72. Dohi O, Yagi N, Onozawa Y, Kimura-Tsuchiya R, Majima A, Kitaichi T, et al. Linked color imaging improves endoscopic diagnosis of active Helicobacter pylori infection. Endosc Int Open. 2016;4:E800-E805.

73. Kato T, Yagi N, Kamada T, Shimbo T, Watanabe H, Ida K. Diagnosis of Helicobacter pylori infection in gastric mucosa by endoscopic features: a multicenter prospective study. Dig Endosc. 2013;25:508-18.

74. Qi Q, Guo C, Ji R, Li Z, Zuo X, Li Y. Diagnostic performance of magnifying endoscopy for Helicobacter pylori infection: a meta-analysis. PLoS One. 2016;11:e0168201.

75. Matrakool L, Tongtawee T, Bartpho T, Dechsukhum C, Loyd RA, Kaewpitoon SJ, et al. Improved detection of Helicobacter pylori infection and premalignant gastric mucosa using conventional white light source gastroscopy. Asian Pac J Cancer Prev. 2016;17:2099-103.

76. Nishikawa K, Sugiyama T, Kato M, Ishizuka J, Kagaya H, Hokari K, et al. A prospective evaluation of new rapid urease tests before and after eradication treatment of $H$. pylori, in comparison with histology, culture and 13C-urea breath test. Gastrointest Endosc. 2000;51:164-8.

77. Yoshimura N, Tajiri H, Sawada A, Kozaiwa K, Ida S, Fujisawa T, et al. A 13C-urea breath test in children with $H$. pylori infection: assessment of eradication therapy and follow-up after treatment. J Gastroenterol. 2001;36:606-11.

78. Graham DY, Opekun AR, Hammoud F, Yamaoka Y, Reddy R, Osato MS, et al. Studies regarding the mechanism of false negative urea breath tests with proton pump inhibitors. Am J Gastroenterol. 2003;98:1005-9.

79. Gatta L, Vakil N, Ricci C, Osborn JF, Tampieri A, Perna F, et al. Effect of proton pump inhibitors and antacid therapy on 13C-urea breath tests and stool test for $\mathrm{H}$. pylori infection. Am J Gastroenterol. 2004;5:823-9.

80. Kuloğlu Z, Kansu A, Kirsaçlioğlu CT, Ustündağ G, Aysev D, Ensari A, et al. A rapid lateral flow stool antigen immunosssay and 14C-urea breath test for diagnosis and eradication of H. pylori infection in children. Diagn Microbiol Infect Dis. 2008;62:351-6.

81. Shirin H, Levine A, Shevah O, Shabat-Sehayek V, Aeed H, Wardi J, et al. Eradication of H. pylori can be accurately confirmed 14 days after termination of triple therapy using a high-dose citric acid-based 13C-urea breath test. Digestion. 2005;71:208-12.

82. Manesa G, Zanetti MV, Piccirillo MM, Lombardi G, Balzano A, Pieramico O. Accuracy of a new monoclonal stool antigen test in post-eradication assessment of $\mathrm{H}$. pylori infection: Comparison with polyclonal stool antigen test and urea breath test. Dig Dis Sci. 2005;37:751-55

83. Perri F, Quitadamo M, Ricciardi R, Piepoli A, Cotugno R, Gentile A, et al. Comparison of a monoclonal antigen stool test (Hp StAR) with the 13C-urea breath test (UBT) in monitoring H. pylori eradication therapy. World J Gastroenterol. 2005;11:5878-81.

84. Gisbert JP, Pajares JM. Stool antigen test for the diagnosis of $H$. pylori infection: A systematic review. Helicobacter 2004;9:347-68.

85. Mégraud F. The challenge of Helicobacter pylori resistance to antibiotics: the comeback of bismuth-based quadruple therapy. Ther Adv Gastroenterol. 2012;5:103-9.

86. Arslan N, Y1lmaz Ö, Demiray-Gürbüz E. Importance of antimicrobial susceptibility testing for the management of eradication in Helicobacter pylori infection. World J Gastroenterol. 2017;23:2854-69. 
87. Alba C, Blanco A, Alarcón T. Antibiotic resistance in Helicobacter pylori. Curr Opin Infect Dis. 2017;30:489-97.

88. Wenzhen Y, Yumin L, Quanlin G, Kehu Y, Lei J, Donghai W, et al. Is antimicrobial susceptibility testing necessary before first-line treatment for Helicobacter pylori infection? Meta-analysis of randomized controlled trials. Inter Med. 2010;49:1103-9.

89. Cosme A, Lizasoan J, Montes M, Tamayo E, Alonso H, Mendarte U, et al. Antimicrobial susceptibility-guided therapy versus empirical concomitant therapy for eradication of Helicobacter pylori in a region with high rate of clarithromycin resistance. Helicobacter. 2015;21:29-34.

90. López-Góngora S, Puig I, Calvet X, Villoria A, Baylina M, Muñoz N, et al. Systematic review and meta-analysis: susceptibility-guided versus empirical antibiotic treatment for Helicobacter pylori infection. J Antimicrob Chemother. 2015;70:2447-55.

91. Park CS, Lee SM, Park CH, Koh HR, Jun CH, Park SY, et al. Pretreatment antimicrobial susceptibility-guided vs. clarithromycin-based triple therapy for Helicobacter pylori eradication in a region with high rates of multiple drug resistance. Am J Gastroenterol 2014;109:1595-602.

92. Lopes AI, Vale FF, Oleastro M. H. pylori infection - recent developments in diagnosis World J Gastroenterol. 2014;20:9299-313.

93. Atkinson NSS, Braden B. H. pylori infection: diagnostic strategies in primary diagnosis and after therapy. Dig Dis Sci. 2015;61:19-24.

94. Burucoa C, Delchier JC, Courillon-Mallet A, de Korwin JD, Mégraud F, Zerbib F, et al. Comparative evaluation of 29 commercial H. pylori serological kits. Helicobacter. 2013;18:169-79.

95. Nilsson I, Ljung A, Aleljung P, Wadstrom T. Immunoblot assay for serodiagnosis of $H$. pylori infections. J Clin Microbiol. 1997:35:427-32.

96. Vale FF, Mégraud F, Vitor JM. Geographic distribution of methyltransferases of $H$. pylori: evidence of human host population isolation and migration. BMC Microbiol. 2009;9:193.

97. Vitoriano I, Rocha-Gonçalves A, Carvalho T, Oleastro M, Calado CR, Roxo-Rosa M. Antigenic diversity among Portuguese clinical isolates of $H$. pylori. Helicobacter 2011;16:153-68.

98. Marchildon PA, Sugiyama T, Fukuda Y, Peacock JS, Asaka M, Shimoyama T, et al. Evaluation of the effects of strain-specific antigen variation on the accuracy of serologic diagnosis of $H$. pylori infection. J Clin Microbiol. 2003;41:1480-5.

99. Khalifeh Gholi M, Kalali B, Formichella L, Göttner G, Shamsipour F, Zarnani AH, et al H.pylori FliD protein is a highly sensitive and specific marker for serologic diagnosis of H. pylori infection. Int J Med Microbiol. 2013;303:618-23.

100. Formichella L, Romberg L, Bolz C, Vieth M, Geppert M, Göttner G, et al. A novel line immunoassay based on recombinant virulence factors enables highly specific and sensitive serologic diagnosis of $H$. pylori infection. Clin Vaccine Immunol. 2013;20:1703-10.

101. Rocha GA, Oliveira AMR, Queiroz DMM, Mendes EN, Moura SB, Oliveira CA, et al Serodiagnosis of $H$. pylori infection by Cobas Core ELISA in adults from Minas Gerais, Brazil. Bras J Med Biol Res. 1998;31:1263-8.

102. Rocha AM, Rocha GA, Leite JL, Lisboa RL, Silva PV, Queiroz DM. Immunoblotting for the serodiagnosis of $H$. pylori infection in Brazilian patients with and without gastric carcinoma. Mem Inst Oswaldo Cruz. 2004:99:189-93.

103. Rocha AM, Rocha GA, Santos A, de Oliveira CA, Queiroz DM. Accuracy of a commercial enzyme-linked immunosorbent assay for $\mathrm{CagA}$ in patients from Brazil with and without gastric carcinoma. J Clin Microbiol. 2003;41:447-8.

104. Peitz U, Leodolter A, Wex T, Schütze D, Wolle K, Welte T, et al. Diagnostics of $H$. pylori infection in patients with peptic ulcer bleeding. Z Gastroenterol. 2004;42:141-6.

105. Kokkola A, Rzautelin H, Puolakkainen P. Diagnosis of $H$. pylori infection in patients with atrophic gastritis: comparison of histology, 13C-urea breath test, and serology. Scan J Gastroenterol. 2000;35:138-41.

106. Lohours P, Ruskone-Fourmestraux A, Lavergne A, Cantet F, Megraud F, Groupe d’Etude des Lymphomes Digestifs (GELD) for the Fédération Française de Cancérologie Digestive (FFCD). Which test to use to detect $H$. pylori infection in patients with low grade gastric MALT lymphoma? Am J Gastroenterol. 2003;98:291-5.

107. Figura N, Crabtree JE, Dattilo M. In-vitro activity of lansoprazole against H. pylori. J Antimicrob Chemother. 1997;39:585-90.

108. Nakao M, Malfertheiner P. Growth inhibitory and bactericidal activities of lansoprazole compared with those of omeprazole and pantoprazole against $H$. pylori. Helicobacter. 1998;3:21-7

109. Levine A, Shevah O, Shabat-Sehayek V, Aeed H, Boaz M, Moss SF, et al. Masking of $13 \mathrm{C}$ urea breath test by proton pump inhibitors is dependent on type of medication: comparison between omeprazole, pantoprazole, lansoprazole and esomeprazole. Aliment Pharmacol Ther. 2004;20:117-22.

110. Parente F, Sainaghi M, Sangaletti O, Imbesi V, Maconi G, Anderloni A, et al. Different effects of short-term omeprazole, lansoprazole or pantoprazole on the accuracy of the 13C-urea breath test. Aliment Pharmacol Ther. 2002;16:553-7.

111. Shimoyama T. Stool antigen tests for the management of $H$. pylori infection. World J Gastroenterol. 2013;19:8188-91.

112. Genta RM, Lash RH. H. pylori-negative gastritis: seek, yet ye shall not always find. Am J Surg Pathol. 2010;34:e25-34

113. Laine L, Estrada R, Trujillo M, Knigge K, Fennerty MB. Effect of proton-pump inhibitor therapy on diagnostic testing for H.pylori. Ann Intern Med. 1998;129:547-50
114. Chen T, Meng X, Zhang H, Tsang RW, Tsang TK. Comparing Multiplex PCR and rapid urease test in the detection of $H$. pylori in patients on proton pump inhibitors. Gastroenterol Res Pract. 2012;2012:898276.

115. Yakoob J, Rasool S, Abbas Z, Jafri W, Abid S, Islam M, et al. Gastric juice for the diag nosis of $\mathrm{H}$ pylori infection in patients on proton pump inhibitors. World $\mathrm{J}$ Gastroenterol. 2008;14:1539-43.

116. Garza-González E, Perez-Perez GI, Maldonado-Garza HJ, Bosques-Padilla FJ. A review of $\mathrm{H}$. pylori diagnosis, treatment, and methods to detect eradication. World J Gastroenterol. 2014;20:1438-49.

117. Calvet X. Diagnosis of $H$.pylori infection in the proton pump inhibitor era. Gastroenterol Clin North Am. 2015;44:507-18.

118. Malfertheiner P. Diagnostic methods for H. pylori infection: choices, opportunities and pitfalls. United European Gastroenterol J. 2015;3:429-31

119. Atkinson NS, Braden B. H. pylori Infection: diagnostic strategies in primary diagnosis and after therapy. Dig Dis Sci. 2016;61:19-24.

120. Saniee P, Shahreza S, Siavoshi F. Negative effect of proton-pump inhibitors (PPIs) on $H$. pylori growth, morphology, and urease test and recovery after PPI removal-An In vitro study. Helicobacter. 2016;21:143-52.

121. Adu-Aryee NA, Aabakken L, Dedey F, Nsaful J, Kudzi W. Comparison of endoscopic based diagnosis with Helicobacter urease test for $H$. pylori infection. BMC Res Notes. 2016;9:421.

122. Dulbecco P, Gambaro C, Bilardi C, Zentilin P, Mele MR, Mansi C, et al. Impact of long-term ranitidine and pantoprazole on accuracy of [13C]urea breath test. Dig Dis Sci. 2003;48:315-21.

123. Houghton J, Ramamoorthy R, Pandya H, Dhirmalani R, Kim H. Human plasma is directly bacteriocidal against $H$. pylori in vitro, potentially explaining the decreased detection of $H$. pylori during acute upper GI bleeding. Gastrointest Endosc. 2002;55:11-6.

124. Archimandritis A, Tzivras M, Sougioultzis S, Papaparaskevas I, Apostolopoulos P, Avlami A, et al. Rapid urease test is less sensitive than histology in diagnosing $H$. pylori infection in patients with non-variceal upper GI bleeding. J Gastroenterol Hepatol. 2000; $15: 369-73$.

125. Lee JM, Breslin NP, Fallon C, O'Morain CA. Rapid urease tests lack sensitivity in $H$. pylori diagnosis when peptic ulcer disease presents with bleeding. Am J Gastroenterol 2000;95:1166-70

126. Schilling D, Demel A, Adamek HE, Nüsse T, Weidmann E, Riemann JF. A negative rapid urease test is unreliable for exclusion of $H$. pylori infection during acute phase of ulcer bleeding - A prospective case control study. Dig Liver Dis. 2003;35:217-21.

127. Tang JH, Liu NJ, Cheng HT, Lee CS, Chu YY, Sung KF, et al. Endoscopic diagnosis of H. pylori infection by rapid urease test in bleeding peptic ulcers: A prospective case-control study. J Clin Gastroenterol. 2009;43:133-9.

128. Colin R, Czernichow P, Baty V, Touzé I, Brazier F, Bretagne JF, et al. Low sensitivity of invasive tests for the detection of $H$. pylori infection in patients with bleeding ulcer. Gastroenterol Clin Biol. 2000;24:31-5.

129. Laine LA, Nathwani RA, Naritoku W. The effect of GI bleeding on H. pylori diagnostic testing: a prospective study at the time of bleeding and 1 month later. Gastrointest Endosc. 2005;62:653-9.

130. Lee TH, Lin CC, Chung CS, Lin CK, Liang CC, Tsai KC. Increasing biopsy number and sampling from gastric body improve the sensitivity of rapid urease test in patients with peptic ulcer bleeding. Dig Dis Sci. 2015;60:454-7.

131. Lin HJ, Lo WC, Perng CL, Tseng GY, Li AF, Ou YH. Mucosal polymerase chain reac tion for diagnosing $H$. pylori infection in patients with bleeding peptic ulcers. World $\mathrm{J}$ Gastroenterol. 2005;11:382-5

132. Saez J, Belda S, Santibáñez M, et al. Real-time PCR for diagnosing H.pylori infection in patients with upper gastrintestinal bleeding: Comparison with other classical diagnostic methods. J Clin Microbio. 2012;50:3233-7.

133. Peitz U, Leodolter A, Kahl S, Agha-Amiri K, Wex T, et al. Antigen stool test for assessment of $H$. pylori infection in patients with upper gastrointestinal bleeding. Aliment Pharmacol Ther. 2003:17:1075-84.

134. Griñó P, Pascual S, Such J, Casellas JA, Niveiro M, Andreu M, et al. Comparison of stool immunoassay with standard methods for detection of $H$. pylori infection in patients with upper-gastrointestinal bleeding of peptic origin. Eur J Gastroenterol Hepatol. 2003; $15: 525-9$.

135. van Leerdam ME, van der Ende A, ten Kate FJW, Rauws EAJ, Tytgat GNJ. Lack of accuracy of the noninvasive $H$. pylori stool antigen test in patients with gastroduodenal ulcer bleeding. Am J Gastroenterol. 2003;98:798-801.

136. Winiarski M, Bielanski W, Plonka M, Dobrzanska M, Kaminska A, Bobrzynski A, et al. The usefulness of capsulated 13C-Urea Breath Test in diagnosis of H.pylori infection in patients with upper gastrointestinal bleeding. J Clin Gastroenterol. 2003;37:34-8.

137. Gisbert JP, Esteban C, Jimenez I, Moreno-Otero R. 13C-Urea Breath Test during hospitalization for the diagnosis of $H$. pylori infection in peptic ulcer bleeding. Helicobacter. 2007;12:231-7

138. Velayos B, Fernández-Salazar L, Pons-Renedo F, Muñoz MF, Almaraz A, Aller R, et al. Accuracy of urea breath test performed immediately after emergency endoscopy in peptic ulcer bleeding. Dig Dis Sci. 2012;57:1880-6.

139. Gisbert JP, Abraira V. Accuracy of $H$. pylori diagnostic tests in patients with bleeding peptic ulcer: a systematic review and meta-analysis. Am J Gastroenterol. 2006;101:848-63. 
140. Güell M, Artigau E, Esteve V, Sánchez-Delgado J, Junqueira F, Calvet X. Usefulness of a delayed test for the diagnosis of $H$. pylori infection in bleeding peptic ulcer. Aliment Pharmacol Ther. 2006;23:53-9.

141. Ford AC, Moayyedi P. Dyspepsia. Curr Opin Gastroenterol. 2013;29:662-8.

142. Mahadeva S, Goh KL. Epidemiology of functional dispepsia: a global perspective. World J Gastroenterol. 2006;12:2661-6.

143. Tack J, Talley NJ. Functional dyspepsia - symptoms, definitions and validity of the Rome III criteria. Nat Rev Gastroenterol Hepatol. 2013;10:134-41

144. Oliveira SS, Santos IS, Silva JFP, Machado E. Prevalência de dispepsia e fatores sócio-demográficos. Rev Saude Publica. 2006;40:420-7.

145. Stanghellini V, Chan FKL, Hasler WL, Malagelada JR, Suzuki H, Tack J, et al. Gastroduodenal Disorders. Gastroenterology. 2016;150:1380-92.

146. Organização Mundial da Saúde. Schistosomiase et géohelminthiases: prevétion et lutte. Genève: OMS, v. 912, 2004. 68 p. tab. (Série de Informes Técnicos). 2005-04-12.

147. Moayyedi P, Soo S, Deeks JJ, Delaney B, Harris A, Innes M, et al. Eradication of Helicobacter pylori for non-ulcer dyspepsia. Cochrane Database Syst Rev. 2011; CD002096.

148. Moayyedi PM, Lacy BE, Andrews CN, Enns RA, Howden CW, Vakil N. ACG and CAG Clinical Guideline: Management of Dyspepsia. Am J Gastroenterol. 2017;112: 988-1013.

149. Lu YX, Owyang C. Duodenal acid-induced gastric relaxation is mediated by multiple pathways. Am J Physiol. 1999;276(6 Pt 1):G1501-6.

150. Signoretti M, Roggiolani R, Stornello C, Delle Fave G, Capurso G. Gut microbiota and pancreatic diseases. Minerva Gastroenterol Dietol. 2017;63:399-410.

151. Chen YF, Chey WY, Chang TM, Lee KY. Duodenal acidification releases cholecystokinin. Am J Physiol. 1985;249(1 Pt 1):G29-33.

152. Schubert ML. Gastric exocrine and endocrine secretion Curr Opin Gastroenterol. 2009;25:529-36.

153. Mazzawi T, Hausken T, Gundersen D, El-Salhy M. Effect of dietary management on the gastric endocrine cells in patients with irritable bowel syndrome. Eur J Clin Nutr. 2015;69:519-24

154. Clarke G, Stilling RM, Kennedy PJ, Stanton C, Cryan JF, Dinan TG. Minireview: gut microbiota: the neglected endocrine organ. Mol Endocrinol. 2014;28:1221-38.

155. Konturek PC, Brzozowski T, Konturek SJ. Stress and the gut: pathophysiology, clinical consequences, diagnostic approach and treatment options. J Physiol Pharmacol. 2011;62:591-9.

156. Kaneko Y, Szallasi A. TRP channels as therapeutic targets. Curr Top Med Chem. 2013;13:241-3

157. Dongarrà ML, Rizzello V, Muccio L, Fries W, Cascio A, Bonaccorsi I, et al. Mucosal immunology and probiotics. Curr Allergy Asthma Rep. 2013;13:19-26.

158. Willing BP, Russell SL, Finlay BB. Shifting the balance: antibiotic effects on host-microbiota mutualism. Nat Rev Microbiol. 2011;9:233-43.

159. Blaser MJ. Antibiotic use and its consequences for the normal microbiome. Science. 2016;352:544-5

160. Jakobsson HE, Jernberg C, Andersson AF, Sjölund-Karlsson M, Jansson JK, Engstrand L. Short-term antibiotic treatment has differing long-term impacts on the human throat and gut microbiome. PLoS One. 2010;5(3):e9836.

161. Ianiro G, Tilg H, Gasbarrini A. Antibiotics as deep modulators of gut microbiota: between good and evil. Gut. 2016;65(11):1906-15.

162. Emara MH, Elhawari SA, Yousef S, Radwan MI, Abdel-Aziz HR. Emerging role of probiotics in the management of Helicobacter pylori infection: Histopathologic perspectives. Helicobacter. 2016;21:3-10.

163. Kafshdooz T, Akbarzadeh A, Majdi Seghinsara A, Pourhassan M, Nasrabadi HT, Milani M. Role of probiotics in managing of Helicobacter pylori infection: A review. Drug Res (Stuttg). 2017;67:88-93.

164. Wang ZJ, Chen XF, Zhang ZX, Li YC, Deng J, Tu J, et al. Effects of anti-Helicobacter pylori concomitant therapy and probiotic supplementation on the throat and gut microbiota in humans. Microb Pathog. 2017;109:156-61.

165. Du YQ, Su T, Fan JG, Lu YX, Zheng P, Li XH, et al. Adjuvant probiotics improve the eradication effect of triple therapy for Helicobacter pylori infection. World J Gastroenterol. 2012;18:6302-7.

166. Wang YH, Huang Y. Effect of Lactobacillus acidophilus and Bifidobacterium bifidum supplementation to standard triple therapy on Helicobacter pylori eradication and dynamic changes in intestinal flora. World J Microbiol Biotechnol. 2014;30: 847-53.

167. Lu C, Sang J, He H, Wan X, Lin Y, Li L, et al. Probiotic supplementation does not improve eradication rate of Helicobacter pylori infection compared to placebo based on standard therapy: a meta-analysis. Sci Rep. 2016;6:23522.

168. Navarro-Rodriguez T, Silva FM, Barbuti RC, Mattar R, Moraes-Filho JP, de Oliveira $\mathrm{MN}$, et al. Association of a probiotic to a Helicobacter pylori eradication regimen does not increase efficacy or decreases the adverse effects of the treatment: a prospective, randomized, double-blind, placebo-controlled study. BMC Gastroenterol. 2013;13:56. doi: $10.1186 / 1471-230 \mathrm{X}-13-560$

169. Gisbert JP, Molina-Infante J, Amador J, Bermejo F, Bujanda L, Calvet X, et al. IV Spanish Consensus Conference on Helicobacter pylori infection treatment. Gastroenterol Hepatol. 2016;39:697-721.
170. Mahachai V, Vilaichone RK, Pittayanon R, Rojborwonwitaya J, Leelakusolvong S, et al. Helicobacter pylori management in ASEAN: The Bangkok consensus report. Helicobacter pylori management in ASEAN: The Bangkok consensus report. J Gastroenterol Hepatol. 2018;33:37-56

171. Pacifico L, Osborn JF, Tromba V, Romaggioli S, Bascetta S, Chiesa C. Helicobacter pylori infection and extragastric disorders in children: A critical update. World J Gastroenterol. 2014;20:1379-401.

172. Hudak L, Jaraisy A, Haj S, Muhsen K. An updated systematic review and meta-analysis on the association between Helicobacter pylori infection and iron deficiency anemia in Helicobacter. 2017;22:12330.

173. Hwang JJ, Lee DH, Yoon H, Shin CM, Park YS, Kim N. The effects of Helicobacter pylori eradication therapy for chronic idiopathic thrombocytopenic purpura. Gut Liver. 2016;10:356-61.

174. Galit HF, Nick D, Paul LB, James GF. Helicobacter pylori eradication in patients with immune thrombocytopenic purpura: a review and the role of biogeography. Helicobacter. 2015;20:239-25.

175. Abdel S, Sarari MAF, Wael H, Tamer A. Helicobacter pylori, a causative agent of vitamin B12 deficiency. J Infect Developing Countries. 2008;2:346-9.

176. Wong F, Rayner-Hartley E, Byrne MF. Extraintestinal manifestations of Helicobacter pylori: a concise review. World J Gastroenterol. 2014;20:11950-61.

177. Yuan W, Li Yumin, Yang Kehu, Ma Bin, Guan Quanlin, Wang D, et al. Iron deficiency anemia in Helicobacter pylori infection: meta-analysis of randomized controlled trials. Scand J Gastroenterol. 2010;45:665-76.

178. Qu XH, Huang XL, Xiong P, Zhu CY, Huang YL, Lu LG, et al. Does Helicobacter pylori infection play a role in iron deficiency anemia? A meta-analysis. World J Gastroenterol. 2010;16:886-96.

179. Goddard AF, James MW, McIntyre AS, Scott BB. Guidelines for the management of iron deficiency anaemia. Gut. 2011;60:1309-16.

180. Jackson S, Beck PL, Pineo GF, Poon MC. Helicobacter pylori eradication: novel therapy for immune thrombocytopenic purpura? A review of the literature Am J Hematol. 2005;78:142-50

181. Suzuki T, Matsushima M, Masui A, Watanabe K, Takagi A, Ogawa Y, et al. Effect of Helicobacter pylori eradication in patients with chronic idiopathic thrombocytopenic purpura-a randomized controlled trial. Am J Gastroenterol. 2005;100:1265-70.

182. Tsutsumi Y, Kanamori H, Yamato H, Ehira N, Kawamura T, Umehara S, et al. Randomized study of Helicobacter pylori eradication therapy and proton pump inhibitor monotherapy for idiopathic thrombocytopenic purpura. Ann Hematol. 2005;84:807-11.

183. Jaing TH, Yang CP, Hung IJ, Chiu CH, Chang KW. Efficacy of Helicobacter pylori eradication on platelet recovery in children with chronic idiopathic thrombocytopenic purpura. Acta Paediatr. 2003;92:1153-7.

184. Stasi R, Sarpatwari A, Segal JB, Osborn J, Evangelista ML, Cooper N, et al. Effects of eradication of Helicobacter pylori infection in patients with immune thrombocytopenic purpura: a systematic review. Blood. 2009;113:1231-40.

185. Brito HS, Braga JA, Loggetto SR, Machado RS, Granato CF, Kawakami E. Helicobacter pylori infection \& immune thrombocytopenic purpura in children and adolescents: A randomized controlled trial. Platelets. 2015;26:336-41.

186. Chmiela M, Gonciarz W. Molecular mimicry in Helicobacter pylori infections. World J Gastroenterol. 2017;23:3964-77.

187. Stabler SP. Vitamin B12 deficiency. N Engl J Med. 2013;368:2041-2

188. Marino MC, de Oliveira CA, Rocha AM, Rocha GA, Clementino NC, Antunes LF, et al. Long-term effect of Helicobacter pylori eradication on plasma homocysteine in elderly patients with cobalamin deficiency. Gut. 2007;56:469-74.

189. He C, Yang Z, Lu NH. Helicobacter pylori-an infectious risk factor for atherosclerosis? J Atheroscler Thromb. 2014;21:1229-42.

190. Sun J, Rangan P, Bhat SS, Liu L. A meta-analysis of the association between Helicobacter pylori infectionand risk of coronary heart disease from published prospective studies. Helicobacter. 2016;21:11-23.

191. Rees K, Stowe R, Patel S, Ives N, Breen K, Clarke CE, et al. Helicobacter pylori eradication for Parkinson's disease. Cochrane Database Syst Rev. 2011;(11):CD008453.

192. Bu XL, Wang X, Xiang Y, Shen LL, Wang QH, Liu YH, et al. The association between infectious burden and Parkinson's disease: a case-control study. Parkinsonism Relat Disord. $2015 ; 21: 877-81$

193. Taye B, Enquselassie F, Tsegaye A, Medhin G, Davey G, Venn A. Is Helicobacter pylori infection inversely associated with atopy? A systematic review and meta-analysis. Clin Exp Allergy. 2015;45:882-90.

194. von Armin U, Wex T, Link A, Messerschmidt M, Venerito, Miehlke S, et al. Helicobacter pylori infection is associated with a reduced risk of developing eosinophilic oesophagitis. Aliment Pharmacol Ther. 2016;43:825-30.

195. Raghunath A, Hungin AP, Wooff D, Childs S. Prevalence of H. pylori in patients with gastro-oesophageal reflux disease: systematic review. BMJ. 2003;326:737-45.

196. Nordenstedt H, Nilsson M, Johnsen R, Lagergren J, Hveem K. H. pylori infection and gastroesophageal reflux in a population-based study (The HUNT Study). Helicobacter. 2007; $12: 16-22$

197. Rubenstein JH, Inadomi JM, Scheiman J, Schoenfeld P, Appelman H, Zhang M, et al. Association between Helicobacter pylori and Barrett's esophagus, erosive esophagitis, and gastroesophageal reflux symptoms. Clin Gastroenterol Hepatol. 2014;12:239-45. 
198. Chung SJ, Lim SH, Choi J, Kim D, Kim YS, Park MJ, et al. H. pylori serology inversely correlated with the risk and severity of reflux esophagitis in H. pylori endemic area: matched case- control study of 5,616 health check-up Koreans. J Neurogastroenterol Motil. 2011;17:267-73.

199. Gatenby P, Soon Y. Barrett's esophagus: evidence from the current meta-analyses World J Gastrointest Pathophysiol. 2014;5:178-87.

200. Vasapolli R, Malfertheiner P, Kandulski A. H. pylori and non-malignant upper gastrointestinal diseases. Helicobacter. 2016;21 Suppl 1:30-3

201. Fischbach LA, Nordenstedt H, Kramer JR, Gandhi S, Dick-Onuoha S, Lewis A, et al The association between Barrett's esophagus and H. pylori infection: a meta-analysis. Helicobacter. 2012;17:163-75.

202. Anderson LA, Murphy SJ, Johnston BT, Watson RGP, Ferguson HR, Bamford KB, et al. Relationship between $H$. pylori infection and gastric atrophy and the stages of the oesophageal inflammation, metaplasia, adenocarcinoma sequence: results from the FINBAR case-control study. Gut. 2008;57:734-39.

203. Wang C, Yuan Y, Hunt RH. H. pylori infection and Barrett's esophagus: a systematic review and meta-analysis. Am J Gastroenterol. 2009;104:492-500.

204. Saad AM, Choudhary A, Bechtold ML. Effect of H. pylori treatment on gastroesophageal reflux disease (GERD): meta-analysis of randomized controlled trials. Scand J Gastroenterol. 2012;47:129-35

205. Qian B, Ma S, Shang L, Qian J, Zhang G. Effects of $H$. pylori eradication on gastroesophageal reflux disease. Helicobacter. 2011;16:255-65.

206. Yaghoobi M, Farrokhyar F, Yuan Y, Hunt RH. Is there an increased risk of GERD after H. pylori eradication?: a meta- analysis. Am J Gastroenterol. 2010;105:1007-13.

207. Xue Y, Zhou LY, Lin SR, Hou XH, Li ZS, Chen MH, et al. Effect of H. pylori eradication on reflux esophagitis therapy: a multi-center randomized control study. Chin Med J (Engl). 2015;128:995-9.

208. Scarpignato C, Hunt RH. Nonsteroidal anti-inflammatory drug-related injury to the gastrointestinal tract: clinical picture, pathogenesis, and prevention. Gastroenterol Clin North Am. 2010;39:433-64.

209. Marshall BJ, Warren JR. Unidentified cueved bacilli in the stomach of patients with gastritis and peptic ulceration Lancet. 1984;1:1311-5.

210. Huang JQ, Sridhar S, Hunt RH. Role of H. pylori and non-steroidal anti-inflammatory drugs in peptic-ulcer disease: a meta-analysis. Lancet. 2002;359:14-22.

211. Lanas A, Fuentes J, Benito R, Serrano P, Bajador E, Sáinz R. H. pylori increases the risk of upper gastrointestinal bleeding in patients taking low-dose aspirin. Aliment Pharmacol Ther. 2002;16:779-86.

212. Uemura N, Sugano K, Hiraishi H, Shimada K, Goto S, Uchiyama S, et al. Risk factor profiles, drug usage, and prevalence of aspirin-associated gastroduodenal injuries among high-risk cardiovascular Japanese patients: the results from the MAGIC study. J Gastroenterol. 2014;49:814-24

213. Kono Y, Okada H, Takenaka R, Miura K, Kanzaki H, Hori K, et al. Does H. pylori exacerbates gastric mucosal injury in users of nonsteroidal anti-inflammatory drugs? A multicenter, restrospective, case-control study. Gut and Liver. 2016;10:69-75

214. Iijima K, Koike T, Ara N, Nakagawa K, Kondo Y, Uno K, et al. Identification of a highrisk group for low-dose aspirin-induced gastropathy by measuring sérum pepsinogen in $H$. pylori-infected subjects. J Gastroenterol. 2015;50:305-12.

215. Sostres C, Carrera-Lasfuentes P, Benito R, Roncales P, Arruebo M, Arroyo MT, et al Peptic ulcer bleeding risk. The role of $H$. pylori infection in NSAID/low-dose aspirin users. Am J Gastroenterol. 2015;110: 684-9.

216. Lanas Á, Carrera-Lasfuentes P, Arguedas Y, García S, Bujanda L, Calvet X, et al. Risk of upper and lower gastrointestinal bleeding in patients taking nonsteroidal anti-inflammatory drugs, antiplatelet agents, or anticoagulants. Clin Gastroenterol Hepatol. 2015;13:906-12.

217. Holster IL, Valkoff VE, Kuipers EJ, Tjwa ET. New oral anticoagulants increase risk for gastrointestinal bleeding: a systematic review and meta-analysis. Gastroenterology. 2013;145:105-12

218. Cheung KS, Leung WK. Gastrointestinal bleeding in patients on novel oral anticoagulants: risk, prevention and management, World J Gastroenterol. 2017;23:1954-63.

219. Gabriel SE, Jaakkimainen L, Bombardier C. Risk for serious gastrointestinal complications related to use of nonsteroidal anti-inflammatory drugs. A meta-analysis. Ann Intern Med. 1991;115:787-96.

220. Laine L, Bombardier C, Hawkey CJ, Davis B, Shapiro D, Brett C, et al. Stratifying the risk of NSAID-related upper gastrointestinal clinical events: results of double-blind outcomes study in patients with rheumatoid arthritis. Gastroenterology. 2002;123:1006-12.

221. Scarpignato C, Gatta L, Zullo A, Blandizzi C; SIF-AIGO-FIMMG Group; Italian Society of Pharmacology, the Italian Association of Hospital Gastroenterologists, and the Italian Federation of General Practitioners. Effective and safe pump inhibitor therapy in acid-related diseases- a position paper addressing benefits and potential harms of acid suppression. BMC Medicine. 2016;14:179213.

222. Chan FK, Ching JY, Suen BY, Tse YK, Wu JC, Sung JJ. Effects of $H$. pylori infection on long-term risk of peptic ulcer bleeding in low-dose aspirin isers. Gastroenterology. 2013;144:528-35

223. Zagari RM, Romano M, Ojetti V, Stockbrugger R, Gullini S, Annibale B, et al. Guidelines for the management of $H$. pylori infection: The III Working Consensus Report 2015.Dig Liv Dis. 2015;47:903-12.
224. Hunt RH, Camilleri M, Crowe SE, El-Omar EM, Fox JG, Kuipers EJ, et al. The stomach in health and disease. Gut. 2015;64:1650-68.

225. Lai KC, Lam SK, Chu KM, Wong BC, Hui WM, Hu WH, et al. Lansoprazole for the prevention of recurrences of ulcer complications from long-term low-dose aspirin use. $\mathrm{N}$ Engl J Med. 2002;346:2033-8.

226. Chan FK, Hung LC, Suen BY, Wong VW, Hui AJ, Wu JC, et al. Celecoxib versus diclofenac plus omeprazole in high-risk arthritis patients: results of a randomized double-blind trial. Gastroenterology. 2004;127:1038-43.

227. Chan FK, Wong VW, Suen BY, Wu JC, Ching JY, Hung LC, et al. Combination of a cyclo-oxigenase-2 inhibitor and a proton pump inhibitor for prevention of recurrent ulcer bleeding in patients at very high risk: a double-blind, randomized trial. Lancet. 2007;369:1621-6.

228. WHO, World Health Statistics, W.H. Organization, Editor. 2013.

229. Instituto Nacional de Câncer - INCA. Incidência de Câncer no Brasil. Coordenação de Prevenção e Vigilância Estimativa 2016: Coordenação de Prevenção e Vigilância. Rio de Janeiro: INCA, 2016.

230. Bosetti C, Malvezzi M, Chatenoud L, Negri E, Levi F, La Vecchia C. Trends in cancer mortality in the Americas, 1970-2000. Ann Oncol. 2005; 16:489-511.

231. Bosetti C, Rodríguez T, Chatenoud L, Bertuccio P, Levi F, Negri E, et al. Trends in cancer mortality in Mexico, 1981-2007. Eur J Cancer Prev. 2011;20:355-63.

232. Chatenoud L, Bertuccio P, Bosetti C, Levi F, Curado MP, Malvezzi M, et al. Trends in cancer mortality in Brazil, 1980-2004. Eur J Cancer Prev. 2010;19:79-86.

233. Silva GA, Gamarra CJ, Girianelli VR, Valente JG. Cancer mortality trends in Brazilian state capitals and other municipalities between 1980 and 2006. Rev Saude Publica. 2011;45:1009-18.

234. Bustamante-Teixeira MT, Faerstein E, Mariotto A, de Britto AV, Moreira Filho Dde C Latorre Mdo R. [Survival in gastric cancer patients in Campinas, São Paulo, Brazil]. Cad Saude Publica. 2006;22:1611-8.

235. Plummer M, de Martel C, Vignat J, Ferlay J, Bray F, Franceschi S. Global burden of cancers attributable to infections in 2012: a synthetic analysis. Lancet Glob Health 2016;4:609-16

236. IARC. Biological agents. IARC Monogr Eval Carcinog Risks Hum. 2012;100B:1-475 [Internet]. [Access 2015 May 12]. Available from: http://monographs.iarc.fr/ENG/ Monographs/vol100B/index.php

237. Correa P, Piazuelo MB. Helicobacter pylori Infection and Gastric Adenocarcinoma. US Gastroenterol Hepatol Rev. 2011;7:59-64.

238. Rokkas T, Rokka A, Portincasa P. A systematic review and meta-analysis of the role of Helicobacter pylori eradication in preventing gastric cancer. Ann Gastroenterol. 2017;30:414-23.

239. Doorakkers E, Lagergren J, Engstrand L, Brusselaers N. Eradication of Helicobacter pylori and Gastric Cancer: A Systematic Review and Meta-analysis of Cohort Studies. J Natl Cancer Inst. 2016;108(9). pii: djw132. doi: 10.1093/jnci/djw132.

240. Jung DH, Kim JH, Chung HS, Park JC, Shin SK, Lee SK, et al. Helicobacter pylori erad ication on the prevention of metachronous lesions after endoscopic resection of gastric neoplasm: a meta-analysis. PLoS One. 2015;10:e124725.

241. González CA, Sanz-Anquela JM, Companioni O, Bonet C, Berdasco M, López C, et al. Incomplete type of intestinal metaplasia has the highest risk to progress to gastric cancer: results of the Spanish follow-up multicenter study. J Gastroenterol Hepatol. 2016;31:953-8.

242. Henson DE, Dittus C, Younes M, Nguyen N, Albores-Saavedra JA. Differential trend in the intestinal and diffuse types of gastric carcinoma in the United States, 1973-2000: increase in the signet ring cell type. Arch Pathol Lab Med. 2004;128:765-70.

243. Wu H, Rusiecki JA, Zhu K, Potter J, Devesa SS. Stomach carcinoma incidence pattern in the United States by histologic type and anatomic site. Cancer Epidemiol Biomarker Prev. 2009;18:1945-52.

244. Rampazzo A, Mott GL, Fontana K, Fagundes RB. Gastric adenocarcinoma trends in the central region of Rio Grande do Sul (Southern Brazil): what has changed in 25 years? Arq Gastroenterol. 2012;49:178-83.

245. Wang LL, Yu XJ, Zhan SH, Jia SJ, Tian ZB, Dong QJ. Participation of microbiota in the development of gastric cancer. World J Gastroenterol. 2014;20:4948-52.

246. Samloff IM. Pepsinogens I and II: purification from gastric mucosa and radioimmunoassay in serum. Gastroenterology. 1982;82:26-33.

247. di Mario F, Cavallaro LG. Non-invasive tests in gastric diseases. Dig Liv Dis. 2008;40:523-30.

248. Iijima K, Sekine H, Koike T, Imatani A, Ohara S, Shimosegawa T. Serum pepsinogen concentrations as a measure of gastric acid secretion in H.pylori- negative and - positive Japanese subjects. J Gastroenterol. 2005;40:938-44.

249. Graham DY, Nurgalieva ZZ, El-Zimaity HM, Opekun AR, Campos A, Guerrero, et al. Noninvasive versus histologic detection of gastric atrophy in a Hispanic population in North America. Clin Gastroenterol Hepatol. 2006;4:306-14.

250. Bornschein J, Selgrad M, Wex T, Kuester D, Malfertheiner P. Serological assessment of gastric mucosal atrophy in gastric cancer. BMC Gastroenterol. 2012;12:10.

251. Lomba-Viana R, Dinis-Ribeiro M, Fonseca F, Vieira AS, Bento MJ, LombaViana H. Serum pepsinogen test for early detection of gastric cancer in a European country. Eur J Gastroenterol Hepatol. 2012;24:37-41. 
252. Dinis-Ribeiro M, Yamaki G, Miki K, Costa-Pereira A, Matsukawa M, Kurihara M. Meta-analysis on the validity of pepsinogen test for gastric carcinoma, dysplasia or chronic atrophic gastritis screening. J Med Screen. 2004;11:141-7.

253. Miki K. Gastric cancer screening using the serum pepsinogen test method. Gastric Cancer. 2006;9:245-53.

254. Agréus L, Kuipers EJ, Kupcinskas L, Malfertheiner P, Di Mario F, Leja M, et al. Rationale in diagnosis and screening of atrophic gastritis with stomach- specific plasma biomarkers. Scand J Gastroenterol. 2012;47:136-47.

255. Tong Y, Wu Y, Song Z, Yu Y, Yu X. The potential value of serum pepsinogen for the diagnosis of atrophic gastritis among the health check-up populations in China: a diagnostic clinical research. BMC Gastroenterology. 2017;17:88.

256. Shiotani A, Cen P, Graham DY. Eradication of gastric cancer is now both possible and practical. Semin Cancer Biol. 2013;23(Pt B):492-501

257. Cao Q, Ran ZH, Xiao SD. Screening of atrophic gastritis and gastric cancer by serum pepsinogen, gastrin-17 and H. pylori immunoglobulin G antibodies. J Dig Dis. 2007;8:15-22.

258. Agreus L, Storskrubb T, Aro P, Ronkainen J, Talley NJ, Sipponen P. Clinical use of proton-pump inhibitors but not $\mathrm{H} 2$-blockers or antacid/alginates raises the serum levels of amidated gastrin-17, pepsinogen I and pepsinogen II in a random adult population. Scand J Gastroenterol. 2009;44:564-70.

259. Leja M, Kupcinskas L, Funka K, Sudraba A, Jonaitis L, Ivanauskas A, et al. The validity of a biomarker method for indirect detection of gastric mucosal atrophy versus standard histopathology. Dig Dis Sci. 2009;54:2377-84.

260. Kikuchi S, Kato M, Katsuyama T, Tominaga S, Asaka M. Design and planned analyses of an ongoing randomized trial assessing the preventive effect of $H$. pylori eradication on occurrence of new gastric carcinomas after endoscopic resection. Helicobacter. 2006;11:147-51

261. Leja M, Camargo MC, Polaka I, Isajevs S, Liepniece-Karele I, Janciauskas D, et al Detection of gastric atrophy by circulating pepsinogens: A comparison of three assays. Helicobacter. 2017;22:e12393.

262. Terasawa T, Nishida H, Kato K, Miyashiro I, Yoshikawa T, Takaku R, et al. Prediction of gastric cancer development by serum pepsinogen test and $H$. pylori seropositivity in Eastern Asians: a systematic review and meta-analysis. PloS One. 2014;9:e109783.

263. Syrjänen K. A panel of serum biomarkers (GastroPanel $\left.{ }^{\circledR}\right)$ in non-invasive diagnosis of atrophic gastritis. Systematic review and meta-analysis. Anticancer Research 2016;36:5133-44.

264. Zagari RM, Rabitti S, Greenwood DC, Eusebi LH, Vestito A, Bazzoli F. Systematic review with metaanalysis: diagnostic performance of the combination of pepsinogen gastrin-17 and anti-H. pylori antibodies serum assays for the diagnosis of atrophic gastritis. Aliment Pharmacol Ther. 2017:46:657-67.

265. Fernández J, De Aretxabala X, D Ricardo S, Sabah S, Jorge M, Navarro A, et al. Detección de lesiones preneoplásicas gástricas mediante niveles séricos de pepsinógeno en población chilena. Rev Méd Chile. 2007;135:1519-25.

266. Fahey MT, Hamada GS, Nishimoto IN, Kowalski LP, Iriya K, Gama Rodrigues JJ, et al. Ethnic differences in serum pepsinogen levels among Japanese and non-Japanese Brazilian gastric cancer patients and controls. Cancer Detect Prev. 2000;24:564-71.

267. Moss SF. The clinical evidence linking Helicobacter pylori to gastric Cancer. Review Cell Mol Gastroenterol Hepatol. 2016;3:183-91.

268. de Martel C, Ferlay J, Franceschi S, Vignat J, Bray F, Forman D, et al. Global burden of cancers attributable to infections in 2008: a review and synthetic analysis. Lancet Oncol 2012;13:607-15

269. IARC Helicobacter pylori Working Group (2014). Helicobacter pylori Eradication as a Strategy for Gastric Cancer Prevention. Lyon, France: International Agency for Research on Cancer (IARC Working Group Reports, No. 8). [Internet]. Available from: http://www.iarc.fr/en/publications/.

270. Herrero R, Park JY, Forman D. The fight against gastric cancer-the IARC Working Group report. Best Pract Res Clin Gastroenterol. 2014;28:1107-14.

271. El-Omar E, Oien K, Murray LS, El-Nujumi A, Wirz A, Gillen D, et al. Increased prevalence of precancerous changes in relatives of gastric cancer patients: critical role of $H$ pylori. Gastroenterology. 2000;118:22-30.

272. Motta CR, Cunha MP, Queiroz DM, Cruz FW, Guerra EJ, Mota RM, et al. Gastric precancerous lesions and Helicobacter pylori infection in relatives of gastric cancer patients from Northeastern Brazil. Digestion. 2008;78:3-8.

273. Oh S, Kim N, Yoon H, Choi YJ, Lee JY, Park KJ, et al. Risk factors of atrophic gastritis and intestinal metaplasia in first-degree relatives of gastric cancer patients compared with age-sex matched controls. J Cancer Prev. 2013;18:149-60.

274. Lee YC, Chen TH, Chiu HM, Shun CT, Chiang H, Liu TY, et al. The benefit of mass eradication of Helicobacter pylori infection: a community based study of gastric cancer prevention. Gut. 2013;62:676-82.

275. Pan KF, Zhang L, Gerhard M, Ma JL, Liu WD, Ulm K, et al. A large randomised controlled intervention trial to prevent gastric cancer by eradication of Helicobacter pylori in Linqu County, China: baseline results and factors affecting the eradication. Gut. 2016;65:9-18.

276. Bornschein J, Selgrad M, Warnecke M, Kuester D, Wex T, Malfertheiner P. H. pylori infection is a key risk factor for proximal gastric cancer. Dig Dis Sci. 2010;55:3124-31.

277. Abrams JA, Gonsalves L, Neugut AI. Diverging trends in the incidence of reflux-related and Helicobacter pylori-related gastric cardia cancer. J Clin Gastroenterol. 2013;47:322-7.
278. Kamada T, Kurose H, Yamanaka Y, Manabe N, Kusunoki H, Shiotani A, et al. Relationship between gastroesophageal junction adenocarcinoma and Helicobacter pylori infection in Japan. Digestion. 2012;85:256-60.

279. Swerdlow SH, Campo E, Harris NL, Jaffe ES, Pileri SA, Stein H, et al., editors. WHO Classification of Tumours of Haematopoietic and Lymphoid Tissues. Lyon: IARC; 2008.

280. Capelle LG, de Vries AC, Looman CW, Casparie MK, Boot H, Meijer GA, et al. Gastric MALT lymphoma: epidemiology and high adenocarcinoma risk in a nation-wide study. Eur J Cancer. 2008;44:2470-6.

281. Nakamura S, Sugiyama T, Matsumoto T, Iijima K, Ono S, Tajika M, et al. Japan Gast Study Group. Long-term clinical outcome of gastric MALT lymphoma after eradication of $H$. pylori: a multicentre cohort follow-up study of 420 patients in Japan. Gut. 2012;61:507-13.

282. Lewin KJ, Appelman HD. Tumors of the esophagus and stomach, Atlas of tumor pathology, vol. 3rd series. Fascicle 18. Washington: AFIP; 1996.

283. Zucca E, Copie-Bergman C, Ricardi U, Thieblemont C, Raderer M, Ladetto M. ESMO Guidelines Working Group. Gastric marginal zone lymphoma of MALT type: ESMO Clinical Practice Guidelines for diagnosis, treatment and follow-up. Ann Oncol. 2013;24 Suppl 6:vi144-8.

284. Dreyling M, Thieblemont C, Gallamini A, Arcaini L, Campo E, Hermine O, et al. ESMO Consensus conferences: guidelines on malignant lymphoma. part 2: marginal zone lymphoma, mantle cell lymphoma, peripheral T-cell lymphoma. Ann Oncol. 2013;24:857-77.

285. Ruskoné-Fourmestraux A, Fischbach W, Aleman BM, Boot H, Du MQ, Megraud F, et al. EGILS Consensus report. Gastric extranodal marginal zone B-cell lymphoma of MALT. Gut. 2011;60:747-58.

286. Isaacson PG, Spencer J. The biology of low grade MALT lymphoma. J Clin Pathol. 1995;48:395-7.

287. Lima KS, Albuquerque W, Arantes VN, Drummond-Lage AP, Coelho LGV. Helicobacter pylori and $\mathrm{t}(11 ; 18)(\mathrm{q} 21 ; \mathrm{q} 21)$ translocation in gastric MALT lymphoma. Arq Gastroenterol. 2014;51:84-9.

288. Radaszkiewicz T, Dragosics B, Bauer P. Gastrointestinal malignant lymphomas of the mucosa-associated lymphoid tissue: factors relevant to prognosis. Gastroenterology. 1992;102:1628-38

289. Rohatiner A, d'Amore F, Coiffier B, Crowther D, Gospodarowicz M, Isaacson P, et al. Report on a workshop convened to discuss the pathological and staging classifications of gastrointestinal tract lymphoma. Ann Oncol. 1994;5:397-400.

290. Ruskoné-Fourmestraux A, Dragosics B, Morgner A, Wotherspoon A, De Jong D. Paris staging system for primary gastrointestinal lymphomas. Gut. 2003;52:912-3.

291. Vannata B, Stathis A, Zucca E. Management of the marginal zone lymphomas. Cancer Treat Res. 2015; 165:227-49.

292. Asano N, Iijima K, Koike T, Imatani A, Shimosegawa T. Helicobacter pylori-negative gastric mucosa-associated lymphoid tissue lymphomas: A review. World J Gastroenterol. 2015;21:8014-20.

293. Raderer M, Wohrer S, Kiesewetter B, Dolak W, Lagler H, Wotherspoon A, et al. Antibiotic treatment as sole management of Helicobacter pylori-negative gastric MALT lymphoma: a single center experience with prolonged follow-up. Ann Hematol. 2015;94:969-73.

294. Genta RM. Le lymphome imaginaire. Hum Pathol. 1998;29:769-70.

295. Copie-Bergman C, Gaulard P, Lavergne-Slove A, Brousse N, Fléjou JF, Dordonne K, et al. Proposal for a new histological grading system for post-treatment evaluation of gastric MALT lymphoma. Gut. 2003;52:1656.

296. Matysiak-Budnika T, Fabiani B, Hennequinc C, Thieblemont C, Malamut G, Cadiot $\mathrm{G}$, Bouchée O, et al. Gastrointestinal lymphomas: French Intergroup clinical practice recommendations for diagnosis, treatment and follow-up (SNFGE, FFCD, GERCOR, UNICANCER, SFCD, SFED, SFRO, SFH). Dig Liv Dis. 2018;50:124-31.

297. Correa P, Haenszel W, Cuello C, Tannenbaum S, Archer M. A model for gastric cancer epidemiology. Lancet. 1975;2:58-60.

298. Correa P. Human gastric carcinogenesis: a multistep and multifactorial process - First American Cancer Society Award Lecture on Cancer Epidemiology and Prevention. Cancer Res. 1992;52:6735-40.

299. Ohata H, Kitauchi S, Yoshimura N, Mugitani K, Iwane M, Nakamura H, et al. Progression of chronic atrophic gastritis associated with $H$. pylori infection increases risk of gastric cancer. Int J Cancer. 2004;109:138-43.

300. Ahn HJ, Lee DS. H. pylori in gastric carcinogenesis. World J Gastroenterol Oncol. 2015;7:455-65.

301. Lage J, Uedo N, Dinis-Ribeiro M, Yao K. Surveillance of patients with gastric precancerous conditions. Best Pract Res Clin Gastroenterol. 2016;30:913-22.

302. Park YH, Kim N. Review of atrophic gastritis and intestinal metaplasia as a premalignant lesion of gastric cancer. J Cancer Prev. 2015;20:25-40.

303. Kim N, Park YS, Cho SI, Lee HS, Choe G, Kim IW, et al. Prevalence and risk factors of atrophic gastritis and intestinal metaplasia in a Korean population without significant gastroduodenal disease. Helicobacter. 2008;13:245-55.

304. Genta RM, Gurer IE, Graham DY. Geographical pathology of $H$. pylori infection: is there more than one gastritis? Ann Med. 1995;27:595-9.

305. Guarner J, Herrera-Goepfert R, Mohar A, Sanchez L, Halperin D, Ley C, et al. Gastric atrophy and extent of intestinal metaplasia in a cohort of $H$. pylori-infected patients. Hum Pathol. 2001;32:31-5. 
306. Kapadia CR. Gastric Atrophy, metaplasia, and dysplasia: a clinical perspective. J Clin Gastroenterol. 2003;36:S29-S36.

307. Barbosa AJA, de Carvalho VOB. Gastric atrophy as a precursor of gastric cancer (letter). Aliment Pharmacol Ther. 2012;36:604.

308. Barbosa AJA, Miranda CG. Atrophic Body gastritis: a challenge for the presumptive endoscopic and histologic diagnosis of autoimmune gastritis. In: Pascu O, ed. Gastrointestinal endoscopy. Rijeka, Croatia: InTech; 2011. p. 169-82.

309. Jass JR, Filipe MI. The mucin profiles of normal gastric mucosa, intestinal metaplasia and its variants and gastric carcinoma. Histochem J. 1981;13:931-9.

310. Gonzalez CA, Sanz-Anquela JM, Gisbert JP, Correa P. Utility of subtyping intestinal metaplasia as marker of gastric cancer risk. A review of the evidence. Int J Cancer. 2003;133:1023-32

311. Masuyama H, Yoshitake N, Sasai T, Nakamura T, Masuyama A, Zuiki T, et al. Relationship between the degree of endoscopic atrophy of the gastric mucosa and carcinogenic risk. Digestion. 2015;91:30-6.

312. de Vries AC, Haringsma J, Kuipers EJ. The detection, surveillance and treatment of premalignant gastric lesions related to $H$. pylori infection. Helicobacter. 2007; 12:1-15

313. Kang KP, Lee HS, Kim N, Kang HM, Park YS, Lee DH, et al. Role of intestinal metaplasia subtyping in the risk of gastric cancer in Korea. J Gastroenterol Hepatol. 2009;24:140-8

314. Genta RM. Gastric atrophy and atrophic gastritis--nebulous concepts in search of a definition. Aliment Pharmacol Ther. 1998;12 Suppl 1:17-23.

315. Malfertheiner P. Gastric atrophy reversible or irreversible after H.pylori eradication - An open question. Digestion. 2011;83:250-2.

316. Rugge M, de Boni M, Pennelli G, de Bona M, Giacomelli L, Fassan M, et al. Gastritis OLGA-staging and gastric cancer risk: a twelve-year clinico-pathological follow-up study. Aliment Pharmacol Ther. 2010;31:1104-11

317. Rugge M, Meggio A, Pennelli G, Piscioli F, Giacomelli L, De Pretis G, et al. Gastritis staging in clinical practice: the OLGA staging system. Gut. 2007;56:631-6.

318. Capelle LG, de Vries AC, Haringsma J, Ter Borg F, de Vries RA, Bruno MJ, et al. The staging of gastritis with the OLGA system by using intestinal metaplasia as an accurate alternative for atrophic gastritis. Gastrointest Endosc. 2010;71:1150-8.

319. Isajevs S, Liepniece-Karele I, Janciauskas D, Moisejevs G, Putnins V, Funka K, et al. Gastritis staging: interobserver agreement by applying OLGA and OLGIM systems. Virchows Arch. 2014;464:403-7.

320. Dinis-Ribeiro M, Areia M, de Vries AC, Marcos-Pinto R, Monteiro-Soares M, O'Connor A, et al. Management of precancerous conditions and lesions in the stomach (MAPS): guideline from the European Society of Gastrointestinal Endoscopy (ESGE), European Helicobacter Study Group (EHSG), European Society of Pathology (ESP), and the Sociedade Portuguesa de Endoscopia Digestiva (SPED). Endoscopy. 2012;44:74-94.

321. Rugge M, Genta RM, Di Mario F, El-Omar EM, El-Serag HB, Fassan M, et al. Gastric Cancer as Preventable Disease. Clin Gastroenterol Hepatol. 2017;15:1833-43.

322. Rugge M, Correa P, Di Mario F, El-Omar E, Fiocca R, Geboes K, et al. OLGA staging for gastritis: a tutorial. Dig Liver Dis. 2008;40:650-8.

323. Rugge M, Meggio A, Pravadelli C, Barbareschi M, Fassan M, Gentilini et al. Gastritis staging in the endoscopic follow-up for the secondary prevention of gastric cancer: a 5-year prospective study of 1755 patients. Gut Published Online First: 06 January 2018. doi: 10.1136/gutjnl-2017-314600.

324. Thung I, Aramin H, Vavinskaya V, Gupta S, Park JY, Crowe SE, et al. The globa emergence of $H$. pylori antibiotic resistance. Aliment Pharmacol Ther. 2016;43:514-33.

325. Li BZ, Threapleton DE, Wang JY, Xu JM, Yuan JQ, Zhang C, et al. Comparative effectiveness and tolerance of treatments for $H$. pylori: systematic review and network meta-analysis. BMJ. 2015;351:h4052

326. Lim SG, Park RW, Shin SJ, Yoon D, Kang JK, Hwang JC, et al. The relationship between the failure to eradicate $H$. pylori and previous antibiotics use. Dig Liver Dis. 2016;48:385-90.

327. Megraud F, Coenen S, Versporten A, Kist M, Lopez-Brea M, Hirschl AM, et al. $H$. pylori resistance to antibiotics in Europe and its relationship to antibiotic consumption. Gut. 2013;62:34-42

328. Padol S, Yuan T, Thabane M, Padol IT, Hunt RH. The effect of CYP2C19 polymorphisms on $H$. pylori eradication rate in dual and triple first-line PPI therapies: a meta-analysis. Am J Gastroenterol. 2006;101:1467-75.

329. Suzuki T, Matsuo K, Ito H, Sawaki A, Hirose K, Wakai K, et al. Smoking increases the treatment failure for H. pylori eradication. Am J Med. 2006;119:217-24.

330. Lee JY, Kim N, Kim MS, Choi YJ, Lee JW, Yoon H, et al. Factors affecting first-line triple therapy of $H$. pylori including Dig Dis Sci. 2014;59:1235-43.

331. Broutet N, Marais A, Lamouliatte H, de Mascarel A, Samoyeau R, Salamon R, et al cagA status and eradication treatment outcome of anti- $H$. pylori triple therapies in patients with nonulcer dyspepsia. J Clin Microbiol. 2001;39:1319-22.

332. Mégraud F, Bénéjat L, Ontsira Ngoyi EN, Lehours P. Molecular approaches to identify H. pylori antimicrobial resistance. Gastroenterol Clin North Am. 2015;44:577-96.

333. Park CY, Kwak M, Gutierrez O, Graham DY, Yamaoka Y. Comparison of genotyping $H$. pylori directly from biopsy specimens and genotyping from bacterial cultures. J Clin Microbiol. 2003;41:3336-8.
334. Lascols C, Lamarque D, Costa JM, Copie-Bergman C, Le Glaunec JM, Deforges L, et al Fast and accurate quantitative detection of $H$. pylori and identification of clarithromycin resistance mutations in $H$. pylori isolates from gastric biopsy specimens by real-time PCR. J Clin Microbiol. 2003;41:4573-7.

335. Cambau E, Allerheiligen V, Coulon C, Corbel C, Lascols C, Deforges L, et al. Evaluation of a new test, genotype HelicoDR, for molecular detection of antibiotic resistance in H. pylori. J Clin Microbiol. 2009;47:3600-7.

336. Lins AK, Lima RA, Magalhaes M. Clarithromycin-resistant H. pylori in Recife, Brazil, directly identified from gastric biopsies by polymerase chain reaction. Arq Gastroenterol. 2010;47:379-82.

337. Eisig JN, Silva FM, Barbuti RC, Navarro-Rodriguez T, Moraes-Filho JP, Pedrazzoli $\mathrm{Jr}$ J. H. pylori antibiotic resistance in Brazil: clarithromycin is still a good option. Arq Gastroenterol. 2011;48:261-4.

338. Suzuki RB, Lopes RA, da Camara Lopes GA, Hung Ho T, Speranca MA. Low H. pylor primary resistance to clarithromycin in gastric biopsy specimens from dyspeptic patients of a city in the interior of Sao Paulo, Brazil. BMC Gastroenterol. 2013;13:164.

339. Picoli SU, Mazzoleni LE, Fernández H, De Bona LR, Neuhauss E, Longo L, et al. Resistance to amoxicillin, clarithromycin and ciprofloxacin of H.pylori isolated from Southern Brazil patients. Rev Inst Med Trop Sao Paulo. 2014;56:197-200.

340. Martins GM, Sanches BSF, Moretzsohn LD, Lima KS, Cota BDC, Coelho LGV. Molecular detection of clarithromycin and fluoroquinolones resistance in $H$. pylori infection, directly applied to gastric biopsies, in an urban Brazilian population. Arq Gastroenterol 2016;53:113-7.

341. Sanches BS, Martins GM, Lima K, Cota B, Moretzsohn LD, Ribeiro LT, al. Detection of H. pylori resistance to clarithromycin and fluorquinolones in Brazil: A national survey. World J Gastroenterol. 2016;22:7587-94.

342. Camargo MC, Garcia A, Riquelme A, Otero W, Camargo CA, Hernandez-Garcia T, et al. The problem of $H$. pylori resistance to antibiotics: a systematic review in Latin America. Am J Gastroenterol. 2014;109:485-95.

343. Kim SE, Park MI, Park SJ, Moon W, Choi YJ, Cheon JH, et al. Trends in H. pylori eradication rates by first-line triple therapy and related factors in eradication therapy. Korean J Intern Med. 2015;30:801-7.

344. Calvet X, Garcia N, Lopez T, Gisbert JP, Gene E, Roque M. A meta-analysis of short versus long therapy with a proton pump inhibitor, clarithromycin and either metronidazole or amoxycillin for treating Helicobacter pylori infection. Aliment Pharmacol Ther. 2000;14:603-9.

345. Ford A, Moayyedi P. How can the current strategies for Helicobacter pylori eradication therapy be improved? Can J Gastroenterol. 2003;17 Suppl B:36B-40B.

346. Fuccio L, Minardi ME, Zagari RM, Grilli D, Magrini N, Bazzoli F. Meta-analysis: duration of first-line proton-pump inhibitor based triple therapy for Helicobacter pylori eradication. Ann Intern Med. 2007;147:553-62.

347. Flores HB, Salvana A, Ang ELR, Estanislao NI, Velasquez ME, Ong J, et al. Duration of proton-pump inhibitor-based triple therapy for Helicobacter pylori eradication: a meta-analysis. Gastroenterology. 2010;138 Suppl 1:S-340.

348. Yuan Y, Ford AC, Khan KJ, Gisbert JP, Forman D, Leontiadis GI, et al. Optimum duration of regimens for $H$. pylori eradication. Cochrane Database Syst Rev. 2013;(12):CD008337.

349. Karatapanis S, Georgopoulos SD, Papastergiou V, Skorda L, Papantoniou N, Lisgos P, et al. 7, 10 and 14-days rabeprazole-based standard triple therapies for $H$.pylori eradication are they still effective? A randomized trial. Acta Gastroenterol Belg. 2011;74:407-12.

350. Filipec Kanizaj T, Katicic M, Skurla B, Ticak M, Plecko V, Kalenic S. Helicobacter pylori eradication therapy success regarding different treatment period based on clarithromycin or metronidazole triple-therapy regimens. Helicobacter. 2009;14:29-35.

351. Arama SS, Tiliscan C, Negoita C, Croitoru A, Arama V, Mihai CM, et al. Efficacy of 7-Day and 14-Day Triple Therapy Regimens for the Eradication of H. pylori: A Comparative Study in a Cohort of Romanian Patients. Gastroenterol Res Pract. 2016;2016:5061640.

352. Puig I, Baylina M, Sánchez-Delgado J, López-Gongora S, Suarez D, García-Iglesias $\mathrm{P}$, et al. Systematic review and meta-analysis: triple therapy combining a proton-pump inhibitor, amoxicillin and metronidazole for $H$. pylori first-line treatment. J Antimicrob Chemother. 2016;71:2740-53

353. Fallone CA, Chiba N, van Zanten SV, Fischbach L, Gisbert JP, Hunt RH, et al. The Toronto Consensus for the treatment of Helicobacter pylori infection in adults. Gastroenterology. 2016;151:51-69.

354. Chey WG, Leontiadis GI, Howden CW, Moss SF. ACG Clinical Guideline: treatment of Helicobacter pylori infection. 2017;112:212-39.

355. Lu H, Zhang W, Graham DY. Bismuth-containing quadruple therapy for Helicobacter pylori: lessons from China. Eur J Gastroenterol Hepatol. 2013;25:1134-40.

356. Salazar CO, Cardenas VM, Reddy RK, Dominguez DC, Snyder LK, Graham DY. Greater than $95 \%$ success with 14-day bismuth quadruple anti-Helicobacter pylor therapy: a pilot study in US Hispanics. Helicobacter. 2012;17:382-90.

357. Rimbara E, Fischbach LA, Graham DY. Optimal therapy for Helicobacter pylori infections. Nat Rev Gastroenterol Hepatol. 2011;8:79-88.

358. Lee ST, Lee DH, Lim JH, Kim N, Park YS, Shin CM, et al. Efficacy of 7-day and 14-day bismuth-containing quadruple therapy and 7-day and 14-day moxifloxacin-based triple therapy as second-line eradication for Helicobacter pylori infection. Gut Liv. 2015;9:478-85. 
359. Choung RS, Lee SW, Jung SW, Han WS, Kim MJ, Jeen YT. et al. Comparison of the effectiveness of quadruple salvage regimen for Helicobacter pylori infection according to the duration of treatment. Korean J Gastroenterol. 2006;47:131-5.

360. Lee BH, Kim N, Hwang TJ, Lee SH, Park YS, Hwang JH, et al. Bismuth-containing quadruple therapy as second-line treatment for Helicobacter pylori infection: effect of treatment duration and antibiotic resistance on the eradication rate in Korea. Helicobacter. 2010;15:38-45

361. Park SC, Chun HJ, Jung SW, Keum B, Han WS, Choung RS, et al. Efficacy of 14 day OBMT therapy as a second-line treatment for Helicobacter pylori infection. Korean J Gastroenterol. 2004;44:136-41.

362. Malfertheiner $\mathrm{P}$, Bazzoli $\mathrm{F}$, Delchier JC, Celiñski K, Giguère $\mathrm{M}$, Rivière $\mathrm{M}$, et al. $\mathrm{He}$ licobacter pylori eradication with a capsule containing bismuth subcitrate potassium, metronidazole, and tetracycline given with omeprazole versus clarithromycin-based triple therapy: a randomised, open-label, non-inferiority, phase 3 trial. Lancet. 2011;377: 905-13

363. Delchier JC, Malfertheiner P, Thieroff-Ekerdt R. Use of a combination formulation of bismuth, metronidazole and tetracycline with omeprazole as a rescue therapy for eradication of Helicobacter pylori. Aliment Pharmacol Ther. 2014;40:171-7.

364. Miehlke S, Frederking D, Günther T, Glocker E, Eisele B, Andresen V, et al. Efficacy of three-in-one capsule bismuth quadruple therapy for Helicobacter pylori eradication in clinical practice in a multinational patient population. Helicobacter. 2017;22(6). doi: 10.1111/hel.12429.25

365. McNicholl A, Molina-Infante J, Bermejo F, Harb Y, Modolell I, Anton R, et al. Non-bismuth quadruple concomitant therapies in the eradication of Helicobacter pylori: standard vs. optimized (14 days, high-dose PPI) regimens in clinical practice. Helicobacter. 2014;19 Suppl 1:11.

366. Molina-Infante J, Lucendo AJ, Angueira T, Rodriguez-Tellez M, Perez-Aisa A, Balboa A, et al. Optimized empiric triple and concomitant therapy for Helicobacter pylori eradication in clinical practice: the OPTRICON study. Aliment Pharmacol Ther. 2015;41:581-9.

367. Park SM, Kim JS, Kim BW, Ji JS, Choi H. Randomized clinical trial comparing 10- or 14-day sequential therapy and 10- or 14-day concomitant therapy for the first line empirical treatment of H. pylori infection. J Gastroenterol Hepatol. 2017;32:589-94.

368. Tepeš B, Vujasinović M, Šeruga M, Stefanovič M, Forte A, Jeverica S. Randomized clinical trial comparing 10-day sequential, 7-day concomitant and 7-day standard triple therapies for H. pylori eradication. Eur J Gastroenterol Hepatol. 2016;28:676-83.

369. Liou JM, Chen CC, Chang CY, Chen MJ, Chen CC, Fang YJ, et al. Sequential therapy for 10 days versus triple therapy for 14 days in the eradication of $H$.pylori in the community and hospital populations: a randomised trial. Gut. 2016;65:1784-92.

370. Charan S, Aggarwal R, Singh G, Garg S, Garg R, Neki NS. To compare efficacy of 10 day sequential triple therapy versus 14-days sequential therapy for the eradication of $H$. pylori. Int J Curr Res Med Sci. 2017;3:102-10.

371. Liou JM, Chen CC, Lee YC, Chang CY, Wu JY, Bair MJ, et al. Systematic review with meta-analysis: 10- or 14-day sequential therapy vs. 14-day triple therapy in the first line treatment of $H$. pylori infection. Aliment Pharmacol Ther. 2016;43:470-81

372. Jung YS, Park CH, Park JH, Nam E, Lee HL. Efficacy of $H$. pylori eradication therapies in Korea: A systematic review and network meta-analysis. Helicobacter. 2017;22(4). doi: 10.1111/hel.12389.

373. Claessens AA, Heerdink ER, van Eijk JT, Lamers CB, Leufkens HG. Continued use of the proton-pump inhibitor lansoprazole following Helicobacter pylori eradication. Eur J Clin Pharmacol. 2000;55:773-6.

374. Gisbert JP, Pajares JM. Systematic review and meta-analysis: is 1-week proton pump inhibitor-based triple therapy sufficient to heal peptic ulcer? Aliment Pharmacol Ther. 2005;21:795-804

375. Higuchi K, Fujiwara Y, Tominaga K, Watanabe T, Shiba M, Tominaga K, et al. Is eradication sufficient to heal gastric ulcers in patients infected with Helicobacter pylori? A randomized, controlled, prospective study. Aliment Pharmacol Ther. 2003;17:111-7.

376. Gisbert JP, Calvet X, Cosme A, Almela P, Feu F, Bory F, et al. Long-term follow-up of 1,000 patients cured of Helicobacter pylori infection following an episode of peptic ulcer bleeding. Am J Gastroenterol. 2012;107:1197-204.

377. Ford AC, Gurusamy KS, Delaney B, Forman D, Moayyedi P. Eradication therapy for peptic ulcer disease in Helicobacter pylori-positive people. Cochrane Database Syst Rev. 2016;4:CD003840.

378. Sugimoto M, Takahisa Furuta. Efficacy of tailored Helicobacter pylori eradication therapy based on antibiotic susceptibility and CYP2C19 genotype. World J Gastroenterol. 2014;20:6400-11.

379. Villoria A, Garcia P, Calvet X, Gisbert JP, Vergara M. Meta-analysis: high-dose proton pump inhibitors vs. standard dose in triple therapy for Helicobacter pylori eradication. Aliment Pharmacol Ther. 2008;28:868-77.

380. McNicholl AG, Linares PM, Nyssen OP, Calvet X, Gisbert JP. Meta-analysis: esomeprazole or rabeprazole vs. first-generation pump inhibitors in the treatment of Helicobacter pylori infection. Aliment Pharmacol Ther. 2012;36:414-25.

381. Tang HL, Li Y, Hu YF, Xie HG, Zhai SD. Effects of CYP2C19 loss-of-function variants on the eradication of $H$. pylori infection in patients treated with proton pump inhibitor-based triple therapy regimens: a meta-analysis of randomized clinical trials. PLoS One. 2013;8:e62162.
382. Prado, Carolina Martins do. Desenvolvimento de metodologia para a determinação dos genótipos principais dos genes CYP2D6, CYP2C19 e CYP2C9: aplicação na farmacologia (dissertação). São Paulo: Universidade de São Paulo, Biotecnologia;2010.

383. Suarez-Kurtz G, Genro JP, de Moraes MO, Ojopi EB, Pena SD, Prini JA, et al. Global pharmacogenomics: Impact of population diversity on the distribution of polymorphisms in the CYP2C cluster among Brazilians. Pharmacogenomics J. 2012;12:267-76.

384. Kohlrausch FB, Carracedo Á and Hutz MH (2014). Characterization of CYP1A2, CYP2C19, CYP3A4 and CYP3A5 polymorphisms in South Brazilians. Mol Biol Rep. 2014;41:1453-60.

385. Nabinger DD, Mazzoleni LE, Sander GB, Mazzoleni F, Osório MC, Klein MG, et al. Influence of CYP2C19 on Helicobacter pylori eradication in Brazilian patients with functional dyspepsia. Genet Mol Res. 2016;15:(3). doi: 10.4238/gmr.15038734.

386. Molina-Infante J, Romano M, Fernandez-Bermejo M, Federico A, Gravina AG, Pozzati $\mathrm{L}$, et al. Optimized nonbismuth quadruple therapies cure most patients with Helicobacter pylori infection in populations with high rates of antibiotic resistance. Gastroenterology. 2013;145:121-8.

387. Apostolopoulos P, Koumoutsos I, Ekmektzoglou K, Dogantzis P, Vlachou E, Kalantzis $\mathrm{C}$, et al. Concomitant versus sequential therapy for the treatment of Helicobacter pylori infection: a Greek randomized prospective study. Scand J Gastroenterol. 2016;51: 145-51.

388. De Francesco V, Hassan C, Ridola L, Giorgio F, Lerardi E, Zullo A. Sequential, concomitant and hybrid first-line therapies for Helicobacter pylori eradication: a prospective randomized study. J Med Microbiol 2014;63(Pt 5):748-52.

389. Zhang W, Chen Q, Liang X, Liu W, Xiao S, Graham DY, et al. Bismuth, lansoprazole, amoxicillin and metronidazole or clarithromycin as first-line Helicobacter pylori therapy. Gut. 2015;64:1715-20

390. Gatta L, Vakil N, Vaira D, Scarpignato C. Global eradication rates for Helicobacter pylori infection: systematic review and meta-analysis of sequential therapy BMJ. 2013;347:f4587.

391. Eisig JN, Navarro-Rodriguez T, Teixeira AC, Silva FM, Mattar R, Chinzon D, et al. Standard Triple Therapy versus Sequential Therapy in Helicobacter pylori Eradication: A Double-Blind, Randomized, and Controlled Trial. Gastroenterol Res Pract. 2015;2015:818043.

392. Marin AC, McNicholl AG, Gisbert JP. A review of rescue regimens after clarithromycin-containing triple therapy failure (for Helicobacter pylori eradication). Expert Opin Pharmacother. 2013;14:843-61

393. Tai WC, Chuah SK, Wu KL. The efficacy of second-line anti-Helicobacter pylori eradication using 10-day and 14-day levofloxacin-containing triple therapy. United European Gastroenterology Journal. 2013;1 (1S):A5

394. Di Caro S, Franceschi F, Mariani A, Thompson F, Raimondo D, Masci E, et al. Second-line levofloxacin-based triple schemes for Helicobacter pylori eradication. Dig Liver Dis. 2009; 41:480-5.

395. Furuta T, Graham DY. Pharmacologic aspects of eradication therapy for Helicobacter pylori Infection. Gastroenterol Clin North Am. 2010;39:465-80.

396. Zullo A, De Francesco V, Manes G, Scaccianoce G, Cristofari F, Hassan C. Second-line and rescue therapies for Helicobacter pylori eradication in clinical practice. J Gastrointestin Liver Dis. 2010;19:131-4.

397. Wong WM, Gu Q, Chu KM, Yee YK, Fung FM, Tong TS, et al. Lansoprazole, levofloxacin and amoxicillin triple therapy vs. quadruple therapy as second-line treatment of resistant Helicobacter pylori infection. Aliment Pharmacol Ther. 2006;23:421-7.

398. Gisbert JP, Romano M, Gravina AG, Solís-Muñoz P, Bermejo F, Molina-Infante J, et al. Helicobacter pylori second-line rescue therapy with levofloxacin- and bismuth-containing quadruple therapy, after failure of standard triple or non-bismuth quadruple treatments. Aliment Pharmacol Ther. 2015;41:768-75.

399. Wu TS, Hsu PI, Kuo CH, Hu HM, Wu IC, Wang SS, et al. Comparison of 10-day levofloxacin bismuth-based quadruple therapy and levofloxacin-based triple therapy for Helicobacter pylori. J Dig Dis. 2017;18:537-42.

400. Gisbert JP, Calvet X. Review article: rifabutin in the treatment of refractory Helicobacter pylori infection. Aliment Pharmacol Ther. 2012;35:209-21

401. Liu X, Wang H, Lv Z, Wang Y, Wang B, Xie Y, et al. Rescue Therapy with a Proton Pump Inhibitor Plus Amoxicillin and Rifabutin for Helicobacter pylori Infection: A Systematic Review and Meta-Analysis. Gastroenterol Res Pract. 2015;2015:415648.

402. Gisbert JP, Castro-Fernandez M, Perez-Aisa A, Cosme A, Molina-Infante J, Rodrigo L. Fourth-line rescue therapy with rifabutin in patients with three Helicobacter pylorieradication failures. Aliment Pharmacol Ther. 2012;35:941-7.

403. Ono S, Kato M, Nakagawa S, Mabe K, Sakamoto N. Vonoprazan improves the efficacy of Helicobacter pylori eradication therapy with a regimen consisting of clarithromycin and metronidazole in patients allergic to penicillin. Helicobacter. 2017;00:e12374.

404. Macy E. Penicillin and beta-lactam allergy: Epidemiology and diagnosis. Curr Allergy Asthma Rep. 2014;14:476.

405. Gisbert JP, Barrio J, Modolell I, Molina-Infante J, Perez Aisa A, Castro-Fernández M, et al. Helicobacter pylori first-line and rescue treatments in the presence of penicillin allergy. Dig Dis Sci. 2015;60:458-64.

(cC) $\mathrm{BY}-\mathrm{NC}$ 